Florida International University FIU Digital Commons

7-7-2004

\title{
Reading comprehension and mathematical concept acquisition through the use of math stories with bilingual children
}

Chan-Ho Chae

Florida International University

DOI: $10.25148 /$ etd.FI14060132

Follow this and additional works at: https://digitalcommons.fiu.edu/etd

\section{Recommended Citation}

Chae, Chan-Ho, "Reading comprehension and mathematical concept acquisition through the use of math stories with bilingual children" (2004). FIU Electronic Theses and Dissertations. 2100.

https://digitalcommons.fiu.edu/etd/2100 
FLORIDA INTERNATIONAL UNIVERSITY

Miami, Florida

READING COMPREHENSION AND MATHEMATICAL CONCEPT ACQUISITION THROUGH THE USE OF MATH STORIES

WITH BILINGUAL CHILDREN

A dissertation submitted in partial fulfillment of the requirements for the degree of DOCTOR OF EDUCATION in CURRICULUM AND INSTRUCTION by

Chan-Ho Chae 
To: Dean Linda Blanton

College of Education

This dissertation, written by Chan-Ho Chae, and entitled Reading Comprehension and Mathematical Concept Acquisition through the Use of Math Stories with Bilingual Children, having been approved in respect to style and intellectual content, is referred to you for judgment.

We have read this dissertation and recommend that it be approved.

Cengiz Alacaci

Leonard Bliss

Mohammed K. Farouk

Lisbeth A. Dixon-Krauss, Major Professor

Date of Defense: July 7, 2004

The dissertation of Chan-Ho Chae is approved.

Dean Linda Blanton
College of Education

Florida International University, 2004 
(C) Copyright 2004 by Chan-Ho Chae All rights reserved. 


\section{DEDICATION}

I would like to dedicate this dissertation to God and to my family: to my wife, Soohee Chae, who has been by my side to watch me accomplish this goal; to my three children, Youngwuk, Jooyoung, and Minyoung, who did not complain too much when I had no time to play with them; and to my parents for their consistent support and encouragement. 


\section{ACKNOWLEDGMENTS}

I would like to express my thanks to my advisor, Lisbeth Dixon-Krauss, for all of her help and guidance. Without her belief in me, I would have had a hard time. Every sentence I have written she has read and critiqued multiple times, without which the final product wouldn't be possible. My thanks also go to my dissertation committee, Cengiz Alacaci, Leonard Bliss, and Mohammed Farouk, whose suggestions, and probing questions challenged me to think more deeply about my findings. 
ABSTRACT OF THE DISSERTATION

\section{READING COMPREHENSION AND MATHEMATICAL CONCEPT ACQUISITION \\ THROUGH THE USE OF MATH STORIES \\ WITH BILINGUAL CHILDREN}

by

\section{Chan-Ho Chae}

Florida International University, 2004

Miami, Florida

Professor Lisbeth A. Dixon-Krauss, Major Professor

Math storybooks are picture books in which the understanding of mathematical concepts is central to the comprehension of the story. Math stories have provided useful opportunities for children to expand their skills in the language arts area and to talk about mathematical factors that are related to their real lives. The purpose of this study was to examine bilingual children's reading and math comprehension of the math storybooks.

The participants were randomly selected from two Korean schools and two public elementary schools in Miami, Florida. The sample consisted of 63 Hispanic American and 43 Korean American children from ages five to seven. A $2 \times 3 \times(2)$ mixed-model design with two between- and one within-subjects variable was used to conduct this study. The two between-subjects variables were ethnicity and age, and the withinsubjects variable was the subject area of comprehension. Subjects were read the three math stories individually, and then they were asked questions related to reading and math comprehension. 
The overall ANOVA using multivariate tests was conducted to evaluate the factor of subject area for age and ethnicity. As follow-up tests for a significant main effect and a significant interaction effect, pairwise comparisons and simple main effect tests were conducted, respectively.

The results showed that there were significant ethnicity and age differences in total comprehension scores. There were also age differences in reading and math comprehension, but no significant differences were found in reading and math by ethnicity. Korean American children had higher scores in total comprehension than those of Hispanic American children, and they showed greater changes in their comprehension skills at the younger ages, from five to six, whereas Hispanic American children showed greater changes at the older ages, from six to seven. Children at ages five and six showed higher scores in reading than in math, but no significant differences between math and reading comprehension scores were found at age seven.

Through schooling with integrated instruction, young bilingual children can move into higher levels of abstraction and concepts. This study highlighted bilingual children's general nature of thinking and showed how they developed reading and mathematics comprehension in an integrated process. 


\section{TABLE OF CONTENTS}

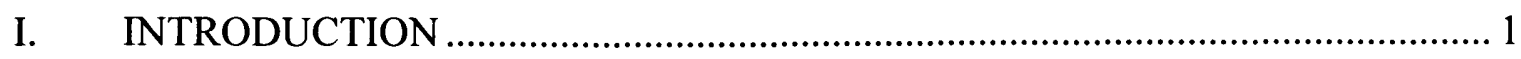

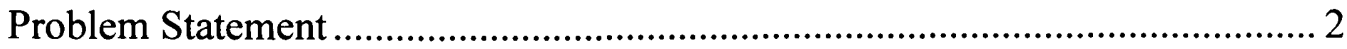

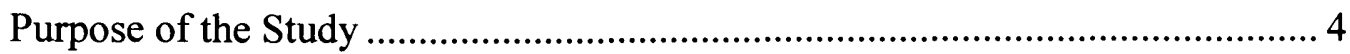

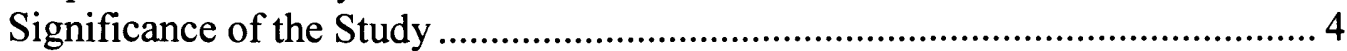

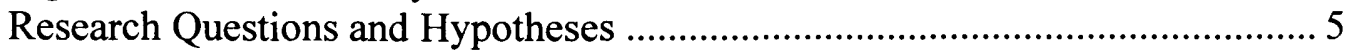

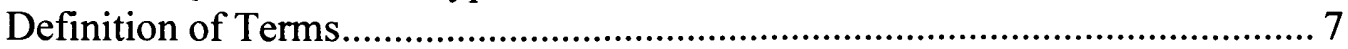

Assumptions of the Study ................................................................................. 9

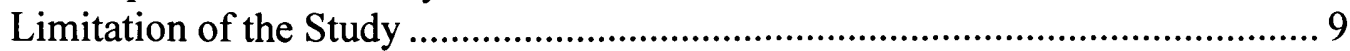

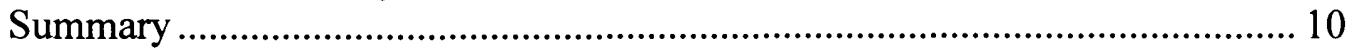

Organization of the Remaining Chapters.................................................... 10

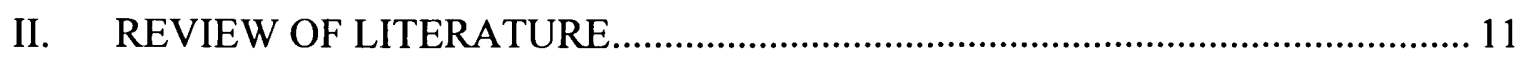

The Theoretical Basis of Narrative Comprehension........................................ 13

Reading Comprehension Theories ................................................................ 14

Story Structure and Reading Comprehension..........................................2 23

Reading Comprehension and Skills by Age and Ethnicity ...........................2 25

The Theoretical Basis of Mathematical Teaching and Learning ..................... 29

Constructivism and Mathematics................................................................... 31

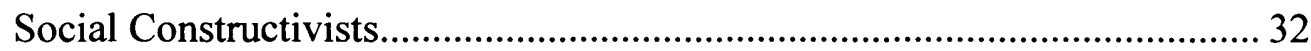

Constructivism and Mathematics Learning Model ...................................... 35

Mathematical Knowledge and Skills by Age............................................... 37

Mathematical Knowledge and Skills by Ethnicity and Culture .................... 39

Bilingualism, Cultural Knowledge, and Cognitive Development .................... 42

Bilingualism and Cognitive Development .......................................................4 43

Language Structures and Cognitive Aspects ................................................ 47

Cultural Knowledge and Comprehension .....................................................48

Rationale for Integration of Literature and Mathematics................................. 51

Children's Books and Math Teaching Categories ........................................52

The National Council of Teachers of Mathematics (NCTM) Standards ...... 52

Research on Integration of Mathematics and Literature ..............................5 54

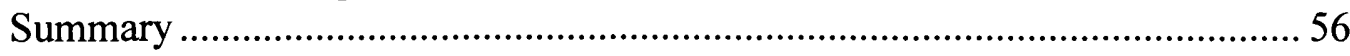

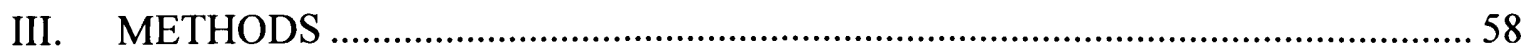

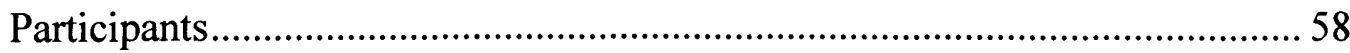

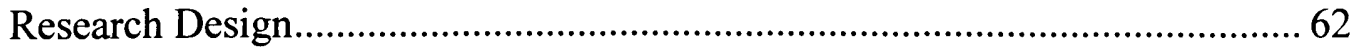

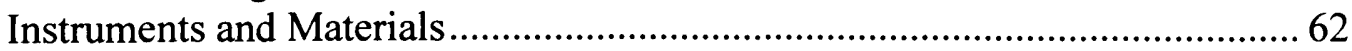

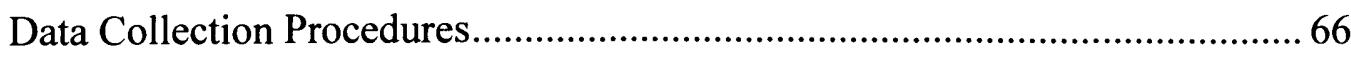

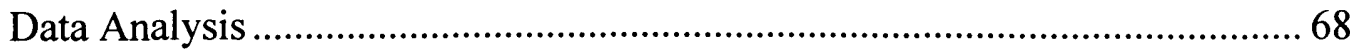

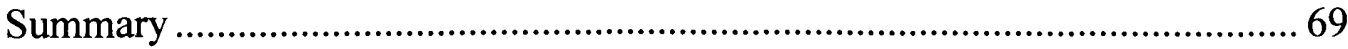




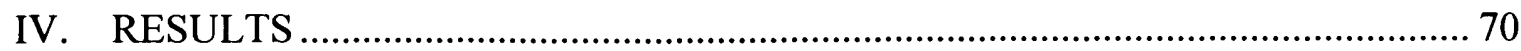

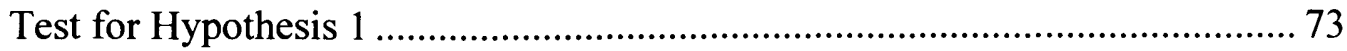

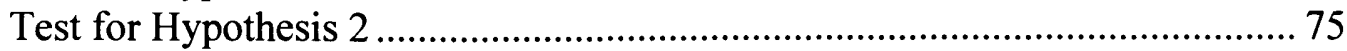

Test for Hypothesis 3 .................................................................................. 76

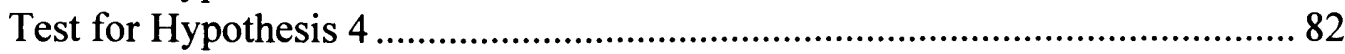

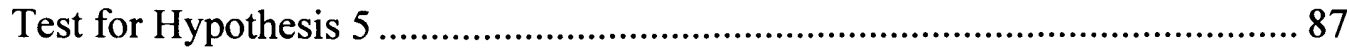

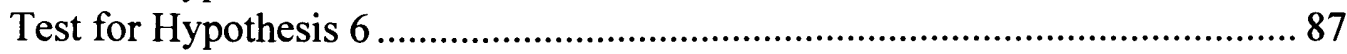

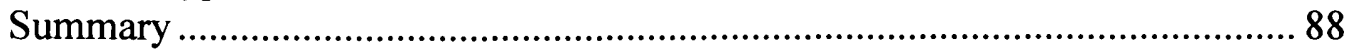

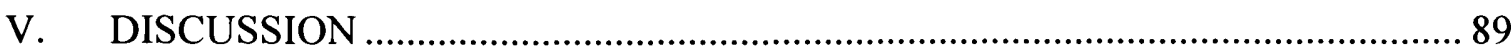

Discussion of Findings...................................................................................... 90

Developmental Trend for Comprehension of Math Storybooks.................... 90

Ethnic Trend for Comprehension of Math Storybooks.................................. 91

Subject Area Trend for Comprehension of Math Storybooks ...................... 93

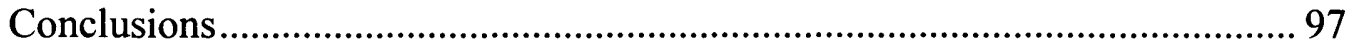

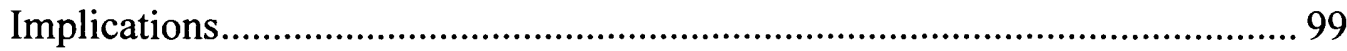

Suggestions for Future Research ............................................................. 101

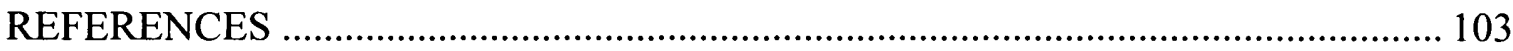

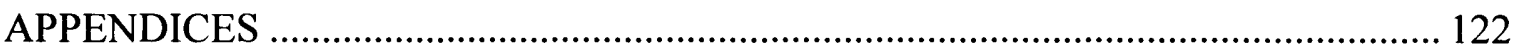

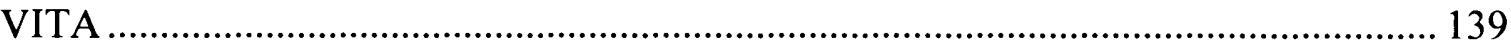




\section{LIST OF TABLES}

TABLE

PAGE

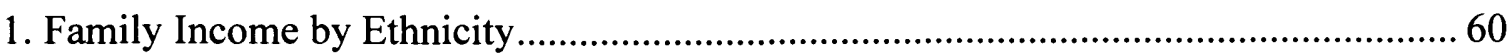

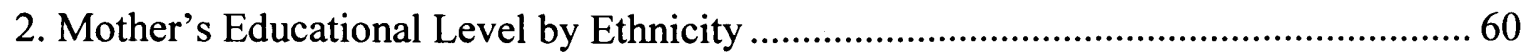

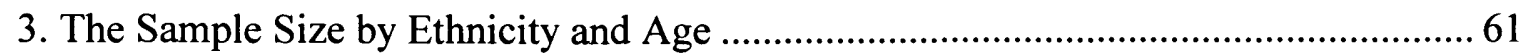

4. The Sample Size by Ethnicity and Gender ................................................................... 61

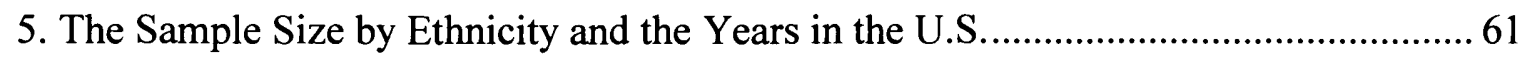

6. Intercorrelations among Three Raters for Math and Reading Comprehension ............. 66

7. Means and Standard Deviation for Three Comprehension Scores

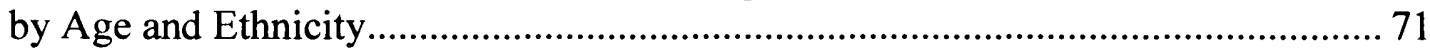

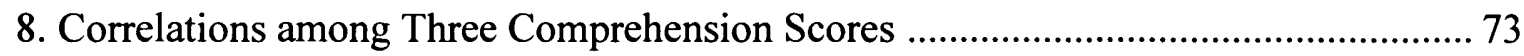

9. Analysis of Variance for Total Comprehension Scores................................................ 74

10. Pairwise Comparison among Ages in Total Comprehension Scores.......................... 75

11. The Results of the Simple Main Effects for Ethnicity within Ages 5, 6, and 7......... 78

12. Means and Standard Deviation for Total Comprehension Scores

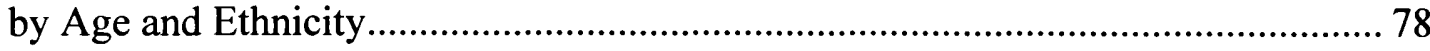

13. The Results of the Simple Main Effects for Age within Korean American Children and Hispanic American Children.

14. Differences among Ages in total comprehension Scores for Korean American Children and Hispanic American Children

15. The Results of the Simple Main Effects for Subject Area within Ages 5, 6, and 7.... 84

16. Means and Standard Deviation for Math and Reading Comprehension Scores by Age

17. The Results of the Simple Main Effects for Age within Math and Reading Comprehension 
18. Pairwise Comparison among Ages within Math Comprehension ............................. 86

19. Pairwise Comparison among Ages within Reading Comprehension .......................... 86 


\section{CHAPTER I \\ INTRODUCTION}

Immigration from other countries, changing societies, and increasing technology applications have made the United States a racially, culturally and linguistically diverse country. As many children enter school from homes where English is not spoken, educators have tried to find appropriate school curricula for bilingual children to gain competence in all subject areas.

Teachers' life experiences differ from those of children from different cultural background, and school curricula also shift from a focus on silent and individual activities to more verbal and social-interactive ones. For these reasons, children are facing new challenges as they develop their comprehension skills in order to solve problems effectively (Garcia, 1999).

Children at schools with broad curricular scopes had higher scores on reading comprehension tests than children with narrower curricular scopes (Singer, McNeil, \& Furse, 1984). Teachers who use children's literature for new ideas, were likely to refresh the curriculum and to find strategies to teach skills in a meaningful and more natural manner, and they were encouraged to consider content, processes, and concepts in school curriculum (Ruddell, 1999).

Vygotsky (1978) stressed that what children are able to do with the assistance of others is more indicative of their mental development than what they are able to do alone. Reading to children and involving them in their learning can strengthen their vocabulary, stimulate their desire to read, and encourage them to think critically about books. These 
early reading activities are vital to their success in learning to read, particularly for children who do not have experiences with books at home (Martinez, 1983; Teale, 1981). When younger children were encouraged to take an active part in reading books, they demonstrated improved oral language skills, story structure awareness, and reading comprehension (Morrow, 1997). Studies of early readers revealed that children who were already able to read and grasp the contents of the text came from homes where many printed materials were available to them. Children's early reading experiences with books create the foundations for later text comprehension (Clark, 1976; Durkin, 1966). This is why early intervention is important for younger children to develop cognitive and affective capabilities for effective reading skills. Children reinforce their comprehension and improve their ability to apply a concept or skill in multiple ways (Burnett \& Wichman, 1997; Monroe, 1996). Integrating school subjects is one way to give children the opportunity to experience concepts from various perspectives.

\section{Problem Statement}

Changing from the traditional, teacher-centered curriculum to the integrated, child-centered curriculum requires considerable reorientation in the ways of instruction and learning. As children mature into school age, literature and language skills are often neglected in mathematics instruction. Traditionally, the math curriculum consisted of instruction in finding answers to math problems and memorizing math skills such as addition, subtraction, multiplication, and division. Much of the math curriculum consisted of skills where the language factor for understanding mathematical concepts was neglected. Through literacy, teachers could integrate mathematics into other curriculum 
areas and help children become active constructors of mathematical concepts (Whitin \& Wilde, 1992).

Although teachers have different philosophies regarding how children best develop active literacy and mathematical concepts in school, they should plan experiences that communicate the structure and conceptual bases of math and reading. When children are encouraged to make estimations in mathematical areas, they are actively involved in solving problems and developing the skills of reasoning, number sense, and estimation. Eventually, children discover that they can apply mathematical approximations to their everyday lives.

Math storybooks are picture books in which the understanding of mathematical concepts is central to the comprehension of the story. Math stories provide useful opportunities, which allow children to expand their skills in the language arts area and to talk about mathematical factors that are related to their real lives (Zanger, 1998; McNair, 2000). When mathematical problem solving and language arts were integrated in the classroom curriculum, it was necessary to examine both children's cognitive and aesthetic responses to the literature (Laupa, 2000). Cognitive aspects of children's responses to literature were their references to mathematical concepts (e.g., place-value, counting, matching, ordering, comparison, computation, and proportional reasoning), story elements (e.g., setting, character, plot, theme, and author/book style), and comprehension of the story plot structures (e.g., setting, initiating event, goals, attempts, outcomes, and reactions) (Swanson \& Sachse-Lee, 2001; Stanford \& Oakland, 2000). As 
a result, it is necessary for us to discover ways to incorporate mathematics into literature through the use of math storybooks (Friedman, 1997).

Purpose of the Study

This study investigated children's individual differences in their comprehension of story and mathematical concepts when literature was integrated with mathematics. Ethnicity-related differences in comprehension were also examined. The children were young Korean American and Hispanic American bilingual children who attended a school district in a large urban area where the majority of the population had a middleclass socioeconomic status. The purpose of this study was to examine five- to seven-yearold Hispanic and Korean children's cognitive responses in reading and math comprehension to math literature.

\section{Significance of the Study}

Involving children with mathematics in various ways could serve to connect math to reality and to provide ample opportunities for problem solving. When mathematics is integrated with the language arts, it is possible for children to have general benefits in their cognitive development and also to achieve a higher level of learning. Previous research showed that there were benefits in children's cognitive development when language arts and mathematics were integrated (Harris, 1999).

This study examined how reading comprehension factors such as story elements and story structure were related to the mathematical concepts in children's comprehension of the story by their developmental levels and their ethnic background. The findings will help educational practitioners who write children's math storybooks 
and pose questions for assessing the children's responses to the literature at the end of reading a storybook.

\section{Research Questions and Hypotheses}

The research question to be examined in this study was: How do younger children respond differently to reading and math comprehension of math stories by their ages and ethnic backgrounds? The subsidiary research questions were:

1. Do total comprehension scores differ by age?

2. Do total comprehension scores differ by ethnicity?

3. Do total comprehension scores differ by ethnicity according to age?

4. Is there an interaction of age and subject area in comprehension?

5. Is there an interaction of ethnicity and subject area in comprehension?

6. Are there any differences between children's reading comprehension and math comprehension by age and ethnicity?

The research hypotheses to be explored in this study are as follows:

1. The total comprehension scores reflect a trend by age. The scores of the five-yearold's are less than those of the six-year-old's. The scores of the seven-year-old's are higher than those of the six-year-old's. The typical finding is that there is a developmental trend in comprehension scores as increased by Kaufman Assessment Battery for Children (K-ABC) test (Rupley, 1995). The betweensubjects effect of age addresses whether the mean scores for the three-age groups differ, regardless of subject area. 
2. A statistically significant difference is expected in the total comprehension scores of Korean American children and Hispanic American children. There will also be an ethnicity effect on total achievement scores (Denton \& West, 2002). The between-subjects effect of ethnicity addresses whether the mean scores for the two-ethnic groups (Korean and Hispanic) differ, regardless of subject area.

3. At age five, Hispanic American children are expected to have higher total comprehension scores than Korean American children. At age seven, however, Korean American children are expected to have higher scores than Hispanic American children. There will be a statistically significant interaction effect in the total comprehension scores of Korean American children and Hispanic American children according to their age level. The interaction of age and ethnicity addresses whether the effect of ethnicity depends on the level of age.

4. Children score higher on story comprehension than they do on math comprehension at age five, but they score lower on story comprehension than they do on math comprehension at age seven. Story comprehension and math comprehension both increase with age. An interaction effect is expected between age and subject area.

5. Korean American children earn higher scores on math than on reading comprehension, but Hispanic American children have the same scores on the two subject areas. There are ethnic differences in early math achievement and in preferences of story elements. There will be an interaction effect of ethnicity and specific reading and mathematical knowledge and skills. 
6. There are significant differences in story comprehension scores and math comprehension scores between Korean American children and Hispanic American children at ages five, six, and seven. There will be a second-order interaction effect of age and ethnicity when the two subject comprehension tests are considered.

\section{Definition of Terms}

Terms that are used throughout this study were operationally defined as follows: Bilingualism. Bilingualism is the ability to speak or understand, with some degree of proficiency, a language beside one's native language (Harris \& Hodges, 1995).

Story plot structure. Story plot structure is the syntax of plot organization in a specific narrative as defined by the story grammar (Thorndyke, 1977). It refers to the set of expectations about the internal structure of stories, usually in simplified terms such as settings, initiating events, goals, attempts, outcomes, and reactions (Harris \& Hodges, 1995).

Story literary elements. Stories have unique elements of structure. The authors manipulate character, plot, setting, and other elements to produce an interesting story. Five literary elements of story structure - setting, character, plot, theme, and point of view - are used in this study (Tompkins, 2000).

Story grammar. Story grammar is the formal rule system devised for the purpose of describing regularities, specifying relations among episodes in narrative text, and generating other stories (Mandler, 1983). It includes the basic elements that make up a well-developed story, such as plot and setting. 
Hispanics. In this study, Hispanics include people who trace their origins to Latin America. The largest subgroup is of Mexican origin who call themselves Chicanos. The next largest group is Puerto Rican, Nuyoricans. The third largest group is Cuban descent. The rest of the Hispanics are of Central American Origin (Guatemala, El Salvador, Honduras, etc.) and South American Origin (Colombia, Peru, Chile, Argentina, Bolivia, etc.).

Hispanic American children. Children with the following characteristics: (a) were born in the United States, (b) were ethnically identified as Hispanic, (c) came from a home where Spanish was spoken as the predominant language, and (d) can fluently speak in both English and Spanish.

Korean American children. Children with the following characteristics: (a) were born in the United States, (b) were ethnically identified as Korean, (c) came from a home where Korean was spoken as the predominant language, and (d) can fluently speak in both English and Korean.

Metacognition. Metacognition is awareness and knowledge of one's mental processes such that one can monitor, regulate, and direct them to a desired end; and it consists of both metacognitive knowledge and metacognitive experiences (Flavell, 1987; Brown, 1987).

Comprehension. Comprehension is a process in which the reader constructs meaning in interacting with text through a combination of prior knowledge and previous experience (Ruddell \& Ruddell, 1994) and creates meaning in response to text (McNeil, 
1992). In this study, total comprehension score means combined scores of the math comprehension and the reading comprehension.

\section{Assumptions of the Study}

Hispanics include people who trace their origins to Latin America and consist of four subgroups, i.e., Mexican, Puerto Rican, Cuban, and Central/South American Origin. These four subgroups will not be different in language and cultural background.

Randomly selected children in this study will be representative of Korean American or Hispanic American children, who are middle socio-economic status and can speak both native language (i.e., Korean or Spanish) and English. All participants (i.e., parents, children, teacher, and rater) in this study will answer the questions and fill out the forms sincerely and honestly.

\section{Limitation of the Study}

This study is limited by focusing on only Korean American and Hispanic American bilingual children from ages five to seven. The sample size may limit the generalization of the results to the population in other parts of the country. Subjects' ethnicity may also limit the validity of comprehension test scores for Hispanic American children due to cultural bias and translation of stories from Korean to English.

It is very difficult to measure the socio-economic status of a child because there are many other factors that contribute to the SES level. One factor (i.e., family monthly income) is considered in this study and is the best available factor to measure child's SES level. 


\section{Summary}

Integrating subjects gives children the opportunity to reinforce and deepen their comprehension. It improves children's abilities to apply a concept or skill in multiple ways. Traditional math curriculum consisted of instruction in finding correct answers to math problems and memorizing math skills. The primary goal of this study was to investigate reading comprehension and the acquisition of mathematical concepts through the use of math stories with bilingual children. The findings of this study will help educational practitioners determine what kinds of mathematical concepts and story structural elements are considered when creating math stories, while considering children's developmental levels and ethnic backgrounds.

\section{Organization of the Remaining Chapters}

Chapter II provides a review of the literature and prior research regarding the theoretical basis of narrative comprehension, mathematical teaching and learning, bilingualism and comprehension, and the rationale for integration of literature and mathematics. Chapter III describes the research methods, design, and procedures of the study. This includes selection of participants, research design, instruments and materials, data collection procedure, and data analyses. Chapter IV presents the results of the data analyses based on the six questions of this study. Chapter $\mathrm{V}$ discusses the major findings of the study and provides conclusions, implications for the practitioners, and suggestions for future research. 


\section{CHAPTER II \\ REVIEW OF LITERATURE}

Literacy has been defined in ways that reflect the nature of the times. By the early 1900 s, literacy was referred as the printed word. It was defined as the ability to read and write. In the later 1900s, the term literacy included all activities for effective functioning in the community. It encompassed the following: (a) the capacity to accomplish a wide range of reading, writing, and speaking, (b) the awareness of numbers, logic, and mathematical operations, and (c) other language tasks associated with everyday life (UNESCO, 1978; National Research Council, 1989; National Literacy Standards for Language Arts, 1996).

While the nature of literature evolved, the social structure of the United States continued to be a mosaic of ethnic, cultural and linguistic diversity with society shifting from the industrial to the informational orientation. The availability of new technologies has also required a broader view of school curriculum and instruction (Romberg, 1990). Schools also gained greater ethnic and language diversity. Some researchers suggested that language minority children who speak a language other than English or who are exposed to a language other than English in the home might be educationally disadvantaged (Turnbull, Turnbull, Shank, Smith, \& Leal, 2001).

Providing all children with adequate and equitable educational services as required by federal, state, and city mandates became a challenge (Garcia, 2001). Research studies and documentations have verified a disproportionate number of school-age 
language minority children placed in special education programs (Harry, 1997; Artiles \& Trent, 1994; Gottlieb, Alter, Gottlieb, \& Wishner, 1994; Baca \& Cervantes, 1998).

Particularly, Hispanic children were identified as being over-represented in special education programs. They were placed in special education programs six times more often than the non-Hispanic population (Garcia, 1997). According to Ortiz and Yates (1988), educators need to determine a range of other characteristics for language minority children (i.e., linguistic, cultural, and other backgrounds) that might influence the educational requirement for these children. Educators realized that mathematics and language are an integral part of children's daily lives in that they serve as a communication system, an essential part of the stories they read and tell, and as tools to help students find meaning in their real lives (Larson, 1992; Karp, 1994).

Traditionally mathematics has been taught apart from other subject areas and from the events of daily living. This narrow-minded vision prevented educators from conveying the importance of mathematical concepts (Kleiman, 1991). In contrast, numerous studies have shown that children's literature provides a meaningful context for mathematics teaching and learning (Lewis, Long, \& Mackay, 1993; Whitin \& Gray, 1994).

Many teachers have integrated children's literature and mathematics using essentially compelling themes. This integration of math and literature has led to linking math with other subject areas. Integrating curriculum was a popular teaching strategy, but it needed research (Kain, 1993). It was the rationale for integrating curricula that allowed children to make their own senses and connection among concepts (Pate, 
Homestead, \& McGinnis, 1997). The use of children's literature in mathematics enriches children's learning and it enhances both reading comprehension in language arts and problem solving ability in mathematics (Gailey, 1993). It also increases children's motivation for math problem solving and the achievement in mathematics (Jennings, Jennings, Richy, \& Dixon-Krauss, 1992).

This literature review presents the rationale for investigating reading comprehension and the acquisition of mathematical concepts through the use of math stories with bilingual children. The literature review focuses on the following: (a) the theoretical basis of narrative comprehension, (b) mathematical teaching and learning, (c) comprehension for bilingual children, and (d) the rationale for integration of literature and mathematics. The review ends with the research that investigates use of math storybooks to develop mathematical concepts.

\section{The Theoretical Basis of Narrative Comprehension}

The conception of narrative comprehension has shifted from the idea that readers try to find author's intent and text meaning to the notion that readers create meaning beyond the text meaning (McNeil, 1992). There are four views on how comprehension has been conceived in the theory and curriculum of reading. In the transmission view, dominant until the $19^{\text {th }}$ century, the author was the key and the focus of meaning. Most emphasis was placed on the ability to retell the written text from memory and to obtain the author's intent. In the translation view, popular in the early 1900 s, focus shifted away from the author's meaning to the reader's translation of text into meaning. By 1970 , the interactive view regarded meaning as a product of the information in the text and the 
reader's prior knowledge. Schema theory and metacognition are concepts that explained the interactive view. The transactional view is now on the cutting edge of theory and practice. This view emphasizes subjective and individual responses to literature for selfactualization. Reader-Response theory underlies this conception. It emphasizes the value of literature to actualize the reader's own purposes (Bogdan and Straw, 1990).

\section{Reading Comprehension Theories}

The reading process depicted the act of reading as a communication event between the author and the reader. The models for reading process were developed to describe the way readers use language information to get or construct meaning from print. How a reader translated print to meaning was the key issue in the building of reading comprehension theories. This issue led to the development of three classes of models: (a) theoretical models of the reading process, (b) reader response theory, and (c) schema theory.

Reading process theories. There are three theoretical models of the reading process, bottom-up, top-down, and interactive. The bottom-up model assumes that the process of translating print to meaning begins with the print. The process of translating print to meaning is initiated by decoding graphic symbols into sounds; and reading involved a series of steps that occur within milliseconds in the mind of the reader (Gough, 1985). In this model, readers must learn to process graphophonemic information so rapidly that they are free to direct attention to comprehending the text materials for meaning (Samuels, 1994). 
The top-down model assumes that the process of translating print to meaning begins with the reader's prior knowledge and experience in relation to the author's message. The process is initiated by using prior knowledge and graphophonemic information to make predictions about the meaning of some unit of print. Readers decode graphic symbols into sounds to test hypotheses about meaning (Kamil \& Pearson, 1979).

The interactive model assumes that the process of translating print to meaning involves making use of both prior knowledge and print. The process is initiated by making predictions about meaning and/or decoding graphic symbols. The reader formulates hypotheses based on the interaction of information from semantic, syntactic, and graphophonemic sources of information (Kamil \& Pearson, 1979).

Reader response theory. Literature works not only in lessons designed to modify attitudes or as didactic materials but it also represents potentiality of possible meanings that might be derived (Iser, 1978). From a reader-response perspective, literature is viewed as an opportunity for a literary experience, and reading is viewed as a complex act involving the reader, the context, and the text. The text is a set of symbols, which serves as a blueprint for the reader's experiences.

Rosenblatt $(1978,1991)$ suggested that readers who become personally involved in a story could obtain a higher level of comprehension than those who were not involved, and she identified two stances from which readers engaged in the text. Readers could experience either an efferent or an aesthetic transaction and move between the two ends of the continuum. These stances have different purposes and influence the way readers responded to the text. The efferent stance is an instructional perspective based on 
the belief that the literature under consideration was for the purpose of retaining information. It focuses the reader's thinking on content and the analytical search for information to be retained. An aesthetic stance draws the reader into the text and is for comprehension, enjoyment, and appreciation. Both aesthetic and efferent stances are legitimate and useful instructional approaches teachers can adopt, depending on their instructional goals and objectives (Leal, 1993; Lehman \& Scharer, 1996).

Children reflect on their personal life experiences through listening to stories and respond differently according to their cultural awareness (Galda, 1990; Young, 1999). Research has revealed a significant relationship between the reader's culture and his or her literary response. Racial imagery and cultural themes are related to the recall and comprehension of the story (Baker 1990; Hopper-Weil, 1989; Lee, 1985; Noda, 1980). Ethnicity also plays on a reader's comprehension of text (Harris, Lee, Hensley, \& Schoen, 1988; Nelson, 1987; Steffensen, Joag-Dev, \& Anderson, 1979).

A preliminary study (Dixon-Krauss, Harlin, \& Chae, 2002) focused on Hispanic, African American, Anglo and Asian children's reading comprehension, metacognitive, and aesthetic responses to multicultural realistic fiction picture books. The sample included 255 K-3rd grade children in public urban elementary schools. Preservice teachers read eight multicultural books to the children, presenting one story with discussion session per week. Three open-ended questions (e.g., story comprehension, affective responses, and metacognitive responses) were discussed after reading. Results indicated that emotional responses of Asian and Hispanic children were related to the 
language used in the text. As age increased, children increased in the number of responses containing incidents from their own specific life experiences.

Altieri (1996) reported that the culture and ethnicities portrayed in the story did not play a significant role in the level of aesthetic involvement demonstrated in response to the stories. Although culture played a significant role in reflections on the story world, culture did not have an influence on readers' decisions to mention specific parts, to make judgments, to apply an element to the real world, or to draw inferences.

Bourg and Stephenson (1997) conducted a study to investigate how readers connect event categories to comprehend character's emotion. They found that the responses of adults and children were similar but not identical. The adults rated reactions as the most important event category in causing emotion, indicating that goals and successful or unsuccessful outcomes were more important than settings, attempts, and neutral outcomes. The children also rated goals, successful or unsuccessful attempts, and reactions higher in causing emotion than settings, attempts, and neutral outcomes. However, a developmental difference emerged in response to character's reactions. Adults rated character's reactions as more important than either goals or outcomes, while children did not.

Mikkelsen (1983) conducted a study to find the patterns of story development in children's responses to literature. Fifteen children from ages seven to ten were asked to retell and write their own stories after reading folk tales. There was a mixture of plot, setting, story situation, or characters from several outside sources. All children retold the story in intricate ways to fuse traditional literary elements with material from their own 
experiences. Maturation, however, appeared to play an important part in children's retelling of literature. Older children produced more blending and transformations while the young ones relied more on borrowings and recreations. Mikkelsen (1983) concluded that children showed a gradual developmental progression from borrowing and recreating to blending and transforming. Blending appeared to be a bridge between reliance on an author's ideas and independence in the creative process.

Schema theory. Schema theory has a special relevance for teachers of reading comprehension in that it questions the conventional view that readers should learn to reproduce the statements in text. The printed words evoke the reader's experiences and repeated experiences that represented a generalized knowledge of how stories are structured and how they proceed. This sense of structure and process is called a schema (Mandler, 1983; McConaughy, 1980). Reader's schema also defined the interrelationships between underlying components and enabled elements to be interpreted in the appropriate context (Adams \& Collins, 1985).

Unless the proper experience or schema is brought to mind, the information will not be assimilated as intended. Children are able to read a text when they could match the concept of the text to their schema for processing it. Story schema typically includes a reader's concept of plot, setting, character and theme, all of which led to the goal of the story as seen in its resolution of the problem (Thorndyke, 1977).

Readers developed a story schema that represented their concept of how a typical story was structured from beginning to end (Mandler, 1983; McConaughy, 1980, 1985); they used this schema to understand and remember stories that they had read or heard and 
to predict what would happen in other, similar stories (McConaughy, 1985). The reader's schema is limited by the attributes associated with a concept, and it signals the reader about which characteristics to notice and what their values are apt to be. It allows the reader to develop expectations, constructs for what he or she is likely to encounter, and options for how to deal with the material to be processed. (Thorndyke, 1984).

McNeil (1992) classified schemata into three levels: (a) Domain is knowledge of specific topics, concepts, or processes for reading a particular subject matter, (b) General world knowledge is understanding social relationships, causes, and activities that were common to many specific situations and domains, and (c) Knowledge of rhetorical structures is the conventions for organizing and signaling the organization of texts.

Bartlett (1932) conducted a multicultural study in reader response and reading comprehension. He emphasized the influence of culture-specific schemata on reading comprehension. He insisted that readers comprehend difficult portions of text in ways that make them compatible with their existing schema. He examined different individuals' reactions to eight culturally diverse short stories and found that readers transformed the information presented in the story to preformed habit patterns and beliefs. Readers understand the meaning of the text according to previously stored memories and socialization patterns,

Riley, Greeno, and Heller (1982) conducted a study to find developmental differences in children's schema. They found that children in grades K-3 all performed well on cause/change problems. Children in grades $\mathrm{K}$ and 1 performed poorly on 
combination and comparison problems, while children in grades 2 and 3 performed well on both of them.

McConaughy (1982) conducted a study to investigate whether the comprehension problems of poor readers would be explained by qualitative differences in the organization of their internal schema as compared to those of good readers. Twenty-one good and poor sixth grade readers were asked to summarize important information in a different short story presented for each condition and then tested for recall. There were four modality combinations for input and output: (a) listening and oral recall, (b) reading and recall, (c) listening and written recall, and (d) reading and written recall. Results showed that there were no significant differences between groups related to modality. Poor readers' patterns of comprehension were similar to those of good readers in terms of the quality of story schema represented, the number and types of inferences drawn, and the selection of important information in the hierarchical structures of the stories.

Turetzky (1982) investigated the effect of story grammar and schema-related questions in improvement of reading comprehension. Thirty-three fifth grade children were introduced to the concepts and categories of story grammar, (i. e., setting, initiating events, responses, reactions, outcomes, theme, plot, and characterization). Children learned to identify the various story categories by analyzing nine short stories, completing a story plot structure chart, and composing a story literary element to fit the category highlighted at each session. The results showed that the high level reading group went from a pretest mean of 3.29 wrong to a posttest mean of 1.4 wrong and the low reading group went from a pretest mean of 3.44 wrong to a posttest mean of 2.41 wrong. 
This suggests that reading comprehension is improved when story grammar is taught using questions that are related to the story schema.

Pearson, Hansen, and Gordon (1979) conducted a study to find the applicability of schema-theoretic notions to children's comprehension of textually explicit and inferable information. Second grade readers with strong and weak schema for knowledge about spiders read a passage about spiders and responded to the questions which stated both information and knowledge that had to be inferred from the text. They found that prior knowledge was important to the comprehension of inferable knowledge but not on explicitly stated information.

Whaley and Spiegel (1982) conducted a study to determine the interrelationships between story schema and reading comprehension. Twenty fourth-graders with poor story concepts were asked to assess if an instruction in narrative schema would enhance children's knowledge of story structure and reading comprehension. Half of them were a control group and received dictionary and word study instruction, and others were placed in the experimental group and received intensive instruction in narrative structure. All children were administered knowledge of story structure tasks and comprehension measures at two points in the study. The results showed that instruction in schematic aspects of narratives had a strong positive effect on reading comprehension and enhanced knowledge of story structure for both average and below average readers. The findings suggest that instruction in schematic aspects of narratives could be powerful tools to develop instructions in reading comprehension. 
Paris (1975) conducted three studies designed to determine whether there are agerelated differences in children's memory for implicit and explicit information in prose. In the first study, six experimental paragraphs were read individually to a total of sixty children in grades K-5. Each child was asked four verbatim recall questions and four inferential questions. The second study used verbatim recall questions with nouns and verbs. Forty-eight children in grades $\mathrm{K}, 2$, and 4 were administered the same tasks as in the first study plus a delayed free recall task. The third study used a cued recall paradigm to determine whether the spontaneity of inference drawing was related to age. Children in grades 1,3 , and 5 heard action sentences with the instruments used stated explicitly in half of the sentences and only implied in the other half. They were then given a cued recall test, which included the appropriate instrument nouns. The results indicate that the amount of both explicit and implicit information comprehended from the paragraphs increases with age, and that children apply inferential operations more often and effectively with increasing age.

Slackman and Hudson (1984) conducted a study to investigate preschool and first-grade children's ability to draw script-based inferences and text-based inferences in comprehension of stories they heard. In two experiments, children were asked to recall brief stories and to answer two inference questions (i.e., script inference question and text inference question). A script inference question required children to fill in information about the event that was not specifically stated in the story, but a text inference question asked them to infer relationships between story propositions that could not be inferred on the basis of event knowledge alone. In one experiment the text inference question 
required a propositional inference on the basis of two premise statements in the story. In the other experiment the text inference question required an invited inference based on children's real world knowledge. Results showed that children from ages four to six were better able to draw inferences based on schematically organized event knowledge than inferences requiring the construction of relationships between propositions not already represented in a schema. This study suggests that development of inferential processing in oral text comprehension is characterized as a progression from the automatic use of a familiar schema to a more deductive reasoning one.

Story Structure and Reading Comprehension

Children can be successful in reading texts, which include story structures defined by story grammar, when the text matches their personal story structures (Mandler, 1978; Brennan et al., 1986). There are two aspects of finding a structural property in the story. The first structural property is the number of causal relations linking a given event to other events in the story. Most story events have at least one causal connection to other events in the story through antecedents or consequences. Some events have more connections than others. The more connections an event has, the more essential it is to the coherence of the story (van den Broek, 1997).

The second relevant structural property of stories is the content of the event. Event content can be categorized based on story grammar theories. Different theories are based on slightly different categories, but most include the following categories: setting information, goals, attempts, outcomes, and reactions. In the setting events, protagonists are introduced and story circumstances are explained. A goal is established and it 
motivates actions. As a result of the actions, an outcome eventually resulted. Any of these events may elicit a reaction, which is a response to other story events. Several occurrences of each story structural category were present in most stories (Mandler \& Johnson, 1977; Stein \& Glenn, 1979).

The ability to understand the causal relations among story events has been the focus of many theories of reading comprehension (Ackerman, Silver, \& Glickman, 1990; Graesser \& Clark, 1997; Trabasso \& Nickels, 1992). The number of causal connections associated with an event and the story grammar category of the event are also used as a basis for judging how well children comprehend the stories (Trabasso \& Sperry, 1985; van den Broek, 1988, 1989).

In order to create a connected relation, a reader must integrate discrete events into a related network by determining how the story events are connected to one another. A network model shows a representation of the different types of story events, how the events are related to one another, and how the relations among events combine to form a coherent story. In the network model, the events in a story are represented as nodes and these nodes are connected to one another through links, which represent the causal relations among the events (Trabasso \& van den Broek, 1985; Trabasso, van den Broek, $\&$ Suh, 1989; van den Broek, 1990).

Trabasso (1989) conducted a study to examine how global coherence in reading comprehension developed in children through causal inference, and he analyzed stories of contrasting structure by a causal network model. The results showed that children understood the roles of goals in motivating actions locally within an episode by the age of 
five, and integration within episodes by eight years of age. However, from ages eight to eleven, changes in the understanding of how states and actions were related across episodes become more marked. By age fourteen, story structures became more important. These findings indicate that development of reading comprehension follows a sequence.

The studies related to reading comprehension have shown that sensitivity to the importance of causal connections and story grammar category increase with age. Younger children are less able than mature readers to utilize story structure variables to determine the cause and effect of the story (van den Broek, 1997). Story structure knowledge, phonemic knowledge, and listening comprehension are increased dramatically with age and these factors are important for younger children's comprehension and recall of information from the stories (Bell \& Clark, 1998). Reading Comprehension and Skills by Age and Ethnicity

There are significant developmental differences in the quantity and quality of children's understanding of text. Younger children sometimes referred to characters' intentions or feelings, but they more frequently focused on outcomes. Younger children do not use causal relations in text as well as older children (van den Broek, 1989, 1997). They were less competent than older children and adults in the ability to understand the unseen, psychological component of emotion. They do not perform as well as the older children, but they are able to answer correctly many of the questions testing knowledge of internal responses (Harris \& Olthof, 1982, Haris, 1985). It is not that the younger children are unable to comprehend the motives and intentions of the story characters, but they place relatively less importance on them than do the older children. 
There are significant age-related differences in word recognition and comprehension performance. At kindergarten entry, sixty-seven percent of kindergartners recognized their letters and they understood the letter-sound relationship. At first grade, fifty percent of them grasped words in context and most first grade children understood these reading skills and recognized common words by sight (Denton \& West, 2002). Older children had better awareness of story structure and inferences during listening to the story as compared to younger children, and they also recall outcomes and the primary goal of the story character more often than other types of events like attempts and reactions (Swanson \& Howell, 2001). Younger children do not spontaneously go beyond the information given to make and use inferences as well as older children, and they recall internal states (e.g., goals and emotions) less often than do older children (Sandora, Beck, \& McKeown, 1999; Stein \& Glenn, 1979; Trabasso, Secco, \& van den Broek, 1984; Mandler \& Johnson, 1977).

Stein and Glenn (1979) conducted a study to examine a developmental increase in sensitivity to internal states on children's recall of stories. Two short stories were read to six- and ten-year-old children, who then recalled them. They found that the older children performed better than the younger children on the recall of characters' internal responses to events. The younger children sometimes referred to characters' intentions or feelings, but they focused more on outcomes. In other words, the older children seemed to be more sensitive to the goals, feelings, and emotions of the protagonists in their free recall of stories than the younger children. Trabasso, Secco, and van den Broek (1984) reanalyzed 
Stein and Glenn's (1979) data, and found that six-year-old children recall fewer internal events, such as goals, and more action events than ten-year-old children.

van den Broek (1997) noted structural features, which define the causal relationships among events, provide coherence to stories and are considered the "cement" of narratives. By the age of eleven, children have the ability to utilize causal connections at a level virtually equal to adults, whereas the younger children demonstrate less ability to recognize and to use the causal connections present in text.

Bourg and Stephenson (1997) reported that the effect of the number of causal connections associated with a goal-attempt-outcome sequence is similar for adults and sixth graders. Sequences with more causal connections in the story are rated as more important for causing characters' emotions. Mature readers use the number of causal connections to determine which events are important to the story characters and whether individual events are important to the story plot.

Harris and Olthof (1982) suggested that younger children, under age ten, attribute emotions not to people's goals but to external events. The older children, rarely mentioned situational factors, focus on internal states and possess a more complex concept of emotion. They are aware of the association between situations and emotions and include mediating or intervening mental states as contributors to emotion.

Wilkinson (1995) conducted a study to characterize younger children's weaknesses in their knowledge and use of story structure in comprehension and recall. Eighty three-year-old children in Australia comprising of good readers and sixty poor readers participated in the study. The poor readers were divided into relatively 
homogeneous subgroups. All children listened to the three stories and retold the stories under free- and probe-recall conditions. Comparison of recalls between the good readers and each of the subgroups of poor readers showed that poor readers in two subgroups displayed reduced sensitivity to story structure. The children in the poor reader group recalled less of the overall stories, and less information from story grammar categories to vary extents. The poor readers showed patterns of category recall, which differed from those of normal readers. The results provided evidence of marked difference in poor readers' uses of story structure from those of good readers in reading comprehension and story recall.

Kintsch and Greene (1978) conducted a study to investigate the effects of story structure and cultural schema on children's story recall. They found that there were not only different cultural schema but also different story schema for different cultures. They concluded that children tended to recall best propositions with a culturally familiar story schema when accompanied by specific requests for accurate story recall and that children's familiarity with the cultural schema and story structure schema of particular texts make children reach higher reading comprehension.

Research shows that there are ethnic differences for younger children to engage in specific reading knowledge and skills. Denton and West (2002) conducted a study to find the relationships between children's literacy at kindergarten entry and their later first grade reading knowledge and skills. The sample was comprised of 22,000 children from 1,000 kindergarten programs. They reported that there were significant differences in specific reading knowledge and skills between the children from different ethnic 
backgrounds. White or Asian children were more likely to recognize sight words and to understand them in context than African American or Hispanic children. Hispanic children were more likely to demonstrate proficiency in the reading areas of beginning and ending sounds than African American children.

The Theoretical Basis of Mathematical Teaching and Learning

There are two views in mathematical teaching and learning. One is a traditional / transmissional view and the other is a constructivist view. These two views are opposite in describing how learning occurs. In the traditional view, teaching math has focused on arithmetic, and math has been viewed as the science of numbers. Children have been asked how to perform algorithms and given time to practice getting the right answer. In classes based on a transmission theory of teaching and learning, teachers offered learning to children as a fixed package. If children followed the teacher's directions and arrived at the correct/fixed answer, then it was assumed that they had learned the materials (Burns, 1992; Clements \& Battista, 1990).

Nolan and Francis (1992) identified five basic beliefs underlying a traditional mode of the teaching-learning process. These included: (a) children learn by their accumulated information and skills, (b) the teacher's role is to transmit his/her knowledge to children, (c) the teacher's main goal is to change children's behavior, (d) teaching and learning occur between the teacher and individual children, and (e) thinking and learning skills are applicable to all content areas. In practice, these beliefs made a teacher-centered classroom, and children had little opportunity for constructing their mathematical concepts and understandings. 
Baroody and Ginsburg (1990) described the traditional teaching of mathematics as a "tell-show-do" approach. The teacher told a class what children needed to know to solve a problem, then showed some examples as a model, and finally provided problems for children to practice until they mastered skills or procedure. Typically, traditional math education emphasized learning skills rather than concepts in carrying out procedures (Mills, O’Keefe, \& Whitin, 1996).

In contrast, there are other views that mathematics is more than numbers. Mathematics is a human endeavor and a communication system devised by people to meet their needs and interests of cultural changes (Whitin \& Wilde, 1992). In a constructivist view, children are required to actively construct knowledge to update it through an interaction of their prior knowledge, beliefs, and new information with their environment rather than passively receiving it (Ball, 1988; Davis, Mahar, \& Noddings, 1990; Noddings, 1990). Children need opportunities to invent their own procedures for developing algorithms rather than following those outlined by a teacher (Kamii, Lewis, \& Livingston 1993). This view implies that math is something a person creates with others, something one constructs, and also something that requires the use of imagination.

It is difficult for teachers to shift from a traditional behaviorist model to a cognitive model because they do not understand how children learn mathematical concepts. In the traditional model, teachers focus their ideas on sequenced procedures outlined in texts, and they do not provide opportunities for children to construct mathematical understanding. Rather than asking questions for fixed or correct answers, 
teachers must provide opportunities and stimulations for children to construct their own mathematical ideas (Battista, 1994; Schifter \& Simon, 1992).

\section{Constructivism and Mathematics}

Constructivism is an epistemological theory that has become the focus of research and discussion in mathematics education. It is based on the philosophical view that human beings have no access to reality. Rather they construct knowledge of the world from their perceptions and prior experiences. Learning is the process by which human beings adapt to their experiential world (Davis, Mahar, \& Noddings, 1990).

Constructivists assume that children naturally construct knowledge as an interrelated whole. Children are limited by the constraints of their current developmental level. Constructing knowledge is an involving and engaging process for all learning areas. It is true even for mathematics that has traditionally been viewed as a subject where learning is equivalent to memorizing a series of steps and facts (Simon, 1995).

Confrey (1990) defined constructivism as a belief that all knowledge is necessarily a product of humans' cognitive acts, and humans cannot have direct or mediated knowledge of any external or objective reality. People could connect new experiences with previous experiences. They try to make sense and connections out of their new experiences by relating them in some way to what they already know. They can revise their thoughts, can make meanings, and can build or create knowledge from their experiences. 
Educators, philosophers, and psychologists have been interested in the topic of research and reflection on how individuals' actions or social interactions affect the acquisition of new knowledge. While there are many interpretations about what constructivism means, there is agreement on two key aspects. The first aspect is that learning is a process of active construction and the second is that learning processes results in qualitative change in understanding (Prawat, 1995). Piaget, Dewey, and Vygotsky have been consistently cited as foundational figures in the dialogue on social constructivism (Ginsburg, 1981).

Piaget. According to Piaget, all knowledge is constructed as a result of a child's action (Wadsworth, 1995). He developed a theory that explains the stages through which children proceed as they develop physical and logico-mathematical knowledge. He also provided the rationale for developing learning environments in which children construct their own knowledge from the inside, through mental activity and in interaction with their environments (Piaget \& Inhelder, 1969; Kamii, 1982).

Mackay (1983) described that Piaget's theory of cognitive development as occurring naturally and as a result of experiencing the world and reflecting on one's experiences. In the early stages of life, many experiences are concrete, based on interaction with objects. Active involvement is a key to the idea of constructivism, and learning is most effective when learners are active participants.

Piaget's work focused on individual intellectual construction without answering questions of how social or cultural influences affected construction (Saxe, Gearhart, 
Note, \& Paduano, 1993). Children can create and construct their own mathematical understandings through collaborating with others, but not in isolation. They interact and verbalize ideas as part of their construction process that broaden and deepen their understandings (Yackel, Cobb, Wood, Wheatley, \& Merkel, 1990). This suggestion is directly supported by the work of Dewey, Vygotsky, and others who applied constructivism to mathematics education.

Dewey. Dewey insisted that education is not a matter of telling and being told in learning, but a constructive process in which children are actively involved (Dewey, 1916). His approach to education is referred to as "learning by doing." His idea is based on the belief that learning occurs when children are actively engaged in socially purposeful activity that has meaning to them. He emphasized the role that communication played in making meaning. He defined society as a number of people held together because they are working along common lines in a common spirit with reference to common aims. A key component of construction is the communication between individuals who are engaged in the learning process. Dewey believed that making meaning occurs through interactions between individuals engaged in purposeful activity. He also stated the role of experience and communication in how individuals construct knowledge, suggesting that learning occurs when lessons are developed with an understanding of children's developmental stages and prior experiences.

Garrison (1994), stating that meaning can be constructed through purposeful activities, emphasized the language factor because it implies two selves involved in a conjoint or shared understanding. These activities are socially relevant to (a) children's 
participation in society, and (b) children's concrete experience with the world that provides a personally meaningful basis for learning.

Prawat (1995) insisted that there exists a triangular relationship between the individual, the community, and the world mediated by socially constructed ideas. $\mathrm{He}$ explained that "knowing is an act of going between" (p. 15). This "going between" is the place where individuals construct their new knowledge and where individuals communicated, interacted and refined their ideas and experiences with others.

Vygotsky. Vygotsky is a theorist who focused on understanding the social and cultural aspects of children's thinking. He insisted that social interaction is a key to the learning process and development is a learning process driven by social interactions with more knowing, experienced others. Children learn more from activities or experiences when they collaborate with others (Vygotsky, 1978). He also suggested there are two types of concepts that learners construct in their cognitive development. One is a spontaneous concept and the other is a scientific concept. A spontaneous concept occurs in an early stage of concept development and it developed primarily through children's play. Children construct a fundamental definition of concept from everyday experiences. In contrast, a scientific concept is formed from structured activity such as classroom instruction. It is a culturally agreed upon, formalized, and more abstract concept (Vygotsky, 1986; Fosnot, 1996).

Vygotsky (1978) maintained that the child follows and works through the adult's example and gradually develops the ability to do certain tasks without assistance. The Zone of Proximal Development (ZPD) is the difference between what a child can do 
alone and what he/she can do by collaborating with more experienced others. It would be the place where spontaneous concepts are transformed or become scientific concepts through interaction with a more experienced peer or adult (Vygotsky, 1978). Vygotsky's zone places communication and social life at the center of meaning making, which occurs through the interactions that individuals engaged in the ZPD (Lerman, 1996).

Carraher $(1989$, p. 320$)$ described mathematical knowledge is a cultural practice in which people become more proficient as they learn and understand particular ways of representing numbers, quantity, and the specific mathematical operations. From this perspective, learning is actually a process of enculturation. Children can acquire mathematical knowledge through their participation in cultural practices and can examine objects that lead them to a beginning understanding of the objects' uses and properties. However, it is through modeling or discussion with an experienced peer or adult that they learned the social and cultural applications for this object (Saxe, 1991; Cobb, 1994).

\section{Constructivism and Mathematics Learning Model}

There have been intense debates among theorists about the role of an individual and the role of the community in constructing mathematical concepts. Radical constructivists tied to the work of Piaget focused on the individual's role, but social constructivists, identified with Dewey and Vygotsky, emphasized the role of the community in developing opportunity for constructing mathematical knowledge.

Constructivist theory implies that children construct knowledge from their experiences. Purpose and meaning are developed through participation in a community, and an individual's cognitive structure cannot be understood without observing it 
interacting in a context (Fosnot, 1996). Children actively construct their mathematical knowledge within the context of their lives, so their daily living situations can be effective activities for fostering construction of their mathematical knowledge (Kamii \& Lewis, 1990).

Pirie and Kieren (1992) suggested that a teacher's role in mathematics instruction was to create a constructivist climate. They identified four key principles for teachers to effectively create a constructivist climate. The four principles are: (a) understanding that children's mathematical learning progresses at various rates resulting in different levels of achievement, (b) acceptance that children travel different routes to gain mathematical understanding, (c) awareness that individuals hold different mathematical understandings, and (d) knowledge that understanding is changeable.

Wood (1993) emphasized that learning occurs over time through conflict, confusion and social interaction. Children should actively engage in solving problematic situations. Teachers should validate children's approaches to solving the problems and should recognize that children's errors are reflections of their current level of understanding.

Frye (1989) provided a more concrete list of activities that could be easily incorporated into a constructivist environment. She stated that children need not only to use calculators and computers, but they also must engage in activities that include hypothesizing and testing, problem posing, experience, and applying their experiences to the mathematics. 
Mathematical Knowledge and Skills by Age

Early mathematical concepts are important for the learning of basic mathematical skills and the development of further mathematical knowledge. The development of basic mathematical skills means the acquisition of problem solving procedures and the development of memory representations for basic number facts (Geary, Bow-Thomas, \& Yao, 1992; Temple, 1991). Lack of early mathematical concepts might result in rushing the child through the rote learning skills and this in turn may negatively affect the development of logical thinking skills (Kirova \& Bhargava, 2002). These can cause a failure to connect concrete and abstract mathematical knowledge and result in early learning problems (Geary, Bow-Thomas, \& Yao, 1992; Temple, 1991).

Mathematical concepts develop at different times and rates for each child. It is difficult to identify any particular moment in a child's life when the first numerical concepts are acquired. Children's mathematical concepts are developed imperceptibly, and the understanding of mathematical concepts by the child is a gradual process (Kennedy, 1984).

Although the responses of younger children are not always accurate, they may be aware of the math principles involved in counting and may understand the process of counting objects (Gelman \& Gallistel, 1978). Most children possess the understanding of some mathematical concepts at an early age. Even preschoolers have considerable mathematical knowledge of basic arithmetical operation and enumeration. Children are able to count and compare simple sets of objects before they receive formal instruction in mathematics (Nunes, 1995; Resnick, 1986; Klein \& Starkey, 1988). But researchers do 
not have enough information about the reasons for ethnic differences in the mathematical knowledge before children begin their formal education.

The early mathematical concepts acquired during the preschool and primary grades are matching, classification, comparing, and ordering or seriation. From a Piagetian perspective, six pre-number concepts that might be added to counting skills are discrete/continuous, matching/comparison, classification, patterns, seriation, and spatial relationships (Kennedy, 1984; van de Rijt \& van Luit, 1998).

Discrete materials are items that can be counted such as coins and pencils and continuous materials are those that are measured such as cans of water. This concept could be used for other pre-number concepts. Matching and comparison refine children's understanding of as many as, more than, and fewer than relationships. Piaget concluded that the inability to grasp the relativity of notions or ideas was one of the principal obstacles to the development of the child's reasoning. Classification skill is the ability to arrange objects in a class or subclass and begins in preschool, kindergarten, and first grade, where children classify objects according to shape, color, size, thickness, etc. Knowledge of classification schemes and processes is an important characteristic of a good problem solver. Patterns are common in mathematics. As children work with patterns, they sharpen their perception and develop awareness of order, sequence, shapes, and aesthetics. Seriation is the ability to order and sequence, and it requires an understanding of inclusion relations. This concept is developed usually at ages seven and eight. Psychological structures such as reversibility and transitivity are highly related to the problems of seriation and ordering. Spatial relationships lead children to understand 
the terms like, around, under, through, far, near, left, right, etc. (Kennedy, 1984; van de Rijt \& van Luit, 1998).

Children enter kindergarten and first grade with various number experiences and different foundational number skills. Counting is one of the first number ideas taught to children but the numbers they recited have little meaning for them. Children learn many things about the physical world in which they lived before they abstract the idea of number. The concept of place-value refers to the numeration value of each place in a number. It is fundamental to understand the operations of addition and multiplication, but most children in initial stages have a poor understanding of place-value. When numerals are written in combination, not only each numeral represent a number itself but also their positions take on value that are some multiples of ten (Labinowicz, 1980). This implies that children need many experiences with grouping before they learn the concept of place-value.

Denton and West (2002) reported that at kindergarten, eighty-eight percent of kindergarteners understood the concept of relative size. They could use nonstandard units of length to compare objects. By the spring of first grade, most children, ninety-six percent, have mastered order and sequence and understand the relative position of objects. Seventy-six percent of first graders become proficient in addition and subtraction with basic whole units.

Mathematical Knowledge and Skills by Ethnicity and Culture

Children grow up in diverse cultures, but mathematical events and phenomena seem to be universal in children's development of mathematical understanding (Ginsburg 
\& Baron, 1993). Children's informal mathematics varied in the rate of its development, however, the acquisition of mathematical principles was invariant and universal (Song \& Ginsburg, 1987). The two reports, America's Kindergartners (West, Denton, \& GerminoHausken, 2000) and The Kindergarten Year (West, Denton, \& Reaney, 2001), revealed that the mathematical knowledge of first-time kindergartners differs in relation to their ages at school entry, ethnicity, home educational experiences, and child care histories.

There are ethnic differences for younger children in the development of mathematical knowledge and skills. Asian children perform on mathematical tasks at higher levels than do American children before receiving formal education in mathematics (Geary, Bow-Thomas, Fan, \& Siegler, 1993; Miura, 1987; Song \& Ginsburg, 1987). Denton and West (2002) explored how children's literacy at kindergarten entry relates to their first grade reading and mathematical knowledge and skills by ethnicity. The sample was comprised of 22,000 children from 1,000 kindergarten programs in the United States. They reported that there were significant differences in specific mathematical knowledge and skills by children's ethnicity. White or Asian children were more likely to be successful in problem solving in addition, subtraction, multiplication, and division than African American or Hispanic children. Hispanic children were more likely to demonstrate proficiency in particular mathematical areas than African American children.

Guberman (1994) conducted a study to find how cultural factors influence children's mathematical achievements. Latino and Korean American children in Grade 13 participated in the study. The results showed that both Latino and Korean American 
children engaged in mathematical activities. Cultural values are associated with differences in out-of-school uses of mathematics. Korean American children more often engaged in formal activities that supported the mathematics they were learning in school. In contrast, Latino children often engaged in activities that employed informal mathematics.

There are also ethnic differences in the attitudes toward mathematics. Garner (1963) reported that the attitude toward mathematics of Whites was significantly higher than that of Hispanics among first year algebra students. For Hispanic students, there was a positive correlation between the teachers' attitudes and the attitudes of their students.

Collins (1992) examined the attitude toward mathematics of various ethnic groups. The Revised Aiken-Dreger Math Attitude Scale (Aiken \& Dreger, 1961) was administered to 480 seventh- and eighth-grade children. This instrument contains two subscales of 10 test items each and assesses students' enjoyment of mathematics and their perceptions of its value as a subject area. The results showed that the Asian American outscored White at the upper grade levels and the mean scores for the Asian American on the pleasure portion of attitude were significantly different from the same measures of White and Hispanic. Asian American children had significantly lower scores on the test items relating to apprehension attitude than any of the ethnic groups except African Americans. The higher means for the Asian American children on the pleasure portion indicate that these children are associating more pleasure with mathematics than other ethnic groups. Lower means for the Asian American children on the apprehension portion 
indicate that they are experiencing less fear or apprehension toward mathematics than those of other ethnic groups.

Cloud (2003) reported the verbal and math scores of the Scholastic Aptitude Test (SAT) by ethnicity. There were significant racial-ethnic differences in math and verbal scores. Asian $(M=575)$ and Whites $(M=534)$ scored higher in SAT I math test than Hispanic $(M=464)$ and African Americans $(M=426)$. Asian Americans have 67 points worth of gap between math and verbal scores but the other ethnic groups did not show big differences whose scores were in a range of 5-7 points.

Moore and Smith (1987) in the National Longitudinal Study reported that African American and Hispanic children were not developing mathematical competence to the same degree as White peers. The Asian American children scored slightly lower than Whites at age nine. At ages thirteen and seventeen, however, the Asian American children significantly outscored their White peers. Previous studies and reports show that mathematical knowledge and attitude toward mathematics vary across cultural/ethnic groups. These can support to lead to the hypotheses that there can be an interaction effect of children's ethnic background and subject area on the comprehension scores.

Bilingualism, Cultural Knowledge, and Cognitive Development

Language is not merely a set of words or grammatical rules but it is a product of culture. It is a tool used by humans to convey meaning within a culture and to be aware of other cultures (Law, 1992; Garcia, 1994; Baker, 2000). Through language children exchange their values (Ovando, 1993), refine intellectual development, and enhance higher abstract thinking (Perez \& Torres-Guzman, 1996; Vygotsky, 1978). The 
development of children's language is continuous (Tiegerman-Farber, 1995; McLaughlin, Blanchard, \& Osani, 1995). Generally, most children by five or six years of age have mastered the basics of language to receive and express meaning, and they can communicate excellently and obviously (DeGaetano, Williams, \& Volk, 1998). Bilingualism and Cognitive Development

Bilingualism is a global phenomenon and a complex array of varieties of languages among all people. It should not be considered as a single homogeneous circumstance. Young bilingual children have one dominant language, which can be changed during childhood. Unequal exposure to the two languages causes for one language to develop faster than the other. It is rare for children to have an equal and strong competence in two languages (Baker, 2001).

Children acquire a second language simultaneously or sequentially. The process of language development also varies between children who learned two languages simultaneously and those who learned sequentially (Langdon \& Merino, 1992). When the second language is learned before three years of age, the child is a simultaneous learner. If the child acquired the second language after three years of age, the child is a sequential learner (Baker, 2000, Baca \& Cervantes, 1998).

At one time it was believed that exposure to two different languages by younger children could delay their language development and their intellectual skills (Genesee \& Nicolasis, 1995; Goodz, 1994; Fradd \& Tikunoff, 1987). However, various studies indicated that children who had learned two languages simultaneously in interactive 
contexts acquired the two languages with minimal interference (Genesee, 1988; Kessler, 1984; Goodz, 1994; Baker, 2000).

Voterra and Taeschner (1978) claimed that there are three simultaneous stages of language development. In the first stage, children's vocabularies are a mixture of nonoverlapping words from different languages (i.e., if the vocabulary is learned in one language, it is used over the corresponding word in the other language, or without regard to the situation or the audience). In the second stage, children can sort out the use of the two languages according to the audience being addressed, and they progress from the use of simpler sentence structure to more complex ones, as if only one language is being used. In the third stage, simultaneous learners sort out both the vocabularies and grammatical rules of the two languages. During this stage they restrict one language used over another, depending on the audience, and they can appropriately switch from one language to another automatically (Voterra \& Taeschner, 1978; McLaughlin, 1998).

Children taught two languages sequentially showed differences from simultaneous language learners in the rate in which they pass through these stages. In the first stage, children use their home language, even when it is not appropriate to use it. In the second stage, they are in the nonverbal period, or "silent period" in the second language setting because their home language is not enough to communicate with others in the new situation (Tabors \& Tabors, 1997; Tabors \& Snow, 1994). If children, whose first language is not English, become linguistically assimilated into the English-speaking context, they do not tend to maintain their home language. When a second language is introduced before native language skills are fully developed, children's language skills 
become limited in both. This can be problematic for younger children because they have not reached a stable level of command over their native language (Moro-Reyes, 2002).

In the third stage, children want to go public with the new language. During this stage, there are two remarkable features in their speech. One is telegraphic speech and the other is formulaic speech. In telegraphic speech, children use a few content words in an entire utterance with few function words or morphological markers (Tabors \& Snow, 1994). Children can understand more than they can express when they reach the stage of early productive language use. In time, they can understand the syntactic system of each language (DeGaetano, Williams, \& Volk, 1998).

It is difficult to determine how to measure children's bilingual competence or whether they acquire languages simultaneously or sequentially since there is uneven development in languages (Pham, 1994; Valdes \& Figueroa, 1994). Regardless of sequential or simultaneous language learners, second language learners are restricted in vocabulary acquisition (Ortiz \& Yates, 1988; Maldonado-Colon, 1986). When evaluating the primary language of sequential language learners, language loss should be also considered, since it is an important aspect of bilingual development (Langdon \& Merino, 1992; Anderson, 1991).

There has been a debate among researchers who stated that bilingualism resulted in a slower rate of vocabulary acquisition than that of monolingualism. Bilingualism had a disadvantageous effect on intellectual functioning. This is due to the fact that bilingual children have to learn two vocabularies and two language systems at the same time (Bialystok, 1988; Doyle, Champagne, \& Segalowitz, 1978). Baker (2000) said that 
bilingual children's vocabulary can be weaker if they are confined to the home and their home language is minimal. The child cannot achieve the same level of competence in the native language as a monolingual child who speaks just English. As opposed to learning only one, simultaneous language learners have to study two vocabularies and language systems at the same time. The vocabulary ability of simultaneous language learners might be limited in both languages.

However, bilingual children had an academic advantage in the domain of cognitive flexibility. Bilingualism has been linked to a variety of positive cognitive benefits, including early reading and math, improved problem-solving skills, and higher scores on the SATs. Bilingual children are more skilled at interpreting and manipulating grammar to communicate clearly and they can also strengthen family ties by allowing relatives to communicate comfortably in the native language of old family members like grandparents (Lambert, 1977; Bialystok, 2001).

The socio-cultural context is also an important factor in second language acquisition and cognitive development. If the two languages are valued enough, the bilingual experiences have a favorable influence on child's cognitive development. Compared to monolingual, bilingual experience acts as an enriching tool that leads to the more flexible cognition. When socio-cultural context is devalued in the child's environment, his cognitive development is delayed in comparison with a monolingual. In some cases, the bilingual child may not recover his or her delay (Hamers \& Blanc, 2000).

There are ethnicity differences in second language learning. Asian children prefer strategies involving rote learning and language rules to communicative strategies 
(Politzer \& McGroarty, 1985; O’Malley \& Chamot, 1990). They prefer working independently and resist social, cooperative learning, unlike Hispanic children (Reid, 1987). However, Hispanics are strongly different from Asians in strategies they used for learning second language. Asians like to choose repetitive and rote memorization learning strategies while Hispanics use more social, interactive strategies (Politzer, 1983; Oxford, 1992).

\section{Language Structures and Cognitive Aspects}

As the number of minority and second language children increases, it is critical for meaningful mathematics learning that children's actual situations should be taken from their own real world experiences. Number systems vary across time and location, and linguistic aspects in number systems are associated with younger children's mastery of mathematical concepts (Ifrah, 1985). Property of number systems may facilitate the development of children's mathematical knowledge (Miura, 1987; Miura, Okamoto, Kim, Chang, Steere, \& Fayol, 1994; Fuson \& Kwon, 1992).

The speed with which number words can be pronounced varies, and the speed is associated with children's memory span for numbers. There are structural differences in pronouncing the number words between Asian languages and European languages. Numbers are organized as structures of tens and ones in Asian languages (i.e., Chinese, Korean, Japanese), but English or Spanish is more likely to have conceptions based on single units (Stigler, Lee, \& Stevenson, 1986).

Asian languages are organized so that numerical names are congruent with the traditional ten numerical systems and spoken numbers correspond to their written form. 
Children who speak Chinese, Japanese, or Korean need to memorize the first nine number words, the words for powers of ten (i. e., ten, hundred, thousand), and the order, from the largest value to the smallest, in which words are said. Korean children master the mathematical concept of counting much earlier than do American children (Song \& Ginsburg, 1987). Korean, Chinese, and Japanese children also understand two digit numbers earlier than children in France, Sweden, and the U.S. (Miura et al., 1994). Korean children in second and third grades were more likely to identify the concept of place-value than American children (Fuson \& Kwon, 1992). In contrast, Englishspeaking children must memorize the number words from eleven through nineteen, and the decade names (i.e., twenty, thirty, etc.) through one hundred because most European systems of number words are considerably irregular through one hundred. The U.S. children were likely to use single-unit blocks in their constructions of place-value (Miura, 1987; Miura et al., 1994).

There are cognitively distinct representations of number between Asian and American children. For Asian speaking children, numbers are organized as tens and ones, and place-value is an integral part of the cognitive representation (Miura, 1987, p. 82). English or Spanish speaking children are slower to construct ten-structured number concepts because they are likely to have conceptions based on single units (Fuson \& Kwon, 1991).

\section{Cultural Knowledge and Comprehension}

There exists a relationship between a reader's culture and comprehension or recall of information from a literary text (Harris, Lee, Hensley, \& Schoen, 1988; Reynolds, 
Taylor, Steffensen, \& Anderson, 1982). Steffensen, Joag-Dev, and Anderson (1979) conducted a study to explore the effects of schemata in cross-cultural studies of reading comprehension. Their experiments involved two groups of children. They read two passages, one passage more familiar to one group's cultural background and the other passage more familiar to the second group's cultural background. They concluded that cultural knowledge is an important source of individual differences in reading comprehension.

Noda (1980) identified a list of fourteen universal cultural and aesthetic values in the stories. The results showed that American children had difficulty in emotionally entering the story and responded to only six of the fourteen Japanese cultural and aesthetic values while showing little or no knowledge of the other eight. They also tended to respond to the stories in a formal mode much more often than Japanese children. In contrast, the Japanese readers were able to respond much more extensively to the works. They acknowledged all fourteen Japanese aesthetic and cultural values. The Japanese readers not only identified the symbols and their meanings but also related the symbols to their personal experiences, cultural or social information, references to folklore, religious beliefs, and philosophical theories.

Jordan and Purves (1993) reported that children tend to respond to texts in personal ways while ignoring the cultural content. When children were asked about the cultural content of the work, they showed some discomfort in analyzing works from another culture because they have little cross-cultural competence. Beach (1994) presented a somewhat similar view of students' involvement with multicultural literature. 
The students from high school and university responded to a number of multicultural short stories. The majorities of students in both cases entered into other culture's stories on a personal basis but were unable or unwilling to take on a larger cultural perspective.

Whereas Jordan and Purves (1993) and Beach (1994) found readers to be hesitant to enter the story worlds of other cultures, Altieri (1995) reported somewhat the opposite results. The purpose of Altieri's study was to test whether the culture embodied in the text or the culture of the student would influence children's aesthetic involvement in multicultural texts. Children listened to two African American, two Hispanic, and two White stories. After listening to the stories, children responded to each story both by a free written response and by a story preference rating. Children consistently showed an aesthetic involvement with the text and culture was not a significant influence on children's ability to become aesthetically involved in a text. This occurred despite the fact that children also significantly preferred to read the literature of their own ethnic group.

Altieri (1995) also reported that both the African American and Hispanic children preferred stories from their own respective cultural group much more than the stories from the other cultural groups. The same was not true for the White children. The Whites were more homogenous than the other two groups as far as demonstrating an interest in the literature from the other two cultural groups. It becomes clear from the results of these previous studies that the nature and role of cultural influence become debatable when the research involves the study of subcultures. The combined results from the previous studies indicate that reader's specific knowledge of cultural schemata as embodied in a text is a strong indicator of comprehension level. 


\section{Rationale for Integration of Literature and Mathematics}

Symbols such as numbers and letters have meaning. Recognizing numbers is related to the mathematical ability and recognizing letters is related to reading ability. Since younger children's reading ability and mathematical ability are found to be related, it is important to consider not only children's reading skills but also their mathematical skills in conceptualizing literacy (West, Denton, \& Germino-Hausken, 2000).

Applying this philosophy to mathematical areas makes sense because concept learning can be done in context. Whole concept mathematics was focused on problem solving that was real and meaningful. It provided children with many skills and literatures to apply their knowledge to real context (Baker \& Baker, 1991; Brown, 1991). When mathematics is presented within a context, children can use it for real purposes and understand the values, the numbers, and symbols represented (Whitin, 1994).

With the use of literature, teachers can benefit in numerous ways. First, they can convey mathematical concepts to children in an easy, relaxed manner and easily followup the story with a discussion. Children can also experience an internal connection of mathematics and literature when they learn mathematical concepts without being aware of it (Lightsey, 1996). Second, math literature lessons can hold children's attention, relieve children's math anxiety, and encourage the employment of numerous teaching strategies that actively engage children. Children learn mathematical concepts with different literacy genre. Numerous children's books, poems, and rhymes may be used to teach mathematical concepts. Literature also adds an aesthetic dimension to mathematical learning (Whitin \& Wilde, 1992). 
Children's Books and Math Teaching Categories

Books for mathematical lessons should be appropriate for children's developmental levels. It is particularly important for younger children who need clear representations of concepts to select appropriate books as their mathematical understandings are just forming. When selecting mathematical concept books, teachers should examine the connection between text and illustrations, and the inclusion of developmentally appropriate concepts (Harsh, 1987; Ballenger, Benham, \& Hosticka, 1984).

According to Gailey (1993), children's books which are appropriate for teaching mathematics might be divided into four categories: (a) counting books which strengthen counting and number concepts and can be used to teach addition, subtraction, and multiplication and division, (b) number books which reinforce a particular number and help children to understand the value and position of the numbers being studied, (c) storybooks which may be used to introduce or reinforce mathematical concepts and highlight the concept of large numbers, addition, and subtraction, and (d) conceptual or informational books which are useful in deepening and extending a mathematical concepts.

The National Council of Teachers of Mathematics (NCTM) Standards

The NCTM (1989) recommended significant changes in teaching mathematics and developed standards in response to nationwide calls for reform in mathematics education due to poor math test results and the recognition of a need for new mathematics curriculum. The NCTM goals have advanced mathematical power for students to 
function as informed citizens in a rapidly changing and technologically complex society (Gailey, 1993) and have made students prepare for participation in a society that has shifted from an industrial to an informational one (Frye, 1989; Johnson, 1990).

The NCTM (2000) also developed professional principles to teach mathematics. The principles described particular features of high-quality mathematics education. The six principles for school mathematics are equity, curriculum, teaching, learning, assessment, and technology. For effective math teaching, students whose native language is not English may need special attention to allow them to participate in classroom activities. Students must also learn mathematics by building new knowledge from prior knowledge, and teachers are required to understand what students know and need to learn.

The inclusion of literature is one change that enables a more effective approach to math. Standards provide a guide for sustained efforts to improve school mathematics. The NCTM standards described what mathematics instruction should enable students to know and supplied outlines, guidance, and visions for teachers on how to integrate children's literature (i.e., reading, writing, listening, and every day languages) with mathematics (NCTM, 1989, 2000).

The NCTM (2000)'s ten standards for Pre-K through grade 2 are as follows: (a) number and operations, (b) algebra, (c) geometry, (d) measurement, (e) data analysis and probability, (f) problem solving, (g) reasoning and proof, (h) communication, (i) connections, and (j) representation (see Appendix K). The numbers and geometric standards are the core area of mathematics in the early years. Once students obtain a 
sense of numbers and geometric concepts, they can construct ideas and skills by connecting new information with their prior knowledge.

Research on Integration of Mathematics and Literature

When children have opportunities to study and apply mathematics through children's literature, they learn mathematical knowledge and skills by analyzing the information in literature (Midkiff \& Cramer, 1993; Monroe, 1996). Through math literature, children can make associations between the abstract mathematical ideas and the concrete elements provided in a story. It provides a context for strengthening and connecting links between content areas and other learning expectations (Richardson \& Monroe, 1989; Monroe, 1996).

Many studies have been done on the whole language approach of integrating mathematics and literature. The contents of literature and mathematics can be best learned not as isolated fragments of knowledge in artificially contrived situations, but as tools for constructing the active meaning. The reasons for integrating curriculum are to provide children with learning opportunities that are more like the real world, to enhance literary growth, to develop communication and problem solving skills, and to accommodate different learning styles (Burnett \& Wichman, 1997).

Math literature offers excellent means to attain these goals. It can become an essential component of a comprehensive mathematical education and a strong method for broadening mathematical thinking in the classroom and beyond. The consequence of teaching mathematics, as a series of rules to follow or facts to memorize, makes children perceive mathematics as not relevant to their own lives. Instead, they perceive 
mathematics as a contrived study of numbers and the exercise of ambiguous skills (Whitin, 1994). Hong (1996) conducted a study to examine the effect of implementing mathematics lessons integrated with a literature selection versus mathematics lessons without literature. He found that kindergarteners taught with lessons using literature spent more time in the mathematical area of the classroom and expressed liking mathematics more than children who had traditional lessons.

Denton and West (2002) studied how children's literacy at kindergarten entry related to their spring kindergarten and first grade reading and mathematical knowledge and skills. The sample was comprised of 22,000 children who attended kindergarten programs during the 1998-99 school year. They reported that children who recognize letters and understand the mathematical concept of basic numbers, shapes, and relative sizes as they enter kindergarten, show significantly higher overall reading and mathematical knowledge and skills in the kindergarten and first grade than children who do not have this knowledge. These results imply that early experiences of mathematical concepts and reading skills pave the way to success in school and enable children to solve problems and make sound decisions. This is because their experiences make them connect mathematical concepts and reading skills to their everyday lives.

Burnett and Wichman (1997) designed a study with the second graders to examine the effects of integrating children's literature with mathematics. They were interested in the effects of math anxiety on children's ability to connect mathematical ideas to their real lives. The results showed that children felt more comfortable and 
enthusiastic about learning mathematical concepts when literature and mathematics were integrated in the mathematical lessons.

Integrating multicultural literature with mathematical concepts gives children of all heritages and backgrounds access to experiences from a variety of perspectives. The social, economic, and cultural settings of books and stories are also important when children share literature with a class. Children demonstrate a need to identify with the characters and stories because they are motivated and affected by them (Price, 1994).

\section{Summary}

The review of literature presented a brief summary of the rationale for investigating reading comprehension and the acquisition of mathematical concepts through the use of math stories with bilingual children. Mathematics and language have always been an integral part of our daily lives and an essential part of the stories people read and tell. The definition of literacy is no longer the ability to read and write but has been augmented to include the tasks associated with everyday life such as: reading, writing, speaking, using logic, and applying mathematical concepts and operations. Many teachers have integrated children's literature and mathematics with many essentially compelling themes. The use of children's literature in mathematics has been shown to enhance both reading comprehension in language arts and problem solving ability in mathematics.

Though children grow up in diverse cultures, they develop similar mathematical understanding (Ginsburg \& Baron, 1993). Bilingualism is a global phenomenon that includes a complex array of a variety of language among all people. Bilingual children 
have demonstrated an academic advantage in the domain of cognitive flexibility including early reading and math, and improved problem-solving skills (Bialystok, 2001). Since younger children's reading ability and mathematical ability are also highly related, not only children's reading ability but also their mathematical skills should be considered in conceptualizing literacy. 


\section{CHAPTER III}

\section{METHODS}

The purpose of this study was to explore the effects of math storybooks on bilingual children's math and reading comprehension and how these effects vary with age and ethnicity. Specifically, this research was designed to identify how math stories impact children's reading comprehension and mathematical concepts by the ages of five, six and seven, and by Korean American and Hispanic American ethnicities. This chapter presents the research method used in this study. It describes the participants, the basic research design of the study, the instruments and materials used, the procedure for the collection of data, and the statistical method used to analyze the data.

\section{Participants}

The target population was Korean American children and Hispanic American children from ages five to seven who spoke English as a second language. They moved to the United States with their parents, and all were non-English or limited English language speakers. The population from which the sample was drawn is the kindergarten, first and second grade children of the metropolitan multiethnic Miami-Dade County Public School District located in South Florida. The median age at time of this study was 6 years of age. The ethnic composition of the district was as follows: (a) 1.5\% Asian American, (b) 60.1\% Hispanic, (c) $18.9 \%$ African American, and (d) $18.4 \%$ White, which was a good ethnic mix of children for studying Hispanic American and Korean American bilingual children. The ratio of boys to girls was approximately the same. Forty-eight percent of the population were boys and fifty-two percent were girls (U.S. Census Bureau, 2002). 
Since the subjects in each level of the within-subjects variable (subject matter tested) are the same subjects, only the two between-subjects variables were needed to determine the power of the sample. The Power Analysis and Sample Size (PASS), statistical power computer software, was used to perform power analysis and calculate sample sizes. The sample size for the appropriate statistical power was a total of 90 subjects, 15 Korean American and 15 Hispanic American children from ages five to seven. It was found that this sample size achieved a statistical power of .96 for testing the main effects of ethnicity at two levels, a statistical power of .92 for testing the main effect of age at three levels, and .92 for testing the two-way interaction of ethnicity and age. These levels of statistical power assumed a standardized effect size of .4 at the alpha level of .05 (Cohen, 1988, 1992).

The participants were randomly selected from two Korean schools and two public elementary schools in Miami, Florida. To control the effect of the SES on math and reading comprehension scores, the family's monthly income was considered. Tables 1 and 2 show the distribution of family income and mother's educational level by ethnicity, respectively. The distribution of the family income is almost the same between two ethnic groups. Most of the family incomes fell between $\$ 2,000$ per month and $\$ 4,000$ per month (92.25\% Hispanic, $88.36 \%$ Korean). But mother's educational level was somewhat different between two groups. As shown in Table 2, 90.70\% of Korean American children's mother and $69.84 \%$ of Hispanic American children's mother have above undergraduate educational level. 
Table 1

Family Income by Ethnicity $(N=106)$

\begin{tabular}{lcc} 
Family Income $^{\mathrm{a}}$ & Hispanic, $n(\%)$ & Korean, $n(\%)$ \\
\hline Below 2000 & $3(4.71 \%)$ & $1(2.33 \%)$ \\
$2000-3000$ & $17(27.36 \%)$ & $13(30.23 \%)$ \\
$3000-4000$ & $41(65.09 \%)$ & $25(58.13 \%)$ \\
Above 4000 & $2(2.83 \%)$ & $4(6.97 \%)$ \\
\hline
\end{tabular}

Note. ${ }^{\mathrm{a}}$ Family income $=\$ /$ month.

Table 2

Mother's Educational Level by Ethnicity $(N=106)$

\begin{tabular}{lcc} 
Educational level & Hispanic, $n(\%)$ & Korean, $n(\%)$ \\
\hline Middle school & $2(3.17 \%)$ & - \\
High school & $17(26.98 \%)$ & $4(9.30 \%)$ \\
Undergraduate & $41(65.08 \%)$ & $35(81.40 \%)$ \\
Graduate & $3(4.76 \%)$ & $4(9.30 \%)$ \\
\hline
\end{tabular}

As shown in Tables 3 and 4, the sample consisted of a total of $59.4 \%$ Hispanic American children $(n=63)$ and $40.6 \%$ Korean American children $(n=43)$. The total of five-year-olds comprised $34.9 \%$, six-year-olds comprised $34.0 \%$, and seven-year-olds comprised $31.1 \%$ of the population. As presented in Table 5, the participants have stayed in the United States for 2-7 years and their parents are first generation immigrants. In the sample $93.4 \%$ of them have lived in the U.S. for three or more years and $6.7 \%$ for two or less. 
Table 3

The Sample Size by Ethnicity and Age $(N=106)$

\section{Age}

\begin{tabular}{lcccc}
\multicolumn{1}{c}{ Ethnicity } & 5 & 6 & 7 & Total \\
\hline Hispanic American & $22(34.9 \%)$ & $24(38.1 \%)$ & $17(27.0 \%)$ & $63(59.4 \%)$ \\
Korean American & $15(34.9 \%)$ & $12(27.9 \%)$ & $16(37.2 \%)$ & $43(40.6 \%)$ \\
Total & $37(34.9 \%)$ & $36(34.0 \%)$ & $33(31.1 \%)$ & $106(100 \%)$ \\
\hline
\end{tabular}

Table 4

The Sample Size by Ethnicity and Gender $(N=106)$

Gender

\begin{tabular}{lccc}
\multicolumn{1}{c}{ Ethnicity } & Male & Female & Total \\
\hline Hispanic American & $24(38.1 \%)$ & $39(61.9 \%)$ & $63(59.4 \%)$ \\
Korean American & $25(58.1 \%)$ & $18(41.9 \%)$ & $43(40.6 \%)$ \\
Total & $49(46.2 \%)$ & $57(53.8 \%)$ & $106(100 \%)$ \\
\hline
\end{tabular}

Table 5

The Sample Size by Ethnicity and the Years in the U.S. $(N=106)$

Years in the U.S.

\begin{tabular}{lcccc}
\multicolumn{1}{c}{ Ethnicity } & $1-2$ & $3-5$ & $6-7$ & Total \\
\hline Hispanic American & $5(7.9 \%)$ & $34(54.0 \%)$ & $24(38.1 \%)$ & $63(59.4 \%)$ \\
Korean American & $2(4.7 \%)$ & $29(67.4 \%)$ & $12(27.9 \%)$ & $43(40.6 \%)$ \\
Total & $7(6.6 \%)$ & $63(59.4 \%)$ & $35(33.0 \%)$ & $106(100 \%)$ \\
\hline
\end{tabular}




\section{Research Design}

A two between- and one within-subjects design was used for this study. Betweensubjects factors subdivided the sample into discrete subgroups and each subject has only one value for a between-subjects factor. The two between-subjects variables were ethnicity (Hispanic and Korean) and age (five, six, and seven). The within-subjects variable was the subject area of comprehension being measured since each person was measured at two subject areas (i.e., mathematics and reading comprehension). The dependent variable was the comprehension scores related to the reading and mathematical concepts. A graphical representation of $2 \times 3 \times(2)$ mixed-model design is shown in Appendix D.

\section{Instruments and Materials}

The experimenter developed a demographic information form to obtain children's educational background and SES information. This form included the child's age, grade, gender, number of siblings, family income, homeowner, and mother's educational level. The information obtained from the form provided the experimenter with the ability to obtain participating children's language and ethnic background.

The three math stories originally written in Korean (Choi, 2001) were translated into English. Each story was about two hundred words in length and appropriate for primary grade children ranging from ages five to seven. To control a cultural effect on children's comprehension level, culturally universal or unbiased story elements (i.e., character, theme, settings, book style, etc.) were used in the three stories (e.g., the main characters were a five-year-old boy, a baker, and an elephant; the story themes were a 
birthday party, baking, and playing on a seesaw; and settings are in a restaurant, a bakery, and a park).

The three math stories, Mom and I are friends, A man who made bread, and This is my first time to ride the seesaw, are shown in Appendix E. The three math stories follow the conventional story structure including setting, initiating event, goals, attempts, outcomes, and reactions (Mandler \& Johnson, 1977). In Mom and I are friends, there were three attempts, three outcomes, four reactions, and nine setting statements. In $A$ man who made bread, there were four attempts, four outcomes, three reactions, and nine setting statements. In This is my first time to ride the seesaw, there were six attempts, six outcomes, three reactions, and eight setting statements (see Appendix F).

The definition of comprehension has changed and it required different ways to assess comprehension progress. Traditional assessments for reading comprehension and mathematical concepts included questions whose answers were stated explicitly in the text, and emphasized the memorization and passage recall for correct answers. The teacher's role was asking questions for correct answers (McNeil, 1992). The instruments for this study consisted of a total of thirty questions including fifteen reading comprehension and fifteen mathematical concept knowledge. Instead of explicit factual comprehension tests, the assessment for this study was based on the interactive view that children would get meaning and clues from their prior knowledge and the author's idea (Kamil \& Pearson, 1979).

Experts in mathematics and language arts reviewed the process used in developing the instruments for this study and assessed whether each question represented 
measurement in the intended content area. Questions for reading comprehension were sequenced from general comprehension to specific story information. The first instrument used was the questionnaire for Measure of Reading Comprehension Ability. The questionnaire, developed by the experimenter, provided an assessment with a broad scope of an individual's ability associated with reading comprehension. The fifteen test items measured an individual's comprehension of story literary elements (i.e., setting, character, plot, theme, style, point of view) and story plot structures (i.e., setting, initiating event, problem/goal, attempt, outcome, reaction, consequence, resolution of the story). The test items that belong to the story literary elements (see Appendix G) and the story plot structure (see Appendix H) are summarized, respectively. The format of the scale was modified from a five-point to a three-point scale to adapt the task to the younger children in the present study. The responses of the test items were classified into three categories: (a) one for incorrect, (b) two for partial, and (c) three for correct.

The second instrument used, developed by the experimenter, was the questionnaire for Measure of Math Concept Ability. The questionnaire provided a broadscope assessment of individual's ability associated with mathematical concepts. The fifteen test items measured comprehension of the following mathematical concepts: (a) place-value, (b) counting, (c) matching, (d) ordering, (e) comparison, (f) computation, and (g) proportional reasoning. The test items that belong to each mathematical concept are shown in Appendix I.

In a pilot study (Chae, 2002), an internal consistency reliability test was used to establish the reliability coefficient to be used in the measurement of the data gathered 
from the test reported here. The testing instrument was designed to measure the relationships between mathematical concepts and reading comprehension in K-2 children. An analysis of the pilot study results reflected Cronbach's alphas for the internal consistency reliability of .90 for reading comprehension test and of .91 for mathematical concept test.

Item analyses were conducted on the thirty test items hypothesized to assess two subject areas of comprehension, fifteen for reading comprehension and fifteen for mathematical concepts. Internal consistency reliability was estimated because there was one administration of a test to a group. It estimates test reliability that examines the extent to which individuals who respond one way to a test item tend to respond the same way to other test items on the test. Cronbach's alphas were computed to obtain internal consistency estimates of reliability for testing the reliability of instruments for the reading comprehension and mathematical concept scale. A copy of questionnaire is included with this study (see Appendix J). The alphas for the reading comprehension and mathematical concept scales were .86 and .87 , respectively.

Inter-rater reliability was also examined to assess whether the different raters gave consistent estimates in their rating of responses. This experimenter took a fifteen samples (14\%) of transcribed sheets and had three raters code them independently to estabilish inter-rater reliability. Three raters, who were doctoral students familiar with the dependent measures in this study were used to determine the reliability of the experimenter's evaluation of the reading and mathematical comprehension. They independently scored the responses from comprehension questions. Although there were 
more than a dozen different techniques designed to evaluate the reliability of inter-rater agreement (Subkoviak, 1984; Taylor \& Lee, 1995), Pearson's product-moment correlation was applied to determine the inter-rater reliability on this $14 \%$ of the data. As presented in Table 6, the correlation coefficients among three raters for reading comprehension, $r=.90, .91, .93, p<.01$ and for math comprehension were $r=.94, .93, .95$, $p<.01$. This supported that inter-rater reliability among three raters was satisfactory.

Table 6

Intercorrelations among Three Raters for Math and Reading Comprehension

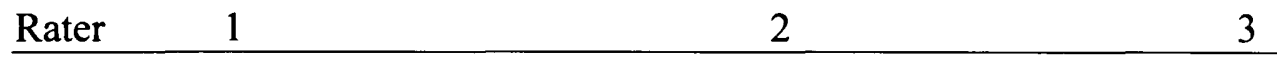

Reading comprehension $(n=15)$

\begin{tabular}{|c|c|c|}
\hline 1 & $.90^{* *}$ & $.91^{* *}$ \\
\hline 2 & - & $.93^{* *}$ \\
\hline 3 & & - \\
\hline
\end{tabular}

Math comprehension $(n=15)$

\begin{tabular}{ccc}
1 & $.94^{* *}$ & $.93^{* *}$ \\
2 & - & $.95^{* *}$ \\
3 & & - \\
\hline Note. & $p<.01$, Correlation is significant at the .01 level (2- tailed).
\end{tabular}

\section{Data Collection Procedures}

Data for this research were gathered through several means: control of language variables, teacher's introductory meeting, parent survey with parental consent form and children's assent form (see Appendix B and C), interview with children, and scoring their response. In conducting this study, the language variable was controlled as follows: (a) 
both Korean American children and Hispanic American children learned to speak and were spoken to at home in their native languages, Korean and Spanish, respectively, (b) both Korean American children and Hispanic American children learned to speak their second language, English, when they entered school, and (c) children in this study could speak both native language, Korean or Spanish, and English.

Ethnic and cultural effects on comprehension scores were also controlled. Culturally or ethnically unbiased, universal, narrative story structural elements (e.g., characters, settings and plot), themes (e.g., birthday celebration, baking, and playing on a seesaw), and characters (e.g., a boy, a baker and an elephant) were used to avoid ethnic and cultural effects on the dependent variable.

The experimenter scheduled an introductory meeting with teachers and explained the purpose and method of the study. The teachers were trained on how to handle the book and how to read stories fluently with expression. Teachers were instructed to follow Barrentine's reading procedure (Barrentine, 1996). Parents were asked to fill out a demographic information form and written consent form for their child to participate in the study before the study began. The administration of each instrument, scoring, and interpretation of the results of the questionnaire were done in accordance with the instrument's instructions. Interviews were conducted by trained teachers and lasted on average from 30 to 40 minutes.

Children listened to the three different math stories and there were limited interactions of the teacher and child. After the oral reading, the teacher asked each child to respond orally to the open-ended reading and math comprehensive questions. Their 
responses were audiotaped and transcribed word by word by the experimenter. Children's responses to each question were scored in three scales: (a) three points for correct answers, (b) two points for partially correct answers, and (c) one point for incorrect answers. Reading comprehension scores and mathematical concept scores were composed of the total points for the fifteen test items in each subject area, respectively.

\section{Data Analysis}

The data was checked for normality and outliers before analyses were carried out. Box's test was used to evaluate whether the assumption of homogeneity of the variancecovariance among the dependent variables was the same for all levels of the factor. The level of significance set by the experimenter was determined to be alpha of .05 .

Mixed-model ANOVAs consisting of two between- one within-subjects were conducted with the between subject factors being the age and the ethnicity, and the within subject factor being subject area of comprehension. The overall ANOVA using multivariate tests for the $2 \times 3 \times(2)$ mixed-model design was conducted to evaluate the factor of subject area for age and ethnicity, and then follow-up tests were conducted.

Simple main effect was used as follow-up test for a significant interaction effect because main effects represented "average" effects of a factor that were known to vary between levels of the other factor. As a follow-up test of significant simple main effect, the pairwise comparisons by the Bonferroni method (Bonferroni, 1936) were used to evaluate which means were significantly different from other means. 


\section{Summary}

The purpose of this study was to explore the effects of math literature on bilingual children's cognitive aspects and how these effects vary with age and ethnicity. This chapter describes the research methods and it includes selection of participants, research design, instruments and materials, data collection procedure, and the statistical method to test six hypotheses. Data were collected during the 2002-2003 school year. The sample consisted of 63 Hispanic American and 43 Korean American children from ages five to seven. The design of study was a $2 \times 3 \times(2)$ mixed-model design with two betweensubjects and one within-subjects variable. The two between-subjects variables were ethnicity and age. The within-subjects variable was the subject area of comprehension (i.e., math and reading). For reliability of the test instrument, internal consistency analysis was conducted on the thirty test items to assess two subject areas of comprehension. Cronbach's alphas for the reading comprehension and mathematical concept scales were reported as .86 and .87 , respectively. Inter-rater reliability among three raters was also satisfactory. The administration of each instrument, scoring, and interpretation of the results of the questionnaire were done in accordance with the experimenter's instructions. Children's responses were audiotaped and transcribed verbatim for analysis. The results of statistical tests regarding six hypohteses are given in chapter IV. 


\section{CHAPTER IV}

\section{RESULTS}

This study examined the differences among bilingual children's reading comprehension and mathematical concepts gained from math storybook reading by (a) from ages five to seven, and (b) Korean American children and Hispanic American children. The results of the statistical analyses used to examine the research questions were presented in this chapter. Six research questions were presented as the basis for this study with the six hypotheses generated from them.

The mixed-model ANOVA has the same basic assumptions as a standard ANOVA. One participant's scores was independent, not influenced by another participant's scores since each subject was assessed individually and independent from one another. Normality assumption requires that the distribution of the dependent variable in the population be normal. The mixed-model ANOVA is considered robust to violation of the normal assumption (Maxwell \& Delaney, 1990; Stevens, 1996). When there are only two levels of the within-subjects variable, the sphericity assumption is met by default if the variances are equal because there were only covariance terms (Weinfurt, 2002).

Levene's test was used to test the assumptgion of equal variance of the dependent variable. No significant effects were found across groups, $F(5,100)=0.12, p>.05$. It surported that the variances of the dependent variable were equal across groups. The multivariate generalization of Box's $M$ test was used to evaluate whether the assumption of homogeneity of the variance-covariance among the dependent variables was the same 
for all levels of the between-subjects variables. The test for homogeneity of dispersion matrices was not significant, $F(15,31478)=0.63, p>.05$, indicating that the variances and covariance among dependent variables were the same, or multivariate assumption of homogeneity was met. Table 7 shows the means and standard deviations for reading and math comprehension scores as a function of the two factors, age and ethnicity.

Table 7

Means and Standard Deviation for Three Comprehension Scores by Age and Ethnicity $(N=106)$

\begin{tabular}{ccccccc} 
& \multicolumn{2}{l}{ Korean $(n=43)$} & \multicolumn{2}{c}{ Hispanic $(n=63)$} & \multicolumn{2}{c}{ Total $(N=106)$} \\
\cline { 2 - 7 } Age & $M$ & $S D$ & $M$ & $S D$ & $M$ & $S D$ \\
\hline
\end{tabular}

Math comprehension scores

\begin{tabular}{ccccccc}
5 & 27.33 & 4.43 & 28.91 & 4.00 & 28.27 & 4.19 \\
6 & 35.75 & 4.71 & 31.17 & 4.60 & 32.69 & 5.07 \\
7 & 38.94 & 4.71 & 34.76 & 4.85 & 36.79 & 5.16 \\
\hline \multicolumn{7}{c}{ Reading comprehension scores } \\
5 & 32.20 & 5.31 & 33.27 & 5.93 & 32.84 & 5.63 \\
6 & 36.75 & 4.96 & 34.87 & 4.88 & 35.50 & 4.91 \\
7 & 41.31 & 3.81 & 37.00 & 4.91 & 39.09 & 4.80 \\
\hline
\end{tabular}

Total comprehension scores ${ }^{\mathbf{a}}$

$\begin{array}{lllllll}5 & 59.53 & 9.01 & 62.18 & 8.55 & 61.11 & 8.11 \\ 6 & 72.50 & 8.64 & 66.04 & 8.63 & 68.19 & 9.05\end{array}$

\begin{tabular}{lllllll}
7 & 80.25 & 7.87 & 71.77 & 9.01 & 75.88 & 9.39 \\
\hline
\end{tabular}

Note. The maximum scores of math and reading comprehension $=45$.

${ }^{\mathrm{a}}$ The maximum scores of total comprehension $=\mathbf{9 0}$. 
In this study, there were two between-subjects factors, ethnicity with two levels (Korean and Hispanic) and age with three levels (five, six, and seven), and one withinsubjects factor, subject area with two levels (math and reading), showing the betweenand within-subjects variables in a $2 \times 3 \times(2)$ mixed-model ANOVA. A two between- one within- subjects ANOVA was conducted to evaluate the effect of age and ethnicity on math, reading, and total comprehension scores.

The main effect for age and ethnicity, and the interaction effect of age and ethnicity were tested after collapsing across the different levels of subject area. This involves taking each child's comprehension scores of two subject areas, and then comparing the scores for main effect and interaction effect. The scores of combined math with reading comprehension are defined as a total comprehension scores. In this case, the mean scores of total comprehension are $59.53(S D=9.01)$ for Korean American children with age five and $62.18(S D=8.55)$ for Hispanic American children with age five (see Table 7).

Pearson's product-moment correlation was computed for relationships among three comprehension scores. The following correlations were obtained: (a) math comprehension with reading comprehension $(r=.73, p<.01)$, (b) math comprehension with total comprehension $(r=.93, p<.01)$, and (c) reading comprehension with total comprehension $(r=.93, p<.01)$. All three-comprehension variables were significantly related (see Table 8). 
Table 8

Correlations among Three Comprehension Scores $(N=106)$

\begin{tabular}{lccc}
\hline \multicolumn{1}{c}{ Subject } & 1 & 2 & 3 \\
\hline 1. Math comprehension & - & $.73^{* *}$ & $.93^{* *}$ \\
2. Reading comprehension & - & $.93^{* *}$ \\
3. Total comprehension & & - \\
\hline No & & &
\end{tabular}

Note. "p<.01, Correlation is significant at the .01 level (2- tailed).

Test for Hypothesis 1

Hypothesis 1: The total comprehension scores of the five-year-old's are less than those of the six-year-old's, and the total comprehension scores of the seven-year-old's are higher than those of the six-year-old's.

The first hypothesis states that the total comprehension scores (math and reading) reflect a pattern of five years old $<$ six years old $<$ seven years old. The univariate ANOVA table for the between-subjects effects is presented in Table 9. As shown in Table 9, there was a significant age main effect in total comprehension scores, $F(2,100)=26.64, p<.01, \eta^{2}=.35$, suggesting that there was ample power to detect age difference in total comprehension scores.

Measures of effect size can be thought of as the correlation between an effect of the independent variable and the dependent variable. The eta-squared $\left(\eta^{2}\right)$ is a measure of effect size, commonly used in ANOVA, which shows the proportion of variance in the dependent variable that is attributable to each independent variable (Maxwell \& Delaney, 1990). Effect sizes of $\eta^{2}$ around .01 are small, those around .09 are medium, and those larger than .25 are large (Pedhazur, 1982; Cohen, 1988, 1992). The $\eta^{2}$ for age effect in 
total comprehension was .35 and it falls within the category of large effect size. This means that $35 \%$ of the variability in total comprehension scores is explained by the effect of age.

Table 9

Analysis of Variance for Total Comprehension Scores

\begin{tabular}{llllll} 
Source & $d f$ & $F$ & $P$ & $\eta^{2}$ \\
\hline
\end{tabular}

Between subjects

\begin{tabular}{lcccc} 
Age (A) & 2 & $26.64^{* *}$ & .00 & .35 \\
Ethnicity (E) & 1 & $5.67^{*}$ & .02 & .05 \\
A $\times$ E & 2 & $4.09^{*}$ & .02 & .08 \\
E within-group error ${ }^{\mathrm{a}}$ & 100 & $(37.17)$ & & \\
\hline & & Within subjects & .35 \\
Type (T) & 1 & $53.97^{* *}$ & .00 & .06 \\
T $\times$ A & 2 & $3.38^{*}$ & .04 & .01 \\
T $\times$ E & 1 & .67 & .42 & .03 \\
T $\times$ A $\times$ E & 2 & 1.43 & .24 & \\
$T \times E$ within-group error & 100 & $(8.89)$ & & \\
\hline
\end{tabular}

Note. Values enclosed in parentheses represent mean square errors. ${ }^{\text {a Subjects within group error. }{ }^{6} \text { Type of }}$ subject area. ${ }^{\mathrm{c}}$ Typexsubjects within group error. ${ }^{*}<.05 . " * p<.01$.

Follow-up test was conducted to examine the three pairwise differences among ages in total comprehension scores. As shown in Table 10, there were significant differences in total comprehension scores between pairs of mean. The total 
comprehension scores increase with age, reflecting a pattern of five years old $<$ six years old $<$ seven years old.

Table 10

Pairwise Comparison among Ages in Total Comprehension Scores $(N=106)$

Mean difference ${ }^{\mathrm{a}}$

\begin{tabular}{|c|c|c|c|c|c|}
\hline Age & $M$ & $S D$ & Age 5 & Age 6 & Age 7 \\
\hline 5 & 61.11 & 8.71 & - & & \\
\hline 6 & 68.19 & 9.05 & $7.08^{*}$ & - & \\
\hline 7 & 75.88 & 9.39 & $14.77^{*}$ & $7.69^{*}$ & - \\
\hline
\end{tabular}

Test for Hypothesis 2

Hypothesis 2: There is a statistically significant difference in the total comprehension scores of Korean American children and Hispanic American children.

As shown in Table 9, there was a significant ethnicity main effect in total comprehension scores, $F(1,100)=5.67, p<.05, \eta^{2}=.05$, suggesting that there was ample power to detect ethnicity differences in total comprehension scores. The $\eta^{2}$ for ethnicity effect in total comprehension was .05 , which falls between small and medium effect size. This means that $5 \%$ of the variability in total comprehension scores is explained by ethnicity.

There was a significant difference in total comprehension scores between Korean American children and Hispanic American children. Korean American children 
$(M=70.86, S D=12.20)$ had statistically higher total comprehension scores than those of Hispanic American children $(M=66.24, S D=9.36)$.

\section{Test for Hypothesis 3}

Hypothesis 3: At age five, Hispanic American children have higher total comprehension scores than Korean American children. At age seven, however, Korean American children have higher scores than Hispanic American children.

The third hypothesis states that there will be a statistically significant interaction effect in the total comprehension scores of Korean American children and Hispanic American children according to their age levels. As shown in Table 9, there was a significant interaction effect of age and ethnicity, $F(2,100)=4.09, p<.05, \eta^{2}=.08$, suggesting that there was ample power to detect age difference in total comprehension scores according to ethnicity. The eta-squared $\left(\eta^{2}\right)$ for the interaction of age and ethnicity was .08 , which was categorized as a medium effect size. This means that $8 \%$ of the variability in total comprehension scores is related to the variability of interaction of age and ethnicity.

As a follow-up test for a significant interaction effect, a simple main effect test was conducted to evaluate for interaction comparisons (Green, Salkind, \& Akey, 2000). In this study, the ethnicity (or the age) simple main effects were examined as a follow-up test. The effect of ethnicity on the total comprehension scores was separately analyzed by each age level, and the effect of age level on the total comprehension scores was 
separately analyzed by each ethnicity. The profile plot in Figure 1 was created by selecting ages as the horizontal axis variables and ethnicity as the separate line variables.

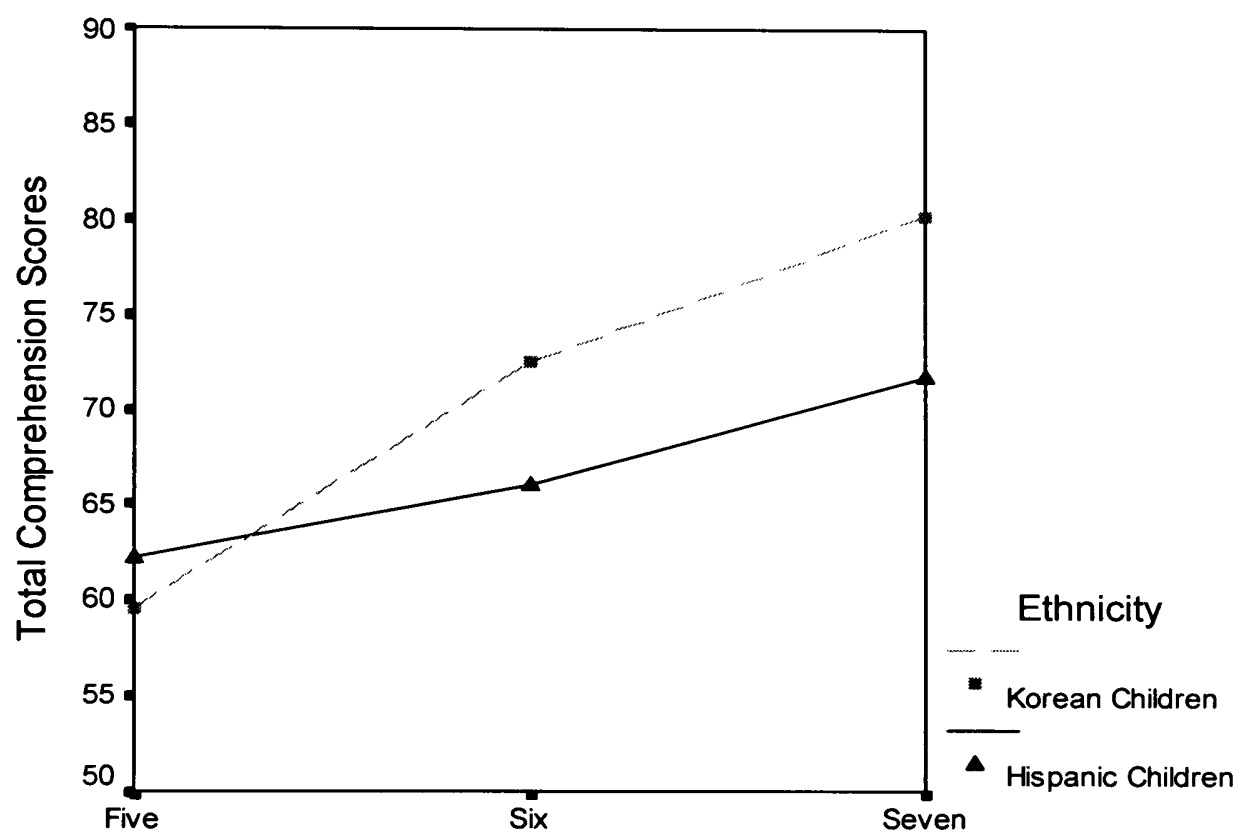

Age

Figure 1. Profile plots of interaction of ethnicity and age in total comprehension scores

As presented in Table 11, there were no statistically significant differences in total comprehension scores between Korean American children and Hispanic American children at age five, $F(1,100)=.84, p>.017, \eta^{2}=.01$, and at age six, $F(1,100)=4.49$, $p>.017, \eta^{2}=.04$. But, significant differences were found between Korean American children and Hispanic American children at age seven, $F(1,100)=7.98, p<.017, \eta^{2}=.07$.

The $\eta^{2}$ for the simple main effect of ethnicity within age seven was .07 and it falls within the category of medium effect size. This means that $7 \%$ of the variability in total comprehension scores is explained by the effect of ethnicity within age seven. 
Table 11

The Results of the Simple Main Effects for Ethnicity within Ages 5, 6, and 7

\begin{tabular}{ccccc} 
Source & $d f$ & $F$ & $P$ & $\eta^{2}$ \\
\hline Age 5 & 1 & .84 & .36 & .01 \\
Age 6 & 1 & 4.49 & .04 & .04 \\
Age 7 & 1 & $7.98^{*}$ & .01 & .07 \\
Error & 100 & $(74.33)$ & & \\
\hline
\end{tabular}

Note.Values enclosed in parentheses represent mean square errors. To control for Type I error $(\alpha=.05)$ across the three simple main effects, alpha was set for each at .017 (i.e., $.05 / 3$ ).

$p<.017$.

Table 12 shows the scores of total comprehension for ages of five through seven.

The Korean American children had statistically higher total comprehension scores than those of Hispanic American children at age seven.

Table 12

Means and Standard Deviation for Total Comprehension Scores by Age and Ethnicity (N=106)

\begin{tabular}{ccccccc} 
& \multicolumn{2}{c}{ Korean $(n=43)$} & \multicolumn{2}{c}{ Hispanic $(n=63)$} & \multicolumn{2}{c}{ Total $(N=106)$} \\
\cline { 2 - 7 } Age & $M$ & $S D$ & $M$ & $S D$ & $M$ & $S D$ \\
\hline 5 & 59.53 & 9.01 & 62.18 & 8.55 & 61.11 & 8.11 \\
6 & 72.50 & 8.64 & 66.04 & 8.63 & 68.19 & 9.05 \\
7 & 80.25 & 7.87 & 71.77 & 9.01 & 75.88 & 9.39 \\
\hline
\end{tabular}

As shown in Table 13, simple main effects for age were examined to evaluate the difference among ages for Korean American children and Hispanic American children, 
separately. The profile plot in Figure 2 was created using ethnicity as the horizontal axis variable and age as the separate bars.

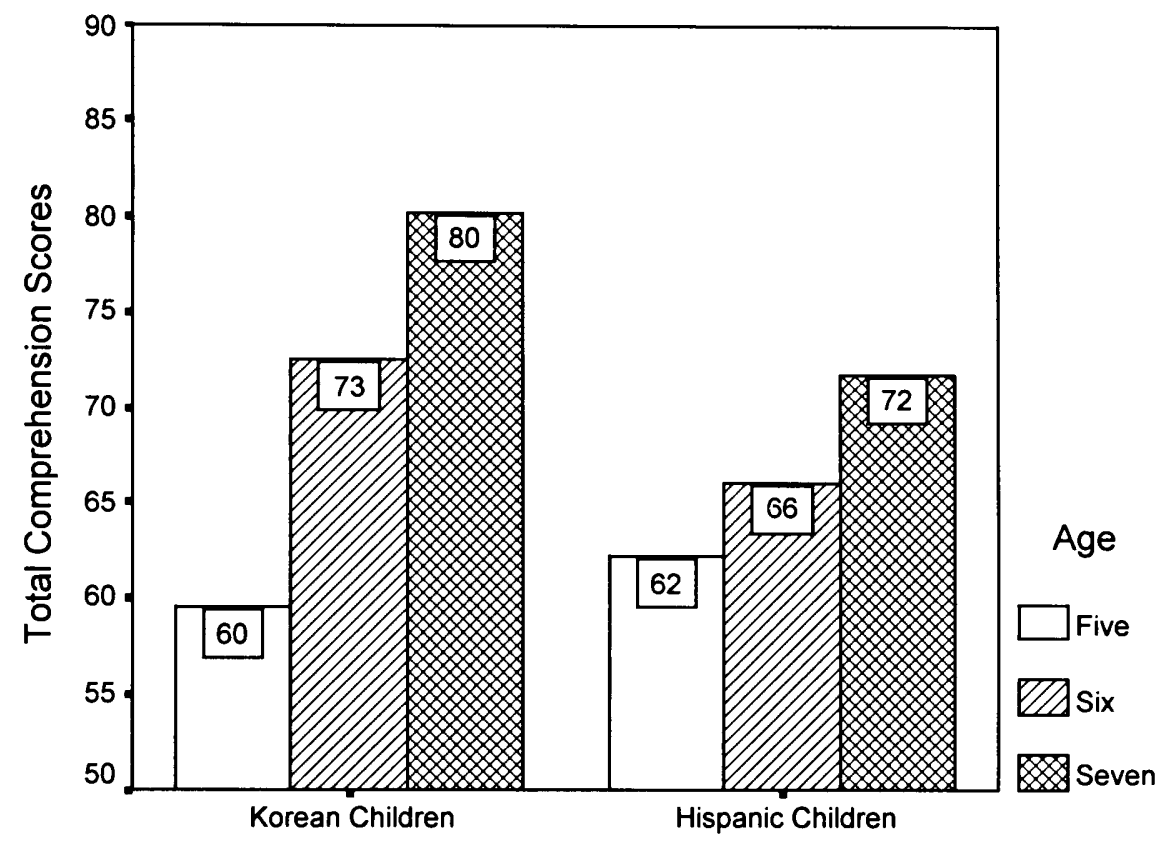

Ethnicity

Figure 2. Bar graphs of interaction of age and ethnicity in total comprehension scores

As shown in Table 13, there were statistically significant differences in total comprehension scores among three different age-groups for Korean American children, $F(2,100)=5.93, p<.025, \eta^{2}=.31$ and for Hispanic American children, $F(2,100)=22.65$, $p<.025, \eta^{2}=.11$. The $\eta^{2}$ for the simple main effect of age within Korean American children was .31 and it falls within the category of large effect size. This means that $31 \%$ of the variability in total comprehension scores is explained by the effect of age within Korean American children. The $\eta^{2}$ for the simple main effect of age within Hispanic American children was .11 and it falls within the category of large effect size. This means 
that $11 \%$ of the variability in total comprehension scores is explained by the effect of age within Hispanic American children. The effect of age is greater in Korean American children than in Hispanic American children.

Table 13

The Results of the Simple Main Effects for Age within Korean American Children and Hispanic American Children

\begin{tabular}{lcccc} 
Source & $d f$ & $F$ & $p$ & $\eta^{2}$ \\
\hline Korean American & 2 & $22.65^{* *}$ & .000 & .31 \\
Hispanic American & 2 & $5.94^{* *}$ & .004 & .11 \\
Error & 100 & $(74.33)$ & & \\
\hline
\end{tabular}

Note. Values enclosed in parentheses represent mean square errors. To control for Type I error $(\alpha=.05)$ across the two simple main effects, alpha was set for each at .025 (i.e., .05/2).

$p<.025$. " $p<.01$.

The error rate across the entire study increased for the multiple significance tests within a single sample. As presented in Table 14, the Bonferroni method of multiple comparisons was conducted as a follow-up test to evaluate the three pairwise differences among means for Korean American children and Hispanic American children.

The results of these tests, as well as the means and standard deviations for the three age groups, are also presented in Table 14. For Korean American children, there were significant differences in total comprehension scores between ages of five and six; and between ages of five and seven. But no significant differences were found between ages of six and seven. 
For Hispanic American children, there were significant differences in total comprehension scores between ages of five and seven. But no significant differences were found in total comprehension scores between ages of five and six; and between ages of six and seven.

\section{Table 14}

Differences among Ages in Total Comprehension Scores for Korean American Children and Hispanic American Children $(N=106)$

Mean difference ${ }^{\mathrm{a}}$

\begin{tabular}{cccccc} 
Age & $M$ & $S D$ & Age 5 & Age 6 & Age 7 \\
\hline & & & \multicolumn{2}{c}{ Korean American children $(n=43)$} \\
& & & & \\
5 & 29.77 & 5.41 & - & - & - \\
6 & 36.25 & 4.76 & $6.48^{*}$ & 3.88 & \\
7 & 40.13 & 4.38 & $10.36^{*}$ & &
\end{tabular}

Hispanic American children $(n=63)$

$\begin{array}{llll}5 & 31.09 & 5.46 & - \\ 6 & 33.02 & 5.05 & 1.93\end{array}$

\begin{tabular}{lccccc}
7 & 35.88 & 4.94 & $4.79^{*}$ & 2.86 & - \\
\hline Note. ${ }^{\mathrm{a}}$ Mean differences between pairs of means. To control for Type I error $(\alpha=.05)$ over the three
\end{tabular} pairwise comparisons within each etnicity, overall alpha rate was divided by the number of significance tests (i.e., $.025 / \times 3=.008$ ).

${ }^{\circ} p<.008$ 
Test for Hypothesis 4

Hypothesis 4: Children score higher on story comprehension than they do on math comprehension at age five, but they score lower on story comprehension than they do on math comprehension at age seven.

The fourth hypothesis states that both story and math comprehension scores increase with age, and there will be an interaction effect of age and subject area in comprehension scores. As shown in Table 9, the ANOVA for the within-subjects effects indicated that there were statistically significant within-subjects effects: the main effect of subject area, $F(1,100)=53.97, p<.01, \eta^{2}=.35$, and the interaction effect of subject area and age, $F(2,100)=3.38, \eta^{2}=.06, p<.05$.

The $\eta^{2}$ for the main effect of subject area was .35 and it falls within the category of large effect size. This means that $35 \%$ of the variability in comprehension scores is explained by the effect of subject area. The $\eta^{2}$ for the interaction effect of subject area and age was .06 and it falls within the category of medium effect size. This means that $6 \%$ of the variability in comprehension scores is explained by the interaction effect of subject area and age.

Because the interaction of subject and age was significant, the subject simple main effect test was conducted (i.e., the differences between math and reading comprehension scores within each age group, and the differences among ages within each subject area). As shown in Figure 3, the profile plots were created by selecting age as the horizontal axis variable and subject area as the separate line variable. 


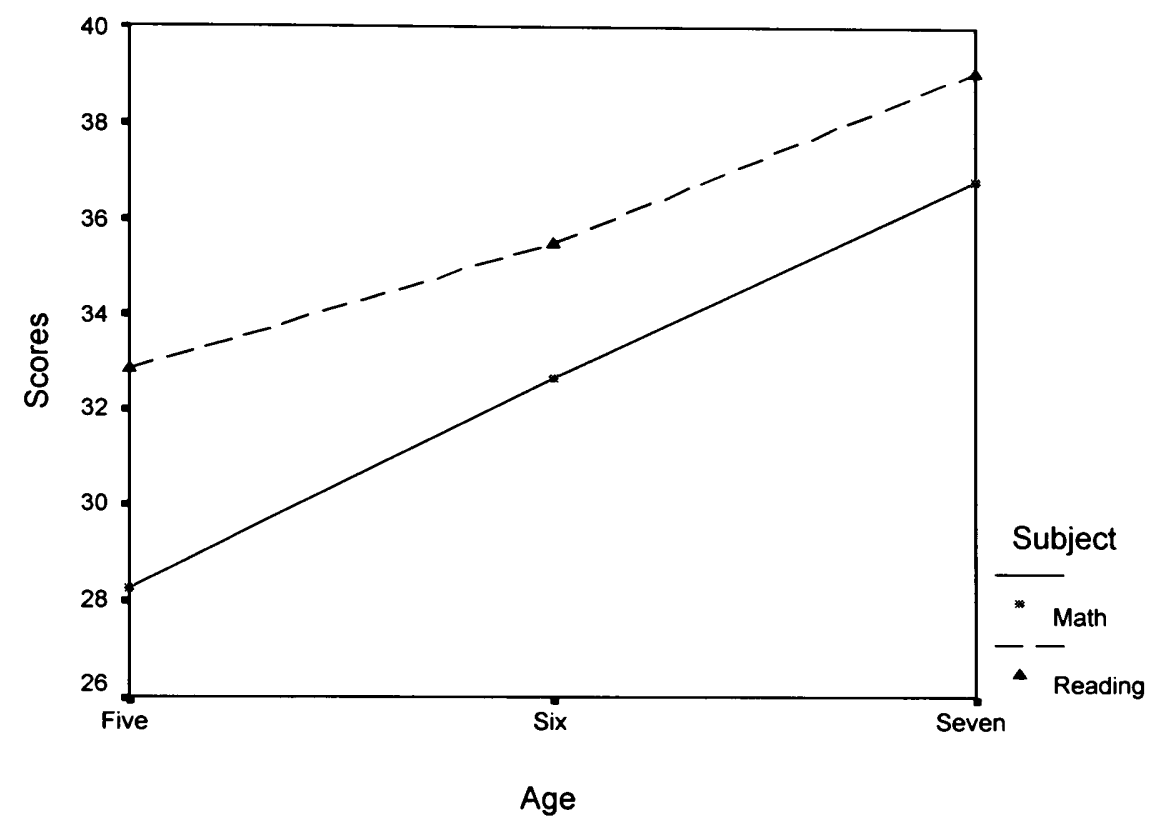

Figure 3. Profile plots of interaction of subject area and age in total comprehension scores

Table 15 showed that there were statistically significant differences between math and reading comprehension scores at age five, $F(1,206)=15.50, p<.017, \eta^{2}=.07$ and at age six, $F(1,206)=5.69, p<.017, \eta^{2}=.03$. No statistically significant differences were found between math and reading comprehension scores at age seven, $F(1,206)=3.51$, $p>.017, \eta^{2}=.02$. The $\eta^{2}$ for the simple main effect of subject area within age five was .07 and it falls within the category of medium effect size. This means that $7 \%$ of the variability in comprehension scores is explained by the effect of subject area within age five. The $\eta^{2}$ for the simple main effect of subject area within age seven was .03 and it falls within the category of small effect size. This means that $3 \%$ of the variability in comprehension scores is explained by the effect of subject area within age seven. The effect size of subject area is greater in five-year-olds than in six-year-olds. 


\section{Table 15}

The Results of the Simple Main Effects for Subject Area within Ages 5, 6, and 7

\begin{tabular}{lcccc} 
Source & $d f$ & $F$ & $p$ & $\eta^{2}$ \\
\hline Age 5 & 1 & $15.50^{*}$ & .00 & .07 \\
Age 6 & 1 & $5.69^{*}$ & .01 & .03 \\
Age 7 & 1 & 3.51 & .06 & .02 \\
Error & 206 & $(24.91)$ & & \\
\hline
\end{tabular}

Note.Values enclosed in parentheses represent mean square errors.To control for Type I error $(\alpha=.05)$ across the three simple main effects of the differences between math and reading comprehension scores within each age group, alpha was set for each at .017 (i.e., $.05 / 3=.017$ ).

" $p<017$.

Table 16 showed the means and standard deviation for math and reading comprehension scores by age. Children aged five and six have statistically higher reading comprehension scores than math comprehension scores. But, there were no statistically significant differences between math comprehension scores and reading comprehension scores at age seven.

Table 16

Means and Standard Deviation for Math and Reading Comprehension Scores by Age $(N=106)$

\begin{tabular}{ccccc} 
Age & $M$ & $S D$ & $M$ & $S D$ \\
\hline 5 & 28.27 & 4.19 & 32.84 & 5.63 \\
6 & 32.69 & 5.07 & 35.50 & 4.91 \\
7 & 36.79 & 5.16 & 39.09 & 4.80 \\
\hline
\end{tabular}


As presented in Table 17, there were statistically significant differences in math comprehension scores among ages five, six, and seven, $F(2,206)=25.48, p<.025, \eta^{2}=.20$ and in reading comprehension among ages five, six, and seven, $F(2,206)=13.73, p<.025$, $\eta^{2}=.12$.

The $\eta^{2}$ for the simple main effect of age within math subject area was .20 and it falls within the category of large effect size. This means that $20 \%$ of the variability in comprehension scores is explained by the effect of age within math subject area. The $\eta^{2}$ for the simple main effect of age within reading subject area was .13 and it falls within the category of large effect size. This means that $13 \%$ of the variability in comprehension scores is explained by the effect of age within reading subject area. The effect size of age is greater in math subject area than in reading subject area.

Table 17

The Results of the Simple Main Effects for Age within Math and Reading Comprehension

\begin{tabular}{lcccc}
\multicolumn{1}{c}{ Source } & $d f$ & $F$ & $p$ & $\eta^{2}$ \\
\hline Math subject & 2 & $25.48^{*}$ & .000 & .20 \\
Reading subject & 2 & $13.73^{*}$ & .000 & .12 \\
Error & 206 & $(24.91)$ & & \\
\hline
\end{tabular}

Note. Values enclosed in parentheses represent mean square errors. To control for type I error $(\alpha=.05)$ across the two simple main effects of the differences among ages 5, 6, and 7 within each subject area, alpha was set for each at .025 (i.e., $.05 / 2=.025$ ). ${ }^{*} p<.025$.

As shown in Table 18, follow-up test were conducted to examine the three pairwise differences among ages within math and reading subject area. There were significant differences in math comprehension scores between ages of five and six, ages of five and seven, and ages of six and seven. 
Table 18

Pairwise Comparison among Ages within Math Comprehension $(N=106)$

Mean difference ${ }^{\mathrm{a}}$

\begin{tabular}{cccccc} 
Age & $M$ & $S D$ & Age 5 & Age 6 & Age 7 \\
\hline 5 & 28.27 & 4.19 & - & & \\
6 & 32.69 & 5.07 & $4.42^{*}$ & - & \\
7 & 36.79 & 5.16 & $8.52^{*}$ & $4.09^{*}$ & - \\
\hline
\end{tabular}

Note. ${ }^{\mathrm{a}}$ Mean differences between pairs of means. To control for Type I error $(\alpha=.05)$ over the three pairwise comparisons alpha was set at $.008\left(\right.$ i.e., .025/3). ${ }^{*} p<.008$.

As shown in Table 19, there were significant differences in reading subject area between ages of five and seven. But, no differences were found between ages of five and six, and ages of six and seven. The results of this comparison supported the research hypothesis IV. This also suggests that developmental trend in reading increases in steady in primary grades.

Table 19

Pairwise Comparison among Ages within Reading Comprehension $(N=106)$

Mean difference ${ }^{\mathrm{a}}$

\begin{tabular}{cccccc} 
Age & $M$ & $S D$ & Age 5 & Age 6 & Age 7 \\
\hline 5 & 32.84 & 5.63 & - & \\
6 & 35.50 & 4.91 & 2.66 & \\
7 & 39.09 & 4.86 & $6.25^{*}$ & 3.59 & - \\
7 & & & & \\
$\begin{array}{l}\text { Note. } \\
\text { pairwise } \text { Mean differences between pairs of means. To control for Type I error }(\alpha=.05) \text { over the three } \\
p<.008 .\end{array}$
\end{tabular}




\section{Test for Hypothesis 5}

Hypothesis 5: Korean American children earn higher scores on math than on reading comprehension, but Hispanic American children have the same scores on the two subject comprehension tests.

The fifth hypothesis states that there are ethnic differences in early math achievement and in reading comprehension. That is, there will be an interaction effect of ethnicity and subject area in comprehension scores. As shown in Table 9, there were no statistically significant two-way interaction of subject area and ethnicity, $F(1,100)=.67$, $p>.05, \eta^{2}=.01$, indicating that there were no ethnic differences between math comprehension scores (Korean: $M=34.00$, Hispanic: $M=31.35$ ) and reading comprehension scores (Korean: $M=36.86$, Hispanic: $M=34.89$ ). The results of this comparison supported the research hypothesis V.

\section{Test for Hypothesis 6}

Hypothesis 6: There are significant differences in story comprehension scores and math comprehension scores between Korean American children and Hispanic American children by ages five, six, and seven.

The sixth hypothesis states that there will be a second-order interaction effect of age and ethnicity when the two subject areas are considered. As shown in Table 9, there was no significant three-way interaction effect of subject area, age, and ethnicity, $F(2,100)=1.43, p>.05, \eta^{2}=.03$. This indicated that there were no significant differences in math comprehension scores and reading comprehension scores between Korean American children and Hispanic American children by the age level. The results of this comparison supported the research hypothesis VI. 


\section{Summary}

This chapter included an analysis of the data relevant to the six hypotheses. The multivariate generalization of Box's $M$ test showed that the test for homogeneity of dispersion matrices was nonsignificant, indicating that the variances and covariance among dependent variables were the same, or multivariate assumption of homogeneity was met. The overall ANOVA for the $2 \times 3 \times(2)$ mixed-model design was conducted to test six hypotheses with the main effect and interaction effect. As a follow-up test, simple main effect and post hoc tests were conducted. Two main effects of age and ethnicity and the interaction effect of age and ethnicity were found to be significant in total comprehension. Significant differences were found in total comprehension scores between Korean American children and Hispanic American children at age seven, but no differences were found between Korean American children and Hispanic American children at ages five and six. There were significant differences in comprehension scores by the main effect of subject area and the interaction effect of subject area and age. But no significant differences were found in the three-way interaction effect (i.e., subject area, age, and ethnicity) and the interaction effect of subject area and ethnicity. At ages five and six, children have higher scores on reading comprehension than on math, but no differences were found between math and reading comprehension scores at age seven. The following chapter will explain the results from this chapter in the framework that motivates this study. In order to critically evaluate the results of this study, implications for future research will be addressed. 


\section{CHAPTER V}

\section{DISCUSSION}

The general and specific problems addressed in this study are now examined in light of the evidence. In this chapter, results of the research are reviewed and are discussed. Conclusions are drawn from the results and findings, implications for classroom instruction are suggested, and ideas for future research are also presented.

Math literature lessons have been used to hold children's attention and add an aesthetic dimension to teaching mathematical concepts (Whitin \& Wilde, 1992). Children could experience connecting math and literature as they learned mathematical concepts and not even be aware of it (Lightsey, 1996). Price (1994) found a dramatic difference in the way children interpreted math stories. Children were motivated and affected by main character's emotions or feelings, but it was hard for them to understand and enjoy the math stories without understanding the mathematical concepts.

In previous research, cultural backgrounds and ethnicity affected children's comprehension and literary responses to storybooks (Galda, 1990; Young, 1999; Bell \& Clark, 1998). In this study, culturally unbiased, universal themes and characters were used as story elements to control for possible ethnic differences between Korean American children and Hispanic American children. Although children's attitudes toward the story were not examined, the experimenter noted that most children who participated in this study paid attention during story reading and seemed to enjoy the three math stories. 


\section{Discussion of Findings}

The findings of this study support prior findings that mathematical concepts in math storybooks affected children's reading comprehension and their acquisition of the mathematical concepts. Children learned at different rates, but they could develop higher mental tools by connecting story structure with mathematical concepts (van den Broek, 1997; Pate, Homestead, \& McGinnis, 1997). Also, children's daily living situations could be used to construct mathematical knowledge (Noddings, 1990; Ball, 1988).

\section{Developmental Trend for Comprehension of Math Storybooks}

Children's mathematical reasoning is dependent on support from others and environmental circumstances, but it develops progressively (Kincade, 1991). In this study, children's comprehension of math storybooks developed progressively as observed in the significant differences by ages (i.e., age five $<$ age six $<$ age seven). Although the stories were not directly related to the children's real lives, the older children responded correctly to the mathematically related questions. Kamii and Lewis (1990) explained this developmental progression as children's connecting their background knowledge with the context to construct psychological meaning, resulting in the development of new mathematical concepts that could be used as new mental tools to solve more challenging problems.

Children use cognitive and metacognitive strategies, (e.g., accessing prior knowledge) to engage their mind in the story so that they can respond to the author's idea (Kamil \& Pearson, 1979; Thorndyke, 1977). The results of this study showed how 
children's cognition developed and how they connected their experiences with a context in the story to solve problems. The three math stories offered the children a bridge to understanding that the characters in the story had problems, feelings and experiences like their own. For example, a five-year-old child began talking about his real life experience instead of the event that occurred in the story (e.g., his birthday, his mom baking bread, when he was on a seesaw). On the contrary, an older child was lengthy, precise, accurate, and creative in his response, and knew how to tie the questions to real life. When asked how a seesaw works, one older child, seven years old, responded, "With a lot of animals. You need almost ten people to play on the seesaw with elephant." In contrast, a five-yearold child answered, "When is even?" and "Somebody on one side and the other one is somebody else." The older children seem to identify story context clues and use their prior knowledge to answer the questions (Kamil \& Pearson, 1979), and they understood the mathematical concepts of weight and balance.

\section{Ethnic Trend for Comprehension of Math Storybooks}

This study examined differences in total comprehension ability between Korean American children and Hispanic American children according to their ages. When the two subject areas of math and reading were combined, there was a significant ethnic difference between Korean American children and Hispanic American children. But, no differences were found when total comprehension was divided into each subject area. Even though there were no ethnic differences in each of two subject areas, children's combined scores on these two subject areas showed a significant ethnic effect for the total 
comprehension scores. This study reported a correlation of the two subject areas of math and reading (see Table 8), also supported by previous studies that recommended an integrated curriculum (Kain, 1993; West, Denton, \& Germino-Hausken, 2000).

The data in this study indicated that there is a significant interaction effect of age and ethnicity in total comprehension ability. For the Korean American children, significant differences were found in total comprehension between ages of five and six, but no differences between ages of six and seven. For Hispanic American children, there were significant differences on total scores between ages of six and seven, but no differences between ages of five and six. It appeared that Korean American children progressed more at younger ages, five to six, while Hispanic American children increased more at older ages, six to seven. Further, by seven years of age, Korean American children have higher total comprehension scores than those of Hispanic American children. It was clear from this measure that the children's cognitive development differs by their ethnic background. Overall comprehension of the Korean American children improves at a faster rate than that of Hispanic American children.

This result can also be related to the studies that examined the relationship between family educational involvement and maternal employment. Maternal employment has been shown to affect a mother's involvement in children's education and to have a negative impact on parenting (Hughes \& Galinsky, 1989; Voydanoff, 1988; Weiss et al., 2003). Previous studies (Chavkin, 1993; Eccles \& Harold, 1993; Nord \& West, 2001) also suggested that full-time working mothers of children had less 
involvement in their children's education and thus, a negative influence on the children's achievement. The distribution of maternal employment in this study was non-working $($ Korean $=76.74 \%$, Hispanic $=63.49 \%)$, part-time employment, $($ Korean $=16.28 \%$, Hispanic $=25.40 \%)$, and full-time employment $($ Korean $=6.98 \%$, Hispanic $=11.11 \%)$. So, it appeared that Hispanic American children's mother has a slightly higher percentage of employment than Korean American children's mother in the sample. The maternal work percentages may be a factor supporting the findings of higher scores in total comprehension for Korean American children than Hispanic American children.

Subject Area Trend for Comprehension of Math Storybooks

This study examined younger children's reading comprehension and mathematical comprehension of math storybooks. Both reading and mathematical comprehension were examined related to age and ethnicty.

Subject area by age. Significant differences were found in the interaction of the subject area and age. At ages five and six, children have higher scores on reading comprehension than on math comprehension but no significant differences were found between math comprehension scores and reading comprehension scores by age seven. Result also showed that mathematical concepts develop more rapidly than that of reading comprehension from ages five through seven. From a Vygotskian perspective (Vygotsky, 1986), children's cognitive skills develop through social interaction. Dixon-Krauss (1996) explained how children develop both spontaneously and scientifically. They gain unstable, concrete knowledge through their everyday life (i.e., spontaneous concepts) or 
learn within a formal instructional system (i.e., scientific concepts). Mathematical concepts are more abstract and logical than the story concepts, and are less susceptible to be learned in everyday life. With schooling, children are moving into scientific concept categories and develop a high level of abstraction and mathematical concepts.

Reading comprehension. Illustrations are also an important factor in children's books because they add interest to a text, and provide clues to the meaning of the story. If they were highly related to the story words and concepts, illustrations could provide excellent support to emerging readers (Combs, 2002).

For example, in the first story, Mom and I Are Friends, the candles on their birthday cake represented the mother's age. The young children counted the illustrated candles to figure out the mother's age without noting the candles were color coded to represent ten or place-value. The seven-year-old seemed to absorb all the reading materials in its full detail including its illustrations.

Mathematics comprehension. Children develop mathematical skills and concepts in their everyday activities and are able to use mathematical concepts that they acquire in informal procedure (i.e., everyday activities) to solve problems that arise in their practice (Lave, 1988). The mathematical concepts might have prompted the children to count and compute the problems instead of actually tying it in with the whole comprehension of the story (Gailey, 1993). They challenged the children and helped with the comprehension of the story by changing the children's thought process. The mathematical concepts made the children use their imaginations or minds to think different possibilities on what to do, 
add or match, and how to do it to understand what is happening in the story. The results of this study showed that the mathematical concepts in the stories had less affect on younger children's comprehension than on older children's comprehension.

In the first story, Mom and I Are Friends, the size of the candles, indicating placevalue, was so subtle that children did not understand all of the conversations about the boy's and the mother's ages in the story. When a five-year-old boy was asked, "Why did Youngwoo think that he and his mom are the same age?"(Question \#M2, see Appendix J), he replied, "Because they were both smaller than the dad." As Labinowicz (1980) suggested, most children from ages five to six did not understand place-value. In this study five- and six-year-old children were confused as to why the candle sizes were different. Younger children were also beginning to develop problem-solving skills and were able to think beyond the text. When a five-year-old girl was asked, "Why are the candles different sizes?"(Question \#M1, see Appendix J), she answered, "Because some melted." The older children were sure that the parents of the boy in the story were laughing because the boy thought he and his mother were the same age, and they recognize that was impossible. On the contrary, the younger children thought they were laughing because they were happy and proud of him.

In response to a question on counting (Question \#M4, see Appendix J), it seemed difficult for the children to determine the number of days on the calendar shown in the book. They looked at all the days one by one instead of just jumping to the end of the 
month to figure out how many days were in May. The response of a younger child was built on the basis of recalling the birthday parties or the presents in the celebration itself.

Subject area by ethnicity. In a previous study, Denton and West (2002) found that there were significant ethnic differences in children's math and reading knowledge/skills. Results from this study indicate that there is no significant difference between math and reading comprehension by ethnicity between Korean American children and Hispanic American children.

Stigler, Lee, and Stevenson (1986) found that the linguistic characteristics of numeration systems are related to children's mathematical competences, and the languages used for numeration systems influence children's mathematical concept development. Previous studies suggested that the languages used for numeration systems influence young children's mathematical competence (Ifrah, 1985; Fuson \& Kwon, 1992). The speed of pronouncing number words can vary across languages, and that speed may be associated with national differences in children's memory span for numbers (Stigler, Lee, \& Stevenson, 1986). In Korean, number words can be said more quickly than in Spanish, causing Korean American children to have a numerical span that exceeds that of Hispanic American children. This ability to keep more Korean than Spanish number words in short term memory may influence the acquisition of early mathematical concepts. If this were true, we would expect that Korean American children would have higher mathematical comprehension scores. But, in this study there was no difference in mathematical comprehension by ethnicity. The results of present study 
showed that language did not significantly contribute to an ethnic difference in children's mathematical concept acquisition.

Stigler et al. (1986) did not examine or control SES or children's educational background in their study. In the present study, children were of similar SES and in U.S. schools with similar educational environments. When schooling and SES are held constant, perhaps ethnicity and native language factors do not explain children's individual differences in comprehension ability. This seems to indicate that SES, and perhaps instructional technique and schooling system are the variables that should be considered to find children's individual differences in their educational achievement, rather than ethnicity itself.

\section{Conclusions}

The findings of this study justify the following conclusions applicable to the population of this study:

1. There was a positive relationship between children's total comprehension scores and age level. Children's total comprehension abilities are developed as a gradual process. As children's age increases, their total comprehension scores also increase. Children aged seven have higher scores in total comprehension than children from ages five to six.

2. There was a significant ethnic difference in total comprehension scores. Korean American children have higher scores in total comprehension than those of Hispanic American children. Korean American children showed greater changes 
in their comprehension skills from kindergarten to first grade (ages five and six), whereas Hispanic American children showed greater changes from first to second grade (ages six and seven).

3. There was a significant interaction effect of age and ethnicity in total comprehension. This means that total comprehension ability develops at different rates by ethnicity. A significant difference was found at age seven. At age seven, Korean American children have higher total comprehension scores than Hispanic American children. No significant differences were found in total comprehension scores between Korean American children and Hispanic American children at ages five and six.

4. There was a significant interaction effect of subject area and age in the comprehension scores. Children have higher scores in reading comprehension ability than in math comprehension at ages five and six, but no significant differences were found between reading and math comprehension scores at age seven.

5. There was no significant two-way interaction of subject area and ethnicity in the comprehension scores. No ethnic differences were found between Korean American children and Hispanic American children in math and in reading comprehension scores.

6. There were no significant differences in math comprehension scores and reading comprehension scores by age and ethnicity. No significant differences were found 
in story comprehension ability and in mathematical concept acquisition for children of ages five, six, and seven according to the ethnicity of Korean and Hispanic.

\section{Implications}

There are a number of implications for practitioners that can be drawn from the findings in this study. Younger children who possess early literacy and mathematical skills perform better in their later formal schooling than those who do not. The findings from this study will help educators understand the importance of bilingual children's early education and will make curriculum designers find methods for enhancing comprehension abilities of bilingual children through integrating specific subjects together.

First, an implication from the findings in this study examines the ways teachers make questions for assessing the children's responses to the mathematical literature. Good assessment should be built on theoretical bases (i.e., reading process theory, reader response theory, and schema theory), and it should be grounded in the kinds of skills and conceptual understandings children will need for their future success. Children should be individually assessed rather than given a paper and pencil form of assessment. The assessments should incorporate various problems that offer a range of difficulty to which children can respond. Teacher's questioning skills should also include an emphasis on requiring children to trace their thought processes and such skills should be applied 
across all subject areas so that children have the opportunity to develop their own metacognitive abilities.

Second, a practical implication that can be drawn from this study is the importance of utilizing an integrated subject approach. Integrated learning experiences furnish bilingual children a more realistic and authentic glimpse of the real world, and it helps children develop thinking and problem-solving skills that are learned through an interdisciplinary approach.

Third, children who have specific cognitive knowledge and skills are likely to be at an advantage in classroom learning compared to peers who do not possess such resources because they possess positive approaches to learning and perform better in reading and mathematics achievement than those without these resources (Denton \& West, 2002). Learning involves everyday conflict-generating problem solving. It is important for children to use mathematical skills in their everyday activities outside of school. Everyday activities may serve and help children to see the real world application of the mathematical concepts in other subject areas. Spontaneous concepts are learned upward from sensory experiences to generalization, whereas scientific concepts are learned downward through written symbols to examples. Schooling should interface spontaneous and scientific concepts to ensure the highest comprehension.

Fourth, culturally relevant math and reading instruction gives new challenges to teachers and educators. Educators continue to seek out different ways to motivate and to educate their children in the area of reading and math. From a culturally relevant 
perspective, all children acquire mathematical concepts and story schema that are required for their cultural circumstances (Pellegrini \& Stanic, 1993). Ethnic and age differences in younger children's cognitive knowledge reflect the opportunities that children have to engage in the integrating activity of mathematic and literature.

Fifth, the teacher's questions in reading time should lead and motivate children to think as they read to acquire information, making them activate their prior knowledge in order to help them understand what they read in the text (Ogle, 1986). The teacher should encourage children to extend their thinking by asking questions that require them to consider the substance of information. Questions based on frequent experiences are more helpful for correct responses than less frequent experiences (Morgan, 1981). Children's reading comprehension can be improved when the story grammar is taught with questions that are related to story schema (Turetzky, 1982). When asking questions, the teacher should pay attention to the source of information the reader needs the most to answer the question. Some questions promote just recall of information that is actually stated in the text or textually explicit. Other questions require that they think about the information presented because it is textually implicit.

\section{Suggestions for Future Research}

The results of this study lead to several recommendations for future research in the area of integration curriculum in younger children. The results of this study showed that integrating children's literacy into mathematics instruction could promote their attitudes toward mathematics and literature. First, future efforts may need to focus on the 
canonical correlations between the set of story literary elements and the set of mathematical concept factors. Which variables in the set of mathematical concepts are related to the variables in the set of story elements according to the developmental stage? That is, do the children who are more capable in the mathematical concepts of counting and matching demonstrate highly on characters and settings in the story elements?

Second, it needs to clarify the effects of mother's employment on children's reading and mathematics achievement. Difference in the amount of time spent volunteering at school, checking homework, and restricting T.V., computer, or video need investigated.

Third, the findings of this study showed that language factor did not contribute to the bilingual children's differences in the subject area of reading and math. It also needs to compare the bilingual children to the native English-speaking children in their comprehension abilitiy. Future study will enable teachers and researchers to draw a more accurate and global picture of integrating mathematics and reading subject areas in culturally or ethnically diverse classrooms. 


\section{REFERENCES}

Ackerman, B. P., Silver, D., \& Glickman, I. (1990). Concept availability in the causal inferences by children and adults. Child Development, 61, 230-246.

Adams, M. J., \& Collins, A. (1985). A schema-theoretic view of reading. In H. Singer \& R. B. Ruddell (Eds.), Theoretic models and processes of reading (3rd ed., pp. 404-425). Newark, DE: International Reading Association (IRA).

Aiken, L. R., \& Dreger, R. M. (1961). The effect of attitudes on performance in mathematics. Journal of Educational Psychology, 52, 19-24.

Altieri, J. L. (1995). Multicultural literature and multiethnic readers: Examining aesthetic involvement and preferences for text. Reading Psychology, 16, 43-70.

Altieri, J. L. (1996). Children's written responses to multicultural texts: A look at aesthetic involvement and the focuses of aesthetically complex responses. Reading Research and Instruction, 35, 237-248.

Anderson, N. J. (1991). Individual differences in strategy use in second language reading and testing. The Modern Language Journal, 75, 460-472.

Anna Kirova, A., \& Bhargava, A. (2002). Learning to guide preschool children's mathematical understanding: A teacher's professional growth. Retrieved June 12, 2004, from http://ecrp.uiuc.edu/v4n1/kirova.html

Artiles, A. J., \& Trent, S. C. (1994). Overrepresentation of minority students in special education: A continuing debate. The Journal of Special Education, 27, 410-437.

Baca, L. M., \& Cervantes, H. T. (1998). The bilingual special education interface. Upper Saddle River, NJ: Prentice-Hall.

Baker, A., \& Baker, J. (1991). Maths in the mind. Portsmouth, NH: Heinemann.

Baker, C. (2000). The care and education of young bilinguals: An introduction for professionals. Clevedon, UK: Multilingual Matters.

Baker, C. (2001). Foundations of bilingual education and bilingualism (3rd ed.). Clevedon, UK: Multilingual Matters.

Baker, J. C., Jr. (1990). An ethnographic study of cultural influences on the responses on college freshmen to contemporary Appalachian short stories. (Doctoral dissertation, Virginia Polytechnic Institute, 1990). Dissertation Abstracts International, 51, 1534A. 
Ball, D. L. (1988). Unlearning to teach mathematics. For the Learning of Mathematics, $8(1), 40-48$.

Ballenger, M., Benham, N., \& Hosticka, A. (1984). Children' counting books. Childhood Education, 61(1), 30-35.

Baroody, A. J., \& Ginsburg, H. P. (1990). Teacher's learning: a cognitive view. In R. B. Davis, C. A. Mahar \& N. Noddings (Eds.), Constructivist views on the teaching and learning of mathematics. Reston, VA: The National Council of Teachers of Mathematics (NCTM).

Barrentine, S. J. (1996). Engaging with reading through interactive read-alouds. Reading Teacher, 50(1), 36-43.

Bartlett, F. C. (1932). Remembering: A study in experimental and social psychology. Cambridge, MA: Cambridge University Press.

Battista, M. T. (1994). Teacher beliefs and the reform movement in mathematics education. Phi Delta Kappa, 75, 462-470.

Beach, R. (1994). Students' resistance to engagement with multicultural literature. In T. Rogers \& A. O. Soter (Eds.), Reading across cultures: Teaching literature in a diverse society (pp. 69-94). New York: Teachers College Press.

Bell, Y. R., \& Clark, T. R. (1998). Culturally relevant reading material as related to comprehension and recall in African American children. Journal of Black Psychology, 24, 455-475.

Bialystok, E. (1988). Levels of bilingualism and levels of linguistic awareness. Developmental Psychology, 24, 560-567.

Bialystok, E. (2001). Bilingualism in development: Language, literacy, and cognition Children. Cambridge, UK: Cambridge University Press.

Bogdan, D., \& Straw, S. B. (1990). Beyond communication: Reading comprehension and criticism. Portsmouth, NH: Boynton/Cook.

Bonferroni, C. E. (1936). Teoria statistica delle classi e calcolo delle probability.[Classical theory of statistics and calculation of the probability] Pubblicazioni del R Istituto Superiore di Scienze Economiche e Commerciali di Firenze, 8, 3-62.

Bourg, T., \& Stephenson, S. (1997). Comprehending characters' emotions: The role of event categories and causal connectivity. In P. W. van den Broek, P. J. Bauer \& T. Bourg (Eds.), Developmental spans in event comprehension and representation: Bridging fictional and actual events (pp. 295-318). Mahwah, NJ: Erlbaum. 
Brennan, A. D., et al. (1986). The effects of structural variation on children's recall of basal reader stories. Reading Research Quarterly, 21, 91-103.

Brown, A. (1987). Metacognition, executive control, self-regulation and other more mysterious mechanisms. In F. E. Weinert \& R. H. Kluwe (Eds.), Metacognition, motivation, and understanding (pp. 65-116). Hillsda1e, NJ: Lawrence Erlbaum.

Brown, C. (1991). Whole concept mathematics: A whole language application. Educational Horizons, 69, 159-163.

Burnett, S. J., \& Wichman, A. M. (1997). Mathematics and literature: An approach to success. (ERIC Document Reproduction Service No. ED414567)

Burns, M. (1992). White Plains. New York: Math Solutions Publications.

Burns, M. (1993). Math standards in action. Imaginative math: Primary, intermediate. Instructor, 102(9), 16.

Cambourne, B., \& Turbill, J. (1990). Assessment in whole-language classrooms: Theory into practice. Elementary School Journal, 90, 337-349.

Carraher, T. N. (1989). The cross-fertilization of research paradigms. Cognition and Instruction, 6, 319-323.

Chae, C. H. (2002). Young children's mathematical concepts and story comprehension. Unpublished manuscript, Miami, FL: Florida International University.

Chavkin, N. (1993). Families and schools in a pluralistic society. Albany, NY: State University of New York Press.

Choi, E. G. (2001). Mathematical fairy tales: Making a child with brain. Seoul, South Korea: nSF.

Clark, M. M. (1976). Young fluent readers. London, UK: Heinemann.

Clements, D. H., \& Battista, M. T. (1990). Constructivist learning and teaching. Arithmetic Teacher, 38, 34-35.

Cloud, J. (2003, October 27). Inside the new SAT. Time, 48-56.

Cobb, P. (1994). Where is the mind? Constructivist and sociocultural perspectives on mathematical development. Educational Researcher, 23(7), 13-20.

Cohen, J. (1988). Statistical power analysis for the behavioral science. Hillsdale, NJ: Lawrence Erlbaum.

Cohen, J. (1992). A power primer. Psychological Bulletin, 112, 155-159. 
Collins, D. W. (1992). Investigating ethnic, gender, and grade-level differences of seventh- and eighth-grade students' attitudes toward mathematics. Unpublished Doctoral Dissertation, University of Houston, Houston.

Combs, M. (2002). Readers and writers in primary grades: A balanced and integrated approach (2nd ed.). Upper Saddle River, NJ: Merrill Prentice Hall.

Confrey, J. (1990). What constructivism implies for teaching. In R. B. Davis, C.A. Mahar $\&$ N. Noddings (Eds.), Constructivist views on the teaching and learning of mathematics (pp. 107-124). Reston, VA: NCTM.

Davis, R. B., Mahar, C. A., \& Noddings, N. (1990). Suggestions for the improvement of mathematics education. In R. B. Davis, C. A. Mahar \& N. Noddings (Eds.), Constructivist views on the teaching and learning of mathematics (pp. 187- 194). Reston, VA: NCTM.

DeGaetano, Y., Williams, L. R., \& Volk, D. (1998). Kaleidoscope: A multicultural approach for the primary school classroom. Upper Saddle River, NJ: Merrill Prentice Hall.

Denton, K., \& West, J. (2002). Children's reading and mathematics achievement in Kindergarten and First grade. (ERIC Document Reproduction Service No. ED461438)

Dewey, J. (1916). Democracy and education. New York: The Free Press.

Dixon-Krauss, L. (1996). Vygotsky in the classroom: Mediated literacy instruction and assessment. White Plains, NY: Longman.

Dixon-Krauss, L. A., Harlin, R., \& Chae, C. H. (2002, April). An analysis of children's cognitive and affective responses to multicultural picture books. Paper presented at the 2002 America Educational Research Association Annual Meeting, New Orleans, LA.

Doyle, A. B., Champagne, M., \& Segalowitz, N. (1978). Some issues in the assessment of the consequences of early bilingualism. In M. Paradis (Ed.), Aspects of bilingualism. Columbia, SC: Hornbeam Press.

Durkin, D. (1966). Children who read early: Two longitudinal studies. New York: Teachers College Press.

Eccles, J. S., \& Harold, R. D. (1993). Parent-school involvement during the early adolescent years. Teachers College Record, 94, 568-587. 
Flavell, J. H. (1987). Speculations about the nature and development of metacognition. In F. E. Weinert \& R. H. Kluwe (Eds.), Metacognition, motivation, and understanding (pp. 21-29). Hillsdale, NJ: Lawrence Erlbaum.

Fosnot, C. T. (1996). Constructivism: Theory, perspectives, and practice. New York: Teachers College Press.

Fradd, S. H., \& Tikunoff, W. J. (1987). Bilingual education and bilingual special education: A guide for administrators. Boston, MA: College-Hill Press.

Friedman, J. E. (1997). What is the math moral of the study? Childhood Education, Fall, 33-35.

Frye, S. M. (1989). The NCTM standards: Challenges for all classrooms. Arithmetic Teacher, 36, 4-7.

Fuson, K. C., \& Kwon, Y. (1991). Learning addition and subtraction: Effects of number words and other cultural tools. In J. Bideaud, C. Meljac \& J. P. Fischer (Eds.), Pathways to number (pp. 283-302). Hillsdale, NJ: Lawrence Erlbaum.

Fuson, K. C., \& Kwon, Y. (1992). Korean children's understanding of multidigit addition and subtraction. Child Development, 63, 491-506.

Gailey, S. K. (1993). The mathematics-children's literature connection, Arithmetic Teacher, 40, 258-261.

Galda, L. (1990). Children's literature as a language experience. New Advocate, 3(4), 247-259.

Garcia, E. (1994). Understanding and meeting the challenge of student cultural diversity. Boston, MA: Houghton Mifflin.

Garcia, E. (1999). Student cultural diversity: Understanding and meeting the challenge (2nd ed.). New York, NY: Houghton Mifflin.

Garcia, E. E. (1997). The education of Hispanics in early childhood: Of roots and wings. Young Children. 52(3), 5-14.

Garcia, E. E. (2001). Hispanic education in the United States: Raices y Alas. Oxford, UK: Rowman \& Littlefield.

Garner, M. V. A. (1963). A study of the educational backgrounds and attitudes of teachers toward algebra as related to the attitudes and achievement of their Latin American pupils in first year algebra classes in Texas. (Doctoral dissertation, North Texas State University, 1963). Dissertation Abstracts International, 24, 13574 DA 634501. 
Garrison, J. (1994). Dewey, contexts and texts. Educational Researcher, 23(1), 19-21.

Geary, D. C., Bow-Thomas, C. C., \& Yao, Y. (1992). Counting knowledge and skills in cognitive addition: A comparison of normal and mathematically disabled children. Journal of Experimental Child Psychology, 54, 372-391.

Geary, D. C., Bow-Thomas, C. C., Fan, L., \& Siegler, R. S. (1993). Even before formal instruction, Chinese children outperform American children in mental addition. Cognitive Development, 8, 517-529.

Gelman, R., \& Gallistel, C. R. (1978). The child's understanding of number. Cambridge, MA: Harvard University Press.

Genesee, F. (1988). Bilingual language development in preschool in preschool children. In D. Bishop \& K. Mogford (Eds.), Language development in exceptional circumstances. London, UK: Churchill Livingstone.

Genesee, F., \& Nicolasis, E. (1995). Language development in bilingual preschool children. In E. E. Garcia, B. McLaughlin, B. Spodek \& O. N. Saracho (Eds.), Meeting the challenge of linguistic and cultural diversity in early childhood education. New York: Teachers College Press.

Ginsburg, H. P. (1981). Piaget and education: the contributions and limits of genetic epistemology. In I. E. Sigel, D. M. Brodzinsky \& R. M. Golinkoff (Eds.), New directions in Piagetian theory and practice (pp. 315-332). Hillsdale, NJ: Lawrence Erlbaum.

Ginsburg, H. P., \& Baron, J. (1993). Cognition: Young children's construction of mathematics. In R. J. Jensen (Ed.), Research ideas for the classroom: Early childhood mathematics (pp. 3-21). New York: Macmillan.

Goodz, N. S. (1994). Interactions between parents and children in bilingual families. In F. Genesee (Ed.), Educating: second language children. Cambridge, MA: Cambridge University Press. .

Gottlieb, J., Alter, M., Gottlieb, B. W., \& Wishner, J. (1994). Special education in urban America: It's not justifiable for many. The Journal of Special Education, 27, 453465 .

Gough, P. (1985). One second of reading. In H. S. Singer \& R. B. Ruddell (Eds.), Theoretical models and processes of reading (3rd ed.). Newark, DE: IRA.

Graesser, A. C., \& Clark, L. F. (1997). The structures and procedures of implicit knowledge. Norwood, $\mathrm{NJ}$ : Ablex. 
Green, S. B., Salkind, N.J., \& Akey, T. M. (2000). Using SPSS for windows: Analyzing and understanding data (2nd ed.). Upper Saddle River, NJ: Prentice-Hall.

Guberman, S. R. (1994). Mathematical activities of Latino and Korean American children outside school. Paper presented at the annual meetings of the American Educational Research Association, New Orleans, LA.

Hamers, J. F., \& Blanc, M. H. A. (2000). Bilinguality and bilingualism. UK: Cambridge University Press.

Harris, J. (1999). Interweaving language and mathematics literacy through a story. Teaching Children Mathematics, 5, 520-525.

Harris, P. L. (1985). What children know about the situations that provoke emotion. In M. Lewis \& C. Saarni (Eds.). The socialization of emotions (pp. 161-185). New York, NY: Plenum.

Harris, P. L., \& Olthof, T. (1982) .The child's concept of emotion. In G. Butterworth \& P. Light (Eds.), Social cognition: Studies of the development of understanding (pp. 188-209). Chicago, IL: Chicago University Press.

Harris, R. J., Lee, D. J., Hensley, D. L., \& Schoen, L. M. (1988). The effect of cultural script knowledge on memory for stories over time. Discourse Processes, 11, 413431.

Harris, T. L., \& Hodges, R. E. (1995). The Literary dictionary: The vocabulary of reading and writing. Newark, DE: IRA.

Harry, B. (1997). Teacher's handbook for cultural diversity, families, and the special education system: Communication and empowerment. New York: Teachers College Press.

Harsh, A. (1987). Teach mathematics with children's literature. Young Children, 42(6), 24-29.

Hong, H. (1996). Effects of mathematics learning through children's literature on math achievement and dispositional outcomes. Early Childhood Research Quartely, 11, 477-492.

Hopper-Weil, S. (1989). Literature and culture: An analysis of the effects of cultural background on Puerto Rican and American reader response to selected short stories. (Doctoral dissertation, New York University, 1989). Dissertation Abstracts International, 52(01), A-397.

Hughes, D., \& Galinsky, E. (1989). Balancing work and family lives: Research and cooperate applications. In A. E. Gottfried \& A. W. Gottfried (Eds.). Maternal 
employment and children's development: Longitudinal research (pp. 233-268). New York: Plenum Press.

Ifrah, G. (1985). From one to zero: A universal history of numbers (translated by L. Blair). New York: Penguin Books.

Iser, W. (1978). The act of reading: A theory of aesthetic response. Baltimore, MD: Johns Hopkins University Press.

Jennings, C. M., Jennings, J. E., Richey, J., \& Dixon-Krauss, L. (1992). Increasing interest and achievement in mathematics through children's literature. Early Childhood Research Quarterly, 7, 263-276.

Johnson, H. C. (1990). How can the curriculum and evaluation standards for school mathematics be realized for all students? School Science and Mathematics, 90, 527-543.

Jordan, S., \& Purves, A. L. (1993). Issues in the responses of students to culturally diverse texts: A preliminary study. New York: National Research Center on Literature Teaching and Learning. (ERIC Document Reproduction Service No. ED 361701)

Kain, D. L. (1993). Cabbages and kings: Research directions in integrated / interdisciplinary curriculum. Journal of Educational Thought, 27, 312-331.

Kamii, C., \& Lewis, B. A., (1990). Constructivism and first-grade arithmetic. Arithmetic Teacher, 38, 36-37.

Kamii, C. (1982). Constructivist education: A direction for the twenty-first century. Paper presented in celebration of the 10th Anniversary of Circle Children's Center, Chicago IL. (ERIC Document Reproduction Service No. ED 221297)

Kamii, C., Lewis, B. A., \& Livingston, S. J. (1993). Primary arithmetic: children inventing their own procedures. Arithmetic Teacher, 41, 200-203.

Kamil, M. L., \& Pearson, P. D. (1979). Theory and practice in teaching reading. New York University Education Quarterly, 10-16.

Karp, K. S. (1994). Telling tales: Creating graphs using multicultural literature. Teaching Children Mathematics, 1(2), 87-91.

Kennedy, L. M. (1984). Guiding children's learning of mathematics. Belmont, CA: Wadsworth. 
Kessler, C. (1984). Language acquisition in bilingual children. In N. Miller (Ed.), Bilingualism and language disability: Assessment and remediation. San Diego, CA: College Hill Press.

Kincade, K. M. (1991). Patterns in children's ability to recall explicit, implicit and metaphorical Information. Journal of Research in Reading, 14(2), 81-98.

Kintsch, W., \& Greene, E. (1978). The role of culture-specific schemata in the comprehension and recall of stories. Discourse Processes, 1, 1-13.

Kirk, R. E. (1994). Experimental design: Procedures for the behavioral sciences. Albany, NY: Brooks/Cole.

Kleiman, G. M. (1991). Mathematics across the curriculum. Educational Leadership, $49(2), 48-51$.

Klein, A., \& Starkey, P. (1988). Universals in the development of early arithmetic cognition. In G. B. Saxe \& M. Gearhart (Eds.), Children's mathematics. New Directions for Child Development (no. 41) (pp. 5-26). San Francisco: JosseyBass.

Labinowicz, E. (1980). The Piaget primer: Thinking, learning, teaching. Menlo Park, CA: Addison-Wesley.

Lambert, W. E. (1977). The effects of bilingualism on the individual: Cognitive and sociocultural consequences. In P. Horn (Ed.), Bilingualism: Psychological, social, and educational implications. New York: Academic Press.

Langdon, H. W., \& Merino, B. J. (1992). Acquisition and development of a second language in the Spanish speaker. In H. W. Langdon \& L. R. L. Cheng (Eds.), Hispanic children and adults with communication disorders: Assessment and intervention. Gaithersburg, MD: Aspen.

Larson, C. N. (1992). Children's literature and mathematics. Paper presented at the 70th Annual Meeting of the NCTM, Nashville, TN.

Laupa, M. (2000). Similarities and differences in children's reasoning about morality and mathematics. New Directions for Child and Adolescent Development, 89, 19-31.

Lave, J. (1988). Cognition in practice: Mind, mathematics and culture in everyday life. UK: Cambridge University Press.

Law, J. (1992). The early identification of language impairment in children. London, UK: Chapman \& Hall. 
Leal, D. J. (1993). The power of literary peer-group discussions: How children collaboratively negotiate meaning. The Reading Teacher, 47, 114-120.

Lee, S. (1985). Comparative responses to literature by Korean and American college students. (Doctoral dissertation, University of Pittsburgh, 1985). Dissertation Abstracts International, 17, 1635A.

Lehman, B. A., \& Scharer, P. L. (1996). Reading alone, talking together: The role of discussion in developing literary awareness. The Reading Teacher, 50, 26-35.

Lerman, S. (1996). Guest editorial. Educational Studies in Mathematics, 31(1-2), 1-9.

Lewis, B. A., Long, R., \& Mackay, M. (1993). Fostering communication in mathematics using children's literature. Arithmetic Teacher, 40, 470-473.

Lightsey. G. E. (1996). Using literature to build first grade math concepts. Reading Horizons, 36, 412-418.

Lukens, R. J. (1999). A critical handbook of children's literature (6th ed.). New York: Longman.

Mackay, C. K. (1983). Piaget and educations positive comment. In S. Modgit, C. Modgil \& G. Brown (Eds.), Jean Piaget: An interdisciplinary critique. London: Routledge \& Kegen Paul.

Maldonado-Colon, E. (1986). Assessment: Considerations upon interpreting data of linguistically/culturally different students referred for disabilities or disorders. A. C. Willig \& H. F. Greenberg (Eds.), Bilingualism and learning disabilities (pp. 69-77). New York: American Library Publishing.

Mandler, J. M. (1978). A code in the node: The use of story schema in retrieval. Discourses Processes, 1, 14-35.

Mandler, J. M. (1983). Stories: The function of structure. Washington, DC: National Science Foundation. (ERIC Document Reproduction Service No. ED238247)

Mandler, J. M., \& Johnson, N. S. (1977). Remembrance of things parsed: Story structure and recall. Cognitive Psychology, 9(1), 111-151.

Martinez, M. (1983). Exploring young children's comprehension through story time talk. Language Arts, 60, 202-209.

Maxwell, S. E., \& Delaney (1990). Designing experiments and analyzing data. Belmont, CA:Wadsworth. 
McConaughy, S. H. (1982). Strategies for comprehending important information in text by good and poor readers. Final Report of a Research Project. (ERIC Document Reproduction Service No. ED229738)

McConaughy, S. H. (1985). Good and poor readers' comprehension of story structure across different input and output modalities. Reading Research Quarterly, 20, 219-231.

McLaughlin, S. (1998). Introduction to language development. San Diego, CA.: Singular.

McLaughllin, B., Blanchard A. G., \& Osani, Y. (1995). Assessing language development in bilingual preschool children. Washington, DC: The National Clearing House for Bilingual Education, Program Information Guide Series.

McNair, R. (2000). Life outside the mathematics classroom: Implications for mathematics teaching reform. Urban Education, 34, 550-570.

McNeil, J. D. (1992). Reading comprehension: New directions for classroom practice. New York, NY: HaperCollins.

Midkiff, B., \& Cramer, M. M. (1993). Stepping stones to mathematical understanding. Arithmetic Teacher, 40, 303-305.

Mikkelsen, N. (1983). Patterns of story development in children's responses to literature. Paper presented at the Annual Meeting of the Canadian Council of Teachers of English (16th, Montreal, Canada, May 10-14, 1983). (ERIC Document Reproduction Service No. ED234399)

Mills,H., O'Keefe, T., \& Whitin, D. J. (1996). Mathematics in the making: Authoring ideas in primary classrooms. Portsmouth, NH: Heinemann.

Miura, I. T. (1987). Mathematics achievement as a function of language. Journal of Educational Psychology, 79, 79-82.

Miura, I. T., Okamoto, Y., Kim, C. C., Chang, C-M., Steere, M., \& Fayol, M. (1994). Comparisons of children's cognitive representation of number: China, France, Japan, Korea, Sweden, and the United States. International Journal of Behavioral Development, 17, 401-411.

Monroe, E. E. (1996). Language and mathematics: A natural connection for achieving literacy. Reading Horizons, 36, 368-379.

Moore, E. G., \& Smith, A. W. (1987). Sex and ethnic group differences in mathematical achievement: Results of the National Longitudinal Study. Journal for Research in Mathematics Education, 18, 25-36. 
Morgan, A. L. (1981). Children's inferential comprehension of pragmatic causal relations in reading. Paper presented at the Annual Meeting of the American Educational Research Association (Los Angeles, CA, April 13-17, 1981). (ERIC Document Reproduction Service No. ED199689)

Moro-Reyes, B. (2002). An exploratory study of linguistic, cognitive, social, and affective factors of young Hispanic language minority children eligible for preschool special education services. Unpublished Doctoral Dissertation, New York University, New York.

Morrow, L. (1997). Literacy development in the early years: Helping children read and write. Needham, MA: Allyn \& Bacon.

National Council of Teachers of Mathematics (1989). Curriculum and evaluation standards for school mathematics. Reston, VA: NCTM.

National Literacy Standards for Language Arts. (1996). National Council for Teachers of English and International Reading Association. Urbana-Champaign, IL.

National Research Council. (1989). Everybody counts: A report to the nation on the future of mathematics education. Washington, DC: National Academy Press.

NCTM. (2000). Principles and standards for school mathematics. Reston, VA: Author.

Nelson, G. A. (1987). Culture's role in reading comprehension: A schematic theoretical approach. Journal of Reading, 30(5), 424-429.

Noda, L. A. (1980). Literature and culture: Japanese and American reader responses to modern Japanese stories. (Doctoral dissertation, New York University, 1980). Dissertation Abstracts International, 41, 4894A.

Noddings, N. (1990). Constructivism in mathematics education. In R. B. Davis, C. A. Maher, \& N. Noddings (Eds.). (1990b). Constructivist views of the teaching and learning of mathematics (Journal for Research in Mathematics Education Monograph No. 4) (pp.7-18). Reston, VA: NCTM.

Nolan, J., \& Francis, P. (1992). Changing perspectives in curriculum and instruction. In C. Glickman (Ed.), Supervision in transition. Alexandria, VA: Association for Supervision and Curriculum Development.

Nord, C. W., \& West, J. (2001). Fathers' and mothers' involvement in their children's schools by family type and resident status. Washington, DC: National Center for Education Statistics, U.S. Department of Education.

Nunes, T. (1995). Cultural practices and the conception of individual differences: Theoretical and empirical considerations. In J. J. Goodnow, P. J. Miller \& F. 
Kessel (Eds.), Cultural practices as contexts for development. New Directions for Child Development (No. 67) (pp. 91-103). San Francisco: Jossey-Bass.

O’Malley, J. M., \& Chamot, A. U. (1990). Learning strategies in second language acquisition. New York: Cambridge University Press.

Ogle, D. (1986). K-W-L: A teaching model that develops active reading of expository text. The Reading Teacher, 39, 564-570.

Ortiz, A. A., \& Yates, J. R. (1988). Characteristics of learning disabled, mentally retarded, and speech-language handicapped Hispanic students at initial evaluation and reevaluation. In A. A. Ortiz, \& B. A. Ramirez (Eds.), Schools and the culturally diverse exceptional student: Promising practices and future directions. Reston, Virginia: Council of Exceptional Children.

Ovando, C. J. (1993). Language diversity and education. In J. A. Banks \& C. A. M. Banks (Eds.), Multicultural education: Issues and perspectives (2nd ed.). Boston, MA: Allyn \& Bacon.

Oxford, R. L. (1992). Language learning strategies in a nutshell: update and ESL suggestion. TESOL Journal, 18-22.

Paris, S. G. (1975). Developmental changes in constructive memory abilities. Paper presented at the Biennial Meeting of the Society for Research in Child Development. Denver, CO. (ERIC Document Reproduction Service No. ED116772)

Pate, P. E., Homestead, E. R., \& McGinnis, K. L. (1997). Making integrated curriculum work. New York: Teachers College Press.

Pearson, P. D., Hansen, J., \& Gordon, C. (1979). The effect of background knowledge on young children's comprehension of explicit and implicit information. Journal of Reading Behavior, 11(3), 201-209.

Pedhazur, E. (1982). Multiple regression in behavioral research (2nd ed.). New York: Holt, Rinehart, \& Winston.

Pellegrini, A. D., \& Stanic, G. M. A. (1993). Locating children's mathematical competence: Application of the developmental niche. Journal of Applied Developmental Psychology, 14, 501-520.

Perez, B., \& Torres-Guzman, M. E. (1996). Learning in two worlds: An integrated Spanish/English biliteracy approach. White Plains, NY: Longman.

Pham, L. (1994). Infant dual language acquisition revisited. Journal of Educational Issues of Language Minority Students, 14, 185-210. 
Piaget, J., \& lnhelder, B. (1969). The psychology of the child. New York: Basic Books.

Pirie, S., \& Kieren, T. (1992). Creating constructivist environments and constructing creative mathematics. Educational Studies in Mathematics, 23, 505-528.

Politzer, R., \& McGroarty, M. (1985). An exploratory study of learning behaviors and their relationships to gains in linguistic and communicative competence. TESOL Quarterly, 19, 103-124.

Politzer, R. (1983). An exploratory study of self-reported language learning behaviors and their relation to achievement. Studies in Second Language Acquisition, 6, 5468.

Prawat, R. S. (1995). Misreading Dewey: Reform, projects, and the language game. Educational Researcher, 24(7), 13-22.

Price, J. (1994). Getting kindergartners involved in math. Teaching Pre K-8, 24(4), 8283.

Reid, J. M. (1987). The learning style preferences of ESL students. TESOL Quarterly, 21, $87-111$.

Resnick, L. B. (1986). The development of mathematical intuition. In M. Perlmutter (Ed.), Minnesota Symposium on Child Psychology, 19, (pp. 159-194). Hillsdale, NJ: Erlbaum.

Reynolds, R. E., Taylor, M. A., Steffensen, M. S., \& Anderson, R. C. (1982). Cultural schemata and reading comprehension. Reading Research Quarterly, 17, 353-363.

Richardson, M. V., \& Monroe, E. E. (1989). Helping young children solve word problems through children's literature. School Science and Mathematics, 89, 515518.

Riley, M., Greeno, J. G., \& Heller, J. (1982). The development of children's problem solving ability in arithmetic. In H. Ginsburg (Ed.), The development of mathematical thinking. New York, NY: Academic Press.

Romberg, T. A. (1990). Evidence which supports NCTM's curriculum and evaluation standards for school mathematics. School Science and Mathematics, 90, 466-479.

Rosenblatt, L. M. (1978). The reader, the text, the poem: The transactional theory of literary work. Carbondale, NY: Southern Illinois University Press.

Rosenblatt, L. M. (1991). Literary theory. In J. Flood, J. M. Jensen, D. Lapp \& J. R. Squire (Eds.), Handbook of research on teaching the English language arts (pp. 57-62). New York, NY: The Free Press. 
Ruddell, R. B. (1999). Teaching children to read and write: Becoming an influential teacher (2nd ed.). Boston, MA: Allyn \& Bacon.

Ruddell, R. B., \& Ruddell, M. R. (1994). Language acquisition and literacy practices. In R. B. Ruddell, M. R. Ruddell \& H. Singer (Eds.). Theoretic models and processes of reading (4th ed., pp. 83-103). Newark, DE: International Reading Association (IRA).

Rupley, W. H. (1995). Contributions of phonemic knowledge, prior knowledge, and listening comprehension to elementary age children's reading comprehension. Paper presented at the Annual Meeting of the Society for the Scientific Study of Reading (2nd), San Francisco, CA. (ERIC Document Reproduction Service No. ED409548)

Samuels, S. J. (1994). Toward a theory of automatic information processing in reading, revisited. In R. B. Ruddell, M. R. Ruddell \& H. Singer (Eds.), Theoretical models and processes of reading (4th ed., pp. 816-837). Newark, DE: IRA.

Sandora, C., Beck, I., \& McKeown, M. (1999). A comparison of two discussion strategies on students' comprehension and interpretation of complex literature. Reading Psychology, 20, 177-212.

Saxe, G. B. (1991). Culture and cognitive development: Studies in mathematical understanding. Hillsdale, NJ: Lawrence Erlbaum.

Saxe, G. B., Gearhart, M., Note, M., \& Paduano, P. (1993). Peer interaction and the development of mathematical understandings. In H. Daniels (Ed.), Charting the agenda: Educational activity after Vygotsky. London: Routledge.

Schifter, D., \& Simon, M. A. (1992). Assessing teacher's development of a constructivist view of mathematics learning. Teaching and Teacher Education, 8(2), 187-197.

Simon, M. A. (1995). Reconstructing mathematics pedagogy from a constructivist perspective. Journal for Research in Mathematics Education, 26(2), 114-145.

Singer, H., McNeil, J. D., \& Furse, L. L. (1984). Relationship between curriculum scope and reading achievement in elementary schools. The Reading Teacher, 37, 608612.

Slackman, E. A., \& Hudson, J. A. (1984). Filling in the gaps: Inferential processes in children's comprehension of oral discourse. Paper presented at the Annual Boston University Conference on Language Development. Boston, MA. (ERIC Document Reproduction Service No. ED255078) 
Song, M-J., \& Ginsburg, H. P. (1987). The development of informal and formal mathematical thinking in Korean and U.S. children. Child Development, 58, 1286-1296.

Stanford, G., \& Oakland, T. (2000). Cognitive deficits underlying learning disabilities: Research perspectives from the United States. School Psychology International, $21,306-321$.

Steffensen, M. S., Joag-Dev, C., \& Anderson, R. C. (1979). A cross-culture perspective on reading comprehension. Reading Research Quarterly, 15, 10-29.

Stein, N. L., \& Glenn, C. G. (1979). An analysis of story comprehension in elementary school children. In R. O. Freedle (Ed.), New directions in discourse processing: Advances in discourse processes, Vol. 2 (pp. 53-120). Norwood, NJ: Ablex.

Stevens, J. P. (1996). Applied multivariate statistics for the social sciences (3rd edi.). Hillsdale, NJ: Lawrence Erlbaum.

Stigler, J. W., Lee, S. Y., \& Stevenson, H. W. (1986). Digit memory in Chinese and English: Evidence for a temporally limited store. Cognition, 23, 1-20.

Subkoviak, M. J. (1984). Estimating the dependability of the scores. In R. A. Berk (Ed.), A guide to criterion-references test construction (pp. 292-334). Baltimore, MD: Johns Hopkins University Press.

Swanson, H. L., \& Sachse-Lee, C. (2001). Mathematical problem solving and working memory in children with learning disabilities: Both executive and phonological processes are important. Journal of Experimental Child Psychology, 79, 294-321.

Tabors, P. O., \& Snow, C. E. (1994). English as a second language in preschool programs. In F. Genesee (Ed), Educating second language children: The whole child, the whole curriculum, the whole community. New York: Cambridge University Press.

Tabors, P. O., \& Tabors, P. (1997). One child, two languages: A guide for preschool educators of children learning English as a second language. Baltimore, MD: Paul H. Brookes.

Taylor, R. G., \& Lee, E. (1995). A review of the methods and problems of measuring reliability for criterion references test items. Journal of Instructional Psychology, 22,1 .

Teale, W. H. (1981). Parents reading to their children: What we know and need to know. Language Arts, 58, 902-912. 
Temple, C. M. (1991). Procedural dyscalculia and number fact dyscalculia: Double dissociation in developmental dyscalculia. Cognitive Neuropsychology, 8, 155176.

Thorndyke, P. W. (1977). Cognitive structures in comprehension and memory of narrative discourses. Cognitive Psychology, 9, 77-110.

Thorndyke, P. W. (1984). Applications of schema theory in cognitive research. In J. R. Anderson \& S. M. Kosslyn (Eds.). Essays on Learning and Memory (pp. 176179). San Francisco, CA: Freeman.

Tiegerman-Farber, E. (1995). Language and communication intervention in preschool children. Boston, MA: Allyn \& Bacon.

Tompkins, G. E. (2000). Teaching writing: Balancing process and product (3rd ed.). Upper Saddle River, NJ: Prentice-Hall.

Trabasso, T. (1989). The development of coherence in narratives by the understanding of intentional action. Revised edition of a paper presented at the 11th Annual Boston University Conference on Story Comprehension and Production. Boston, MA. (ERIC Document Reproduction Service No. ED302080)

Trabasso, T., \& Nickels, M. (1992). The development of goal plans of action in the narration of picture stories. Discourse Processes, 15, 249-275.

Trabasso, T., \& Sperry, L. (1985). Causal relatedness and importance of story events. Journal of Memory and Language, 24, 595-611.

Trabasso, T., \& van den Broek, P. (1985). Causal thinking and the representation of narrative events. Journal of Memory and Language. 24, 612-630.

Trabasso, T., Secco, T., \& van den Broek, P. (1984). Causal cohesion and story coherence. In H. Mandl, N. L. Stein \& T. Trabasso (Eds.), Learning and comprehension of text (pp. 83-111). Hillsdale, NJ: Lawrence Erlbaum.

Trabasso, T., van den Broek, P., \& Suh, S. Y. (1989). Logical necessity and transitivity of causal relations in stories. Discourse Processes, 21, 1-25.

Turetzky, L. G. (1982). Does the Teaching of "Story Schema" and the use of schema related questioning improve reading comprehension? (ERIC Document Reproduction Service No. ED237943)

Turnbull, R., Turnbull, A., Shank, M., Smith, S., \& Leal, D. (2001). Exceptional lives: Special education in today's schools (3rd ed.). Columbus, OH: Prentice Hall. 
U.S. Census Bureau (2002). The 2002 American community survey profile, American Community Survey Office. Retrieved January 20, 2004, from

http://www.census.gov/acs/www/Products/Profiles/Single/2002/ACS/FL.htm

UNESCO. (1978). Revised recommendation concerning the international standardization of educational statistics. Paris: Author.

Valdes, G., \& Figueroa, R. (1994). Bilingualism and testing: A special case of bias. Norwood, NJ: Ablex.

van de Rijt, B. A. M., \& van Luit, J. E. H. (1998). Effectiveness of the AEM program for teaching children early mathematics. Instructional Science, 26, 337-358.

van den Broek, P. (1988). The effects of causal relations and hierarchical position on the importance of story statements. Journal of Memory and Language, 27, 1-22.

van den Broek, P. (1989). Causal reasoning and inference making in judging the importance of story statements. Child Development, 60, 286-297.

van den Broek, P. (1990). The causal inference maker: Towards a process model of inference generation in text comprehension. In D. A. Balota, G. B. Flores d Arcais \& K. Rayner (Eds.), Comprehension processes in reading (pp. 423-445). Hillsdale, NJ: Lawrence Erlbaum.

van den Broek, P. (1997). Discovering the cement of the universe: The development of event comprehension form childhood to adulthood. In P. W. van den Broek, P. J. Bauer \& T. Bourg (Eds.), Developmental spans in event comprehension and representation (pp. 321-342). Mahwah, NJ: Lawrence Erlbaum.

Volterra, V. and Taeschner, T. (1978). The acquisition and development of language by bilingual children. Journal of Child Language, 5, 311-326.

Voydanoff, P. (1988). Work and family: A review and expanded conceptualization. Journal of Social Behavior \& Personality, 3(4), 1-22.

Vygotsky, L. S. (1978). Mind in society: The development of higher psychological processes. Cambridge, MA: Harvard University Press.

Vygotsky, L. S. (1986). Thought and language (A. Kozulin, Ed.). Cambridge, MA: MIT Press.

Wadsworth, B. J. (1995). Piaget's theory of cognitive and affective development. Menlo Park, CA: Addison-Wesley.

Weinfurt, K. P. (2002). Repeated measures analyses: ANOVA, MANOVA, and HLM. In L. G. Grimm \& P. R. Yarnold (Eds.). Reading and understanding more 
multivariate statistics (pp. 317-361). Washington, DC: American Psychological Association.

Weiss, H. B., Mayer, E., Kreider, H., Vaughan, M., Dearing, E., \& Hencke, R. (2003). Making it work: Low-income working mothers' involvement in their children's education. American Educational Research Journal, 40, 879-901.

West, J., Denton, K., \& Germino-Hausken, E. (2000). America's kindergarteners. NCES 2000-070. Washington, DC: National Center for Educational Statistics.

West, J., Denton, K., \& Reaney, L. (2001). The kindergarten year. NCES 2001-023. Washington, DC: National Center for Educational Statistics.

Whaley, J. F., \& Spiegel, D. L. (1982). Improving Children's Reading Comprehension through Instruction in Schematic Aspects of Narratives. Paper presented at the 1982 American Educational Research Association Annual Meeting, New York, NY. (ERIC Document Reproduction Service No. ED215333)

Whitin, D. J. (1994). Literature and mathematics in preschool and primary: The right connection. Young Children, 49(2), 4 -11.

Whitin, D. J., \& Gary, C. C. (1994). Promoting mathematical explorations through children's literature. Arithmetic Teacher, 41, 394 -399.

Whitin, D. J., \& Wilde, S. (1992). Read any good math lately? Children's books for mathematical learning, $K-6$. Portsmouth, NH: Heinemann.

Wilkinson, I. A. G. (1995). Individual differences in story comprehension and recall of poor readers. Technical Report No. 611. (ERIC Document Reproduction Service No. ED381742)

Wood, T. (1993). Creating an environment for learning mathematics: Social interaction perspective. Journal for Research in Mathematics Education (Monograph No. 6). Reston, VA: NCTM.

Yackel, E., Cobb, P., Wood, T., Wheatley, G., \& Merkel, G. (1990). The importance of social interaction in children's construction of mathematical knowledge. In T. J. Cooney \& C. R. Hirsch (Eds.) Teaching and learning mathematics in the 1990's (pp. 12-21). Reston, VA: NCTM.

Young, T. (1999). Master class: Children's literature and mathematics - an unhealthy alliance? Journal of Children's Literature, 25(1), 70-71.

Zanger, V. V. (1998). Math storybooks. Teaching Children Mathematics, October, 98102. 
APPENDICES 


\section{MEMORANDUM}

To:

CC:

From:

Date:

Proposal Title:
Chanho Chae

Dr. L. Dixon-Krauss

Yvette Peterson, Coordinator Institutional Revieve Bdars

December 17, 2002

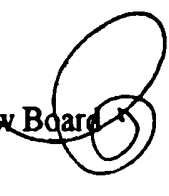

An Investigation of Children's Aestjetoc and Cognitive Responses to Math Storybooks

Approval \# 112502-01

The Institutional Review Board of Florida International University has approved your study for the use of human subjects. Your annual report will be due November 2003. As a requirement of IRB approval you are required to:

1) Provide immediate written notification to the IRB of:

- Any additions to, or changes in the procedures involving human subjects,

- Every serious or unusual or unanticipated adverse event as well as problems with the rights or welfare of the human subjects. Confirmation of receipt of serious AE reports must be made with the IRB office.

2) Utilize copies of the date stamped consent document(s) for the recruitment of subjects and receive annual renewal of consent documents.

3) Receive annual review and re-approval.

Special Conditions: None

Please note your approval number is indicated above. For further information, you may contact the IRB Coordinator by email at irbiacuc@fiu.edu or visit the DSRT - Human Subject web site at www.dsrt. fiu.edu. 


\section{PARENTAL CONSENT FORM}
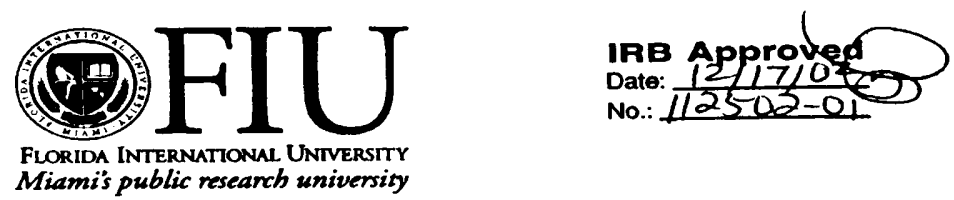

\section{PARENTAL CONSENT TO PARTICIPATE IN A RESEARCH STUDY}

Title: Children's Aesthetic and Cognitive Responses to Math Storybooks

My name is Chanho Chae. I am a doctoral student at Florida International University. I would like for your child to be in my research study. I will be studying how reading math storybooks to children helps their reading and their math comprehension. $\mathrm{He} / \mathrm{she}$ will listen to three different math stories, discuss the stories, and answer questions about them. Your child will hear the stories in his/her native language. It will take about 30-45 minutes.

There are no risks to your child as a participant in this study. There is no cost and no payment to your child. There are no direct benefits to participants in this study. However, your help will give us information on how children respond to the math storybooks both cognitively and aesthetically.

Your child's responses will be confidential. A random number, not your child's name, will identify the data. All data and materials related to this study are private and will not be shared with anyone unless required by law.

I understand that my child or I can ask questions now or later pertaining to this research I understand that I can contact Mr. Chae, at 305-275-1223 (cchae01@fiu.edu) for answers to questions. If I have questions about my child as a research subject I can contact the Chairperson of the Institutional Review Board at Florida International University, Dr. Bernard Gerstman at 305-348-3115 or 305-348-2494.

I give permission for my child, to participate in this study.

$$
\text { Child's Name }
$$

I have explained the research procedure, subject rights and answered questions asked by the participant. I have offered him/her a copy of this informed consent form. 


\section{CHILDREN'S ASSENT FORM}

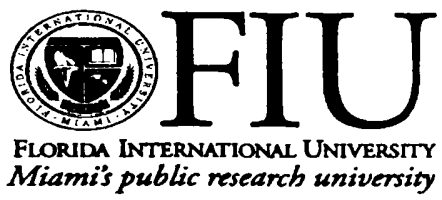

IRB Approved

Date: $1217 / 020$

No.: $112502-01$

\section{ASSENT TO PARTICIPATE IN A RESEARCH STUDY}

Title: Children's Aesthetic and Cognitive Responses to Math Storybooks

My name is Chanho Chae. I am a student at Florida International University. You are being asked to be a part of my research, my schoolwork for my class at the university.

I will be studying how to read math storybooks to children. You will listen to three math storybooks, talk about the stories and answer questions about them. You will hear the stories in Spanish, Korean, or English. It will take about 30-45 minutes.

I will ask your parents if you can be in my research to help me with my schoolwork. If you get tired at any time while we are reading the storybooks, you can stop. Do you understand what we will be doing?

$$
\text { YES ( ) NO( ) }
$$




\section{TWO BETWEEN - ONE WITHIN SUBJECTS DESIGN}

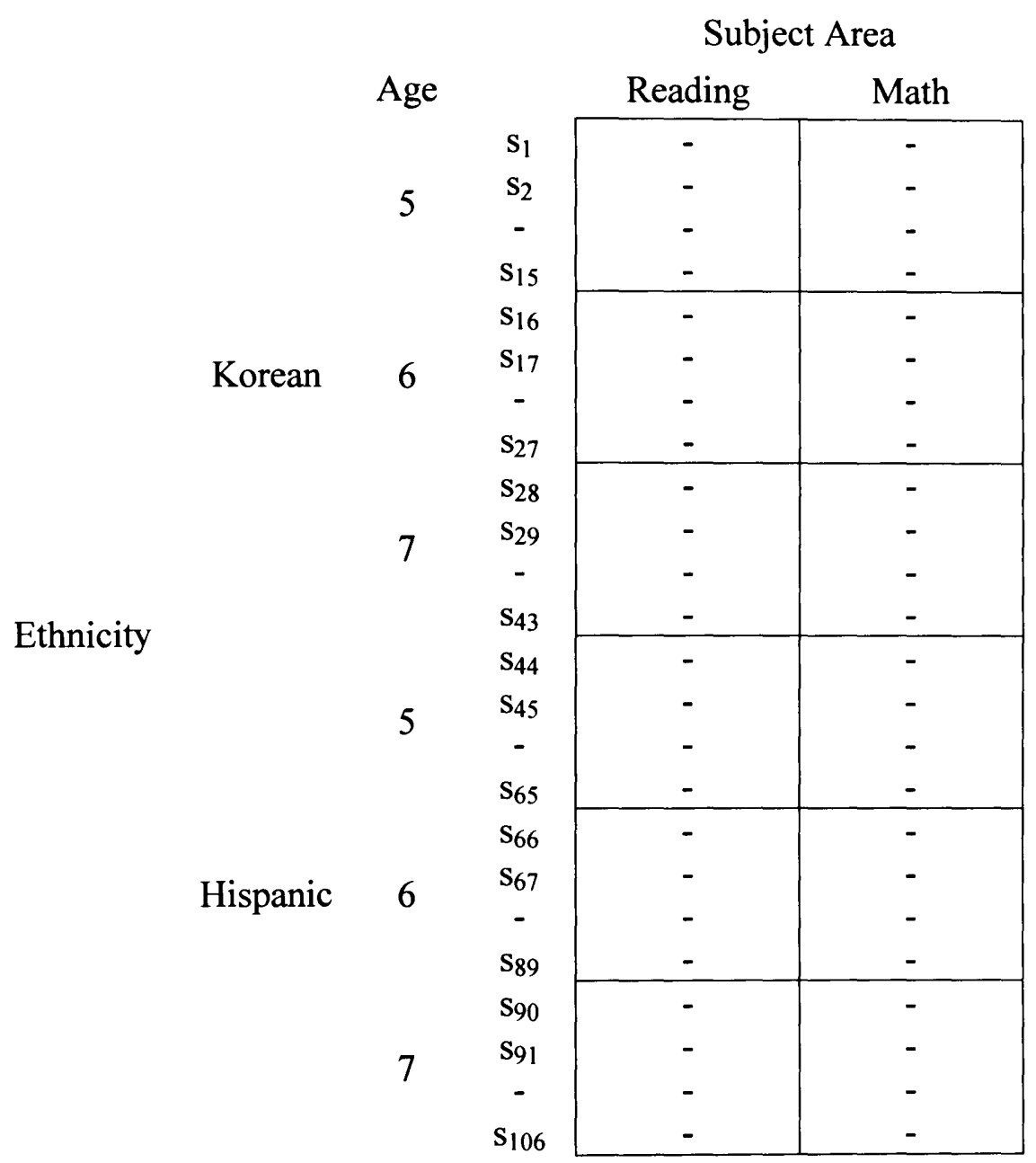

Note. The layout of this design is based on Kirk (1994), Jude and McClelland (1989). 


\section{APPENDIX E}

\section{THE THREE MATH STORIES}

\section{STORY 1}

\section{Mom And I Are Friends}

Youngwoo's eyes became round as he looked at the calendar.

Laugher came from his mouth.

On the 3 rd, there was a red flower drawn.

"That's right. Today is mom's birthday!"

In the evening, Youngwoo went to the bus station.

He met his dad and bought red roses and a cake.

In a hurry, Youngwoo and his father went to the biggest restaurant in the neighborhood.

Mother was already there.

"Happy birthday."

Dad gave mom the flowers. Mom's eyes sparkled with happiness.

"Shall we light the candles and sing?" Dad took out the cake and Youngwoo took the candles from the white envelope.

Then, his eyes became big and his mouth became squiggled.

"What's wrong?" Mom and dad asked.

"We are in big trouble."

"Why?"

"The bakery lady must have thought it was my birthday."

"Look at this."

"What?"

"One, two, three, four, five! We have only five candles."

"Mom only needs five candles." Dad said.

"Yeah, just light the candles." Mom said.

Youngwoo put the candles on the cake.

So with his finger, he counted each of the candles.

"One, two, three, four, five! Mom and I are the same age!"

"One, two, three, four, five! Youngwoo and Mom are the same age!"

Youngwoo bursted out laughing.

Mom and Dad bursted out laughing, too. 


\section{STORY 2}

\section{A Man Who Made Bread}

In a village, there lived a baker who made delicious bread.

The man's bread was unique.

The bread was rolled like Cinnamon Bread and it was thick and round.

If you buy bread once, it will last for a few days.

One day the man's oven broke.

Every time the fire went out, and the fire was getting weaker.

The baker called someone to fix the oven.

After the repairman worked here and there on the oven he said,

"It's too old so I can't fix it. I suggest you buy a new oven."

The man jumped in surprise.

"No, it can't be. This oven is my friend. I can't throw my friend away."

The man tried and tried to make the bread again.

But it did not go well.

'How can I cook from this oven again?'

The man hugged his bowl and thought deeply.

Then he hit his knee.

"Eureka!"

The man made the batter into skinny rolls.

The man made it as thin as his finger.

He put the new batter in the oven. It came out as a crispy cracker.

The baker's store got more customers.

In the morning, people waited in line to buy the thin bread.

"Baker, this thin bread is tastier than the thick one. You make good bread."

The people praised the baker's skill.

The baker was very happy.

He covered his mouth and whispered to himself.

"Thank you. Oven." 


\section{STORY 3}

This Is My First Time to Ride the Seesaw

At one end of the seesaw an elephant sat sadly.

He wanted to ride the seesaw, but no one wanted to play with him

Nobody could ride the seesaw with the elephant.

The elephant was so heavy that the seesaw wouldn't move.

Two bunnies passing the playground asked, "Elephant, what are you doing?"

"Just sitting."

"Do you want to ride the seesaw?"

"Yeah."

"Really? Then lets ride together."

The bunnies got on the seesaw.

But the seesaw did not move.

The elephant was too heavy and the bunnies were too light.

The bunnies called some passing foxes.

"Foxes, play with us."

"OK, let's play together."

Three foxes climbed onto the seesaw. But the seesaw did not move.

The elephant is heavy but the bunnies and foxes are light.

The foxes were looking around and saw some raccoons.

"Raccoons, play with us."

"OK, lets play together."

Two raccoons got on the seesaw. The seesaw moved a little.

But it was still impossible to play.

The elephant is heavy but the bunnies, foxes, and raccoons are light.

The raccoons smelled and then found the squirrels.

"Squirrels, play with us."

"OK, let's play together."

Four squirrels got on the seesaw. Then the seesaw became more even.

"Shall we find more friends to play with us?"

The squirrels called some monkeys playing on the tree.

"Monkeys, play with us."

"OK, let's play together."

Three monkeys got on the seesaw.

The seesaw became more even.

Flying birds asked, "Can we play too?"

"OK, come here. Play together."

Four Birds sat on their friends' heads and shoulders.

Finally, the seesaw became even.

Elephant went up and down and had fun.

"It is really fun to play!"

The elephant's sad face turned happy.

"Wow! Fun for real!" 


\section{APPENDIX F}

\section{ANALYSES OF STORY STRUCTURE FOR THE THREE MATH STORIES}

\begin{tabular}{|c|c|c|c|}
\hline \multirow[b]{2}{*}{ Structure } & \multicolumn{3}{|c|}{ Math stories } \\
\hline & Mom and I are friends & A man who made bread & $\begin{array}{c}\text { This is my first time to ride the } \\
\text { seesaw }\end{array}$ \\
\hline $\begin{array}{l}\text { Settings } \\
\text { (Characters, } \\
\text { place, time) }\end{array}$ & $\begin{array}{l}\text { mom, dad, Youngwoo, } \\
\text { bakery lady, on the third, } \\
\text { mom's birthday, in the } \\
\text { evening, bus station, the } \\
\text { biggest restaurant, }\end{array}$ & $\begin{array}{l}\text { a baker, the repairman, the } \\
\text { oven, customers, one day, } \\
\text { from the morning, every } \\
\text { time, in a village, the } \\
\text { baker's store. }\end{array}$ & $\begin{array}{l}\text { elephant, bunnies, foxes, } \\
\text { raccoons, squirrels, monkeys, } \\
\text { birds, at the end of seesaw. }\end{array}$ \\
\hline $\begin{array}{l}\text { Initiating } \\
\text { event }\end{array}$ & He looked at the calendar. & The man's oven broke. & $\begin{array}{l}\text { At one end of the seesaw an } \\
\text { elephant sat sadly. }\end{array}$ \\
\hline Goals & $\begin{array}{l}\text { To give mama } \\
\text { Happy birthday! }\end{array}$ & $\begin{array}{l}\text { The fire went out. } \\
\text { To fix the oven. }\end{array}$ & $\begin{array}{l}\text { He wanted to ride the seesaw, } \\
\text { but nobody could ride the } \\
\text { seesaw with the elephant. }\end{array}$ \\
\hline Attempts & $\begin{array}{l}\text { A1: Youngwoo went to } \\
\text { the bus station. } \\
\text { A2: Dad gave mom the } \\
\text { flowers. } \\
\text { A3 Mom and I are the } \\
\text { same age. }\end{array}$ & $\begin{array}{l}\text { A1: The repair man worked } \\
\text { here and there. } \\
\text { A2: I suggest you buy a new } \\
\text { one. } \\
\text { A3: The man tried to make } \\
\text { the bread again. } \\
\text { A4: The man made the } \\
\text { batter into skinny rolls. }\end{array}$ & $\begin{array}{l}\text { A1: The bunnies got on the } \\
\text { seesaw. } \\
\text { A2: Three foxes climbed onto } \\
\text { the seesaw. } \\
\text { A3: Two raccoons got on the } \\
\text { seesaw. } \\
\text { A4: Four squirrels got on the } \\
\text { seesaw. } \\
\text { A5: Three monkeys got on the } \\
\text { seesaw. } \\
\text { A6: Four birds sat on their } \\
\text { friends' head and } \\
\text { shoulders. }\end{array}$ \\
\hline Outcomes & $\begin{array}{l}\text { O1: He met his dad. } \\
\text { O2: Mom's eyes sparkled } \\
\text { with happiness. } \\
\text { O3: Mom and dad burst } \\
\text { out laughing. }\end{array}$ & $\begin{array}{l}\text { O1: I can't fix it. } \\
\text { O2: I can't throw my friend } \\
\text { (oven) away. } \\
\text { O3: It did not go well. } \\
\text { O4: The baker's store got } \\
\text { more customers. }\end{array}$ & $\begin{array}{l}\text { O1: The seesaw did not move. } \\
\text { O2: The seesaw did not move. } \\
\text { O3: The seesaw moved a little. } \\
\text { O4: The seesaw became more } \\
\text { even. } \\
\text { O5: The seesaw became more } \\
\text { even. } \\
\text { O6: Elephant went up and } \\
\text { down and had fun. }\end{array}$ \\
\hline Reactions & $\begin{array}{l}\text { R1: Laugher came from } \\
\text { his mouth. } \\
\text { R2: Mom's eyes sparkled. } \\
\text { R3: Mouth became } \\
\text { squiggled. } \\
\text { R4: Mom and dad burst } \\
\text { out laughing. }\end{array}$ & $\begin{array}{l}\text { R1: The man jumped in } \\
\text { surprise. } \\
\text { R2: Eureka! } \\
\text { R3: The baker was very } \\
\text { happy. }\end{array}$ & $\begin{array}{l}\mathrm{R} 1 \text { : The elephant sat sadly. } \\
\mathrm{R} 2 \text { : To play on the seesaw is } \\
\text { really fun. } \\
\mathrm{R} 3 \text { : The elephant's sad face } \\
\text { turned happy. }\end{array}$ \\
\hline
\end{tabular}




\section{APPENDIX G}

\section{TEST ITEMS FOR STORY LITERARY ELEMENTS}

Story structural

elements

Setting

(place, time)

Character

(main character, supporting character)
R3. Where did Youngwoo's family go for his mother's birthday party?

R10. Why did more customers visit the bakery store?

R3. Where did Youngwoo's family go for his mother's birthday party?

R5. Why did Youngwoo think that the bakery lady had thought it was his birthday?

R8. After the repairman examined the oven, what did he tell the baker to do?

$\mathrm{R} 10$. Why did more customers visit the bakery store?

$R 13$. Name the animals in this story.

Plot

R1. Why did Youngwoo's parent laugh?

R2. What did Youngwoo and his father buy for his mother's birthday?

R4. Where did Youngwoo take candles from?

R5. Why did Youngwoo think that the bakery lady had thought it was his birthday?

R6. What was the baker's problem?

$\mathrm{R} 10$. Why did more customers visit the bakery store?

R11. What did the elephant want to do?

R12. Why did the seesaw not work for the elephant?

R14. What were the first animals that played seesaw with the elephant?

R2. What did Youngwoo and his father buy for his mother's birthday?

Theme

(Birthday celebration, baking, playing the seesaw)

Point of view (Omniscient)
R3. Where did Youngwoo's family go for his mother's birthday party?

R7. How did the baker solve his problem?

R9. How did the baker plan to use the oven?

$\mathrm{R} 15$. When was the seesaw finally even?

R5. Why did Youngwoo think that the bakery lady had thought it was his birthday?

R9. How did the baker plan to use the oven?

R11. What did the elephant want to do? 


\section{APPENDIX H}

TEST ITEMS FOR STORY PLOT STRUCTURE

Story structure

Setting

(Time, places, characters)
Test item number
Initiating Event

(set in problem, start the action)

Problems/ Goals (Character's problems/ goals)

\section{Attempts}

(Main character's action to solve the problems)
Outcomes

(The results of the action or attempt)
R3. Where did Youngwoo's family go for his mother's birthday party? R10. Why did more customers visit the bakery store?

R13. Name the animals in this story.

R2. What did Youngwoo and his father buy for his mother's birthday? R6. What was the baker's problem?

R12. Why did not the seesaw work for the elephant?

R2. What did Youngwoo and his father buy for his mother's birthday? R3. Where did Youngwoo's family go for his mother's birthday party? R6. What was the baker's problem?

R11. What did the elephant want to do?

R2. What did Youngwoo and his father buy for his mother's birthday?

R3. Where did Youngwoo's family go for his mother's birthday party?

R4. Where did Youngwoo take candles from?

R8. After the repairman examined the oven, what did he tell the baker to do?

R7. How did the baker solve his problem?

R14. What were the first animals that played seesaw with the elephant?

R1. Why did Youngwoo's parent laugh?

R8. After the repairman examined the oven, what did he tell the baker to do?

R9. How did the baker plan to use the oven?

$\mathrm{R} 15$. When was the seesaw finally even?

R1. Why did Youngwoo's parent laugh?

R9. How did the baker plan to use the oven?

R1. Why did Youngwoo's parent laugh?

R10. Why did more customers visit the bakery store?

$\mathrm{R} 15$. When was the seesaw finally even? 
Mathematical

Concepts

Counting

Matching

Ordering

Comparison

Place-value

Computation

Proportional reasoning

\section{Test item number}

M2. Why did Youngwoo think that he and his mom are the same age?

M3. How old is Youngwoo now?

M4. How many days are there in May?

M14. Match the animals that have the same number.

M1. Why are the candles different sizes?

M14. Match the animals that have the same number.

M5. When is Youngwoo's mother's birthday?

M7. Which came first in the story - thick and round bread, thin and crispy bread, broken oven?

M1. Why are the candles different sizes?

M6. Why did the baker make the batter as thin as his finger?

M8. If the lengths are the same, which bread needs more heat for baking, the thin or the thick?

M11. How does the seesaw work?

M12. When two bunnies got on the seesaw, why didn't the seesaw move?

M13. What would happen if there were two elephants on the left side of the seesaw?

M1. Why are the candles different sizes?

M2. Why did Youngwoo think that he and his mom are the same age?

M10. If the thick bread lasts for 2 days and the thin for 1 day, for how many days can you eat one thick and two thin breads?

M15. If three monkeys, two bunnies, and two raccoons are added up, what are the total animals? (Counting and Computation)

M9. If you buy one thin-bread, it lasts for 1 day. How many thin-breads are needed for 4 days? (Proportional reasoning, problem solving) 


\title{
Questionnaire for Children's Literary Elements, Metacognitive Responses, Reading Comprehension, and Math Concept Acquisitions
}

\begin{abstract}
$<$ Instructions $>$
Three different math stories will be provided to observe children's responses to the math story. Include children's age, grade, gender, ethnicity, home language, language spoken, and the number of brothers and sisters in child's information box. First read the three math stories to each child and tape child's own answers and transcribe taped answers word by word for each question.
\end{abstract}

\section{$<$ Child's Information $>$}
1. Age (years old): a. 5
b. 6
c. 7

2. Grade: a. Kindergarten

b. First

c. Second

3. Gender: a. male

b. female

4. Ethnicity: a. Hispanic American

b. Korean American

c. other

5. Home Language: a. English

b. Spanish c. Korean

d. other

6. Languages Spoken: a. English

b. Spanish

c. Korean

d. other

7. \# of Brothers: a. 0

b. 1

c. 2

d. 3

e. 4 or more

8. \# of Sisters: a. 0

b. 1

c. 2

d. 3

e. 4 or more

9. Family income (\$/month): a. below 2000 b. $2000-3000$

c. $3000-4000$

d. above 4000

10. Mother's educational level:
a. middle school
b. high school
c. undergraduate
d. graduate

11. Stay in U.S.(years):
a. 1-2
b. 3-5
c. 6-7

\section{Chan-Ho Chae}

Curriculum and Instruction

College of Education

Florida International University 


\section{Story 1. Mom And I Are Friends}

I. Reading comprehension (incorrect: 1, partial:2, correct:3)

R1. Why did Youngwoo's parenst laugh?

R2. What did Youngwoo and his father buy for his mother's birthday?

R3. Where did Youngwoo's family go for his mother's birthday party?

R4. Where did Youngwoo take candles from?

R5. Why did Youngwoo think that the bakery lady had thought it was his birthday?

II. Math Concept Ability (incorrect:1, partial:2, correct:3)

M1. (Show candles in page 3) Why are the candles different sizes? (Place-value)

M2. Why did Youngwoo think that he and his mom are the same age? (Place-value, Comparison)

M3. How old is Youngwoo now? (Counting)

M4. (Show calendar in page 1) How many days are there in May? (Counting)

M5. (Show calendar in page 1) When is Youngwoo's mother's birthday? (Ordering)

\section{Story 2. A Man Who Made Bread}

I. Reading comprehension (incorrect:1, partial:2, correct:3)

R6. What was the baker's problem?

R7. How did the baker solve his problem?

R8. After the repairman examined the oven, what did he tell the baker to do?

R9. How did the baker plan to use the oven?

R10. Why did more customers visit the bakery store?

II. Math Concept Ability (incorrect:1, partial:2, correct:3)

M6. Why did the baker make the batter as thin as his finger? (Amount)

M7. Which came first in the story - thick and round bread, thin and crispy bread, broken oven? (Ordering)

M8. If the lengths are the same, which bread needs more heat for baking, the thin or the thick? (Amount comparison)

M9. If you buy one thin-bread, it lasts for 1 day. How many thin-breads are needed for 4 days? (Proportional reasoning, problem solving)

M10. If the thick bread lasts for 2 days and the thin for 1 day, for how many days can you eat one thick and two thin breads? (Computation)

\section{Story 3. This Is My First Time to Ride the Seesaw}

1. Reading comprehension (incorrect:1, partial:2, correct:3)

R11. What did the elephant want to do?

R12. Why did the seesaw not work for the elephant?

R13. Name the animals in this story.

R14. What were the first animals that played seesaw with the elephant?

$\mathrm{R} 15$. When was the seesaw finally even?

II. Math Concept Ability (incorrect:1, partial:2, correct:3)

M11. How does the seesaw work? (Prenumber concept: Comparison)

M12. When two bunnies got on the seesaw, why didn't the seesaw move? (Prenumber concept:

Comparison)

M13. (Point on page 12) What would happen if there were two elephants on the left side of the seesaw?

(Weight Comparison)

M14. (Show page 12) Match the animals that have the same number. (Counting, Matching)

M15. If three monkeys, two bunnies, and two raccoons are added up, what are the total animals?

(Counting and Computation) 


\section{APPENDIX K}

\section{NCTM STANDARDS AND EXPECTATIONS FOR PRE-K THROUGH GRADE 2}

\section{Number and Operations Standard}

\begin{tabular}{|c|c|}
\hline \multirow{2}{*}{$\begin{array}{l}\text { Instructional programs from } \\
\text { prekindergarten through } \\
\text { grade } 12 \text { should enable all } \\
\text { students to- }\end{array}$} & Expectations \\
\hline & In prekindergarten through grade 2 all students should - \\
\hline $\begin{array}{l}\text { Understand numbers, ways } \\
\text { of representing numbers, } \\
\text { relationships among } \\
\text { numbers, and number } \\
\text { systems }\end{array}$ & $\begin{array}{l}\text { 1. count with understanding and recognize "how many" in sets of objects; } \\
\text { 2. use multiple models to develop initial understandings of place-value and the } \\
\text { base-ten number system; } \\
\text { 3. develop understanding of the relative position and magnitude of whole } \\
\text { numbers and of ordinal and cardinal numbers and their connections; } \\
\text { 4. develop a sense of whole numbers and represent and use them in flexible ways, } \\
\text { including relating, composing, and decomposing numbers; } \\
\text { 5. connect number words and numerals to the quantities they represent, using } \\
\text { various physical models and representations; } \\
\text { 6. understand and represent commonly used fractions, such as } 1 / 4,1 / 3 \text {, and } 1 / 2 \text {. }\end{array}$ \\
\hline $\begin{array}{l}\text { Understand meanings of } \\
\text { operations and how they } \\
\text { relate to one another }\end{array}$ & $\begin{array}{l}\text { 1. understand various meanings of addition and subtraction of whole numbers } \\
\text { and the relationship between the two operations; } \\
\text { 2. understand the effects of adding and subtracting whole numbers; } \\
\text { 3. understand situations that entail multiplication and division, such as equal } \\
\text { groupings of objects and sharing equally. }\end{array}$ \\
\hline $\begin{array}{l}\text { Compute fluently and make } \\
\text { reasonable estimates }\end{array}$ & $\begin{array}{l}\text { 1. develop and use strategies for whole-number computations, with a focus on } \\
\text { addition and subtraction; } \\
\text { 2. develop fluency with basic number combinations for addition and subtraction; } \\
\text { 3. use a variety of methods and tools to compute, including objects, mental } \\
\text { computation, estimation, paper and pencil, and calculators. }\end{array}$ \\
\hline
\end{tabular}

\section{Algebra Standard}

\begin{tabular}{|l|l|}
\hline $\begin{array}{l}\text { Instructional programs from } \\
\text { prekindergarten through } \\
\text { grade } 12 \text { should enable all } \\
\text { students to - }\end{array}$ & \multicolumn{1}{c|}{ Expectations } \\
\cline { 2 - 3 } $\begin{array}{l}\text { Understand patterns, } \\
\text { relations, and functions }\end{array}$ & $\begin{array}{l}\text { In prekindergarten through grade 2 all students should - } \\
\text { 2. recognize, describe, and extend patterns such as sequences of sounds and } \\
\text { shapes or simple numeric patterns and translate from one representation to } \\
\text { another; } \\
\text { 3. analyze how both repeating and growing patterns are generated. }\end{array}$ \\
\hline $\begin{array}{l}\text { Represent and analyze } \\
\text { mathematical situations and } \\
\text { structures using algebraic } \\
\text { symbols }\end{array}$ & $\begin{array}{l}\text { 1. illustrate general principles and properties of operations, such as } \\
\text { commutativity, using specific numbers; }\end{array}$ \\
\hline $\begin{array}{l}\text { 2. use concrete, pictorial, and verbal representations to develop an understanding } \\
\text { of invented and conventional symbolic notations. }\end{array}$ \\
$\begin{array}{l}\text { Usepresent and understand } \\
\text { quantitative relationships }\end{array}$ & $\begin{array}{l}\text { 1. model situations that involve the addition and subtraction of whole numbers, } \\
\text { using objects, pictures, and symbols. }\end{array}$ \\
\hline $\begin{array}{l}\text { Analyze change in various } \\
\text { contexts }\end{array}$ & $\begin{array}{l}\text { 1. describe qualitative change, such as a student's growing taller; } \\
\text { 2. describe quantitative change, such as a student's growing two inches in one } \\
\text { year. }\end{array}$ \\
\hline
\end{tabular}




\section{Geometry Standard}

\begin{tabular}{|l|l|}
\hline $\begin{array}{l}\text { Instructional programs from } \\
\text { prekindergarten through } \\
\text { grade I2 should enable all } \\
\text { students to - }\end{array}$ & \multicolumn{1}{|c|}{ Expectations } \\
\cline { 2 - 3 } $\begin{array}{l}\text { Analyze characteristics and } \\
\text { properties of two- and three- } \\
\text { dimensional geometric } \\
\text { shapes and develop } \\
\text { mathematical arguments } \\
\text { about geometric } \\
\text { relationships }\end{array}$ & $\begin{array}{l}\text { 1. recognize, name, build, draw, compare, and sort two- and three-dimensional } \\
\text { shapes; }\end{array}$ \\
$\begin{array}{l}\text { 2. describe attributes and parts of two- and three-dimensional shapes; } \\
\text { 3. investigate and predict the results of putting together and taking apart two- and } \\
\text { three-dimensional shapes. }\end{array}$ \\
\hline $\begin{array}{l}\text { Specify locations and } \\
\text { describe spatial relationships } \\
\text { using coordinate geometry } \\
\text { and other representational } \\
\text { systems }\end{array}$ & $\begin{array}{l}\text { 1. describe, name, and interpret relative positions in space and apply ideas about } \\
\text { relative position; } \\
\text { 2. describe, name, and interpret direction and distance in navigating space and } \\
\text { apply ideas about direction and distance; } \\
\text { 3. find and name locations with simple relationships such as "near to" and in } \\
\text { coordinate systems such as maps. }\end{array}$ \\
\hline $\begin{array}{l}\text { Apply transformations and } \\
\text { use symmetry to analyze } \\
\text { mathematical situations }\end{array}$ & $\begin{array}{l}\text { 1. recognize and apply slides, flips, and turns; } \\
\text { 2. recognize and create shapes that have symmetry. }\end{array}$ \\
\hline $\begin{array}{l}\text { Use visualization, spatial } \\
\text { reasoning, and geometric } \\
\text { modeling to solve problems }\end{array}$ & $\begin{array}{l}\text { 1. create mental images of geometric shapes using spatial memory and spatial } \\
\text { visualization; }\end{array}$ \\
$\begin{array}{l}\text { 2. recognize and represent shapes from different perspectives; } \\
\text { 4. recognize geometric shapes and structures in the environment and specify their } \\
\text { location. }\end{array}$ \\
\hline
\end{tabular}

\section{Measurement Standard}

\begin{tabular}{|c|c|}
\hline \multirow{2}{*}{$\begin{array}{l}\text { Instructional programs from } \\
\text { prekindergarten through } \\
\text { grade } 12 \text { should enable all } \\
\text { students to - }\end{array}$} & Expectations \\
\hline & In prekindergarten through grade 2 all students should - \\
\hline $\begin{array}{l}\text { Understand measurable } \\
\text { attributes of objects and the } \\
\text { units, systems, and processes } \\
\text { of measurement }\end{array}$ & $\begin{array}{l}\text { 1. recognize the attributes of length, volume, weight, area, and time: } \\
\text { 2. compare and order objects according to these attributes; } \\
\text { 3. understand how to measure using nonstandard and standard units; } \\
\text { 4. select an appropriate unit and tool for the attribute being measured. }\end{array}$ \\
\hline $\begin{array}{l}\text { Apply appropriate } \\
\text { techniques, tools, and } \\
\text { formulas to determine } \\
\text { measurements }\end{array}$ & $\begin{array}{l}\text { 1. measure with multiple copies of units of the same size, such as paper clips laid } \\
\text { end to end; } \\
\text { 2. use repetition of a single unit to measure something larger than the unit, for } \\
\text { instance, measuring the length of a room with a single meterstick: } \\
\text { 3. use tools to measure; } \\
\text { 4. develop common referents for measures to make comparisons and estimates. }\end{array}$ \\
\hline
\end{tabular}




\section{Data Analysis and Probability Standard}

\begin{tabular}{|l|l|}
\hline & \multicolumn{1}{|c|}{ Expectations } \\
\hline $\begin{array}{l}\text { Instructional programs from } \\
\text { prekindergarten through grade } 12 \\
\text { should enable all students to - }\end{array}$ & In prekindergarten through grade 2 all students should - \\
\hline $\begin{array}{l}\text { Formulate questions that can be } \\
\text { addressed with data and collect, } \\
\text { organize, and display relevant data } \\
\text { to answer them }\end{array}$ & $\begin{array}{l}\text { 1. pose questions and gather data about themselves and their surroundings; } \\
\text { about the objects; } \\
\text { 3. represent data using concrete objects, pictures, and graphs. }\end{array}$ \\
\hline $\begin{array}{l}\text { Select and use appropriate } \\
\text { statistical methods to analyze data }\end{array}$ & $\begin{array}{l}\text { 1. describe parts of the data and the set of data as a whole to determine } \\
\text { what the data show. }\end{array}$ \\
\hline $\begin{array}{l}\text { Develop and evaluate inferences } \\
\text { and predictions that are based on } \\
\text { data }\end{array}$ & 1. discuss events related to students' experiences as likely or unlikely. \\
\hline $\begin{array}{l}\text { Understand and apply basic } \\
\text { concepts of probability }\end{array}$ & \\
\hline
\end{tabular}

\section{6-10 Instructional programs from prekindergarten through grade 12 should enable all students to--}

\section{Problem Solving Standard}

Build new mathematical knowledge through problem solving;

Solve problems that arise in mathematics and in other contexts;

Apply and adapt a variety of appropriate strategies to solve problems;

Monitor and reflect on the process of mathematical problem solving.

\section{Reasoning and Proof Standard}

Recognize reasoning and proof as fundamental aspects of mathematics;

Make and investigate mathematical conjectures;

Develop and evaluate mathematical arguments and proofs;

Select and use various types of reasoning and methods of proof.

\section{Communication Standard}

Organize and consolidate their mathematical thinking through communication

Communicate their mathematical thinking coherently and clearly to peers, teachers, and others

Analyze and evaluate the mathematical thinking and strategies of others

Use the language of mathematics to express mathematical ideas precisely

\section{Connections Standard}

Recognize and use connections among mathematical ideas;

Understand how mathematical ideas interconnect and build on one another to produce a coherent whole;

Recognize and apply mathematics in contexts outside of mathematics.

\section{Representation Standard}

Create and use representations to organize, record, and communicate mathematical ideas;

Select, apply, and translate among mathematical representations to solve problems;

Use representations to model and interpret physical, social, and mathematical phenomena. 
VITA

\section{CHAN-HO CHAE}

1993

Bachelor of Public Administration

Minor: Economics

College of Law

Kyungpook National University

Taegu, South Korea

1997

Master of Public Administration

Kyungpook National University

Taegu, South Korea

1998

Master of Arts, Child Studies

Taegu Catholic University

Kyungsan, South Korea

2000

Graduate Research Assistant

College of Education

Florida International University

Miami, Florida

2001

Research Assistant

Statistical Consulting

Florida International University

Miami, Florida

2002-2003

Graduate Teaching Assistant

College of Education

Florida International University

Miami, Florida

AWARDS AND HONORS

2000

Phi Kappa Phi Awards

The Honer Society of Phi Kappa Phi

2002-2003

Friends of the College of Education Scholarship

College of Education, Florida International University

2003

Dissertation Award Program: Selected as a Finalist

American Education Research Association (AERA)-OERI

2003-2004

Dissertation Year Fellowship Award

Graduate School Dissertation Fellowship

Florida International University 


\section{PUBLICATIONS AND PRESENTATIONS}

Moon, S. B., \& Chae, C. H. (1996). The analysis and interpretation of experimental research data using SAS package. Seoul, South Korea: Jungang.

Chae, C. H., \& Moon, S. B. (1997). The analysis and interpretation of experimental research data using SPSS program. Seoul, South Korea: Hakjisa.

Chae, C. H., \& Moon, S. B. (1998). Joint factor analysis of the K-ABC and WPPSI. Research Bulletin: Catholic Univ. of Taegu-Hyosung, Vol. 56. 383-397.

Chae, C. H., Dixon-Krauss, L. A., \& Harlin, R. (in review). The Effects of Narration Rates on Children's Reading While Listening Comprehension, Early Childhood Research Quarterly.

Harlin, R., Dixon-Krauss, L. A., \& Chae, C. H. (2001, November). Children's grade and aesthetic involvement in multiethnic books. Paper presented at the $46^{\text {th }}$ Florida Educational Research Association Annual Meeting, Marco Island, Florida.

Chae, C. H., \& Dixon-Krauss, L. A. (2002). An investigation of narration rates for the reading while listening strategy. The First Annual College of Education Research Conference Proceedings. (ERIC Document Reproduction Service: ED475074)

Harlin, R., Dixon-Krauss, L. A., \& Chae, C. H. (2002, April). An analysis of children's cognitive and affective responses to multicultural picture books. Paper presented at the 2002 America Educational Research Association Annual Meeting, New Orleans, Louisiana.

Chae, C. H., \& Dixon-Krauss, L. A. (2002, November). The effects of narration rates on children's reading while listening comprehension. Paper accepted for presentation at the $47^{\mathrm{h}}$ Florida Educational Research Association Annual Meeting, Gainesville, Florida.

Chae, C. H., \& Dixon-Krauss, L. A. (2002, April). An investigation of narration rates for the reading while listening strategy. Paper presented at the $1^{\text {st }}$ Annual College of Education Research Conference, Florida International University, Miami, Florida.

Dixon-Krauss, L. A., Harlin, R., \& Chae, C. H. (2003, May). Children's metacognitive and ethnic related responses during multicultural literature read alouds. Paper presented at the 2003 International Reading Association OTER (Organization of Teacher Educators in Reading) Meeting, Orlando, Florida. 